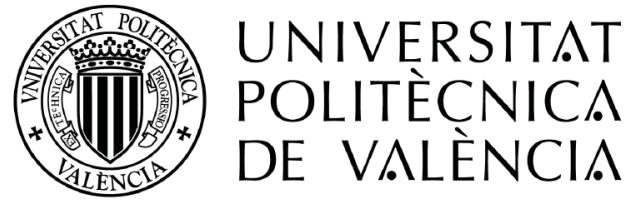

Departamento de Economía y Ciencias Sociales

Programa de Doctorado en Economía Agroalimentaria

\title{
Políticas, marcos legales y mecanismos de acaparamiento de tierras en Colombia
}

Tesis Doctoral

Presentada por:

Carolina Hurtado

Dirigida por:

Dr. Eladio Arnalte Alegre

Dr. Dionisio Ortiz Miranda 
Departamento de Economía y Ciencias Sociales Programa de Doctorado en Economía Agroalimentaria

\title{
Tesis Doctoral \\ Políticas, marcos legales y mecanismos de acaparamiento de tierras en Colombia
}

\author{
Presentada por: \\ Carolina Hurtado
}

\author{
Dirigida por: \\ Dr. Eladio Arnalte Alegre \\ Dr. Dionisio Ortiz Miranda
}

Valencia, noviembre de 2018 



\section{Agradecimientos}

Quiero expresar en primer lugar, mi más profundo agradecimiento a mis directores de tesis Eladio y Dionisio por su acompañamiento, dedicación y valiosa guía durante la elaboración de esta investigación. Sus aportes y apoyo sobre todo en los momentos menos lúcidos, así como su calidad intelectual y humana han sido fundamentales para iniciar y llegar hasta el final de este proceso.

A las coordinadoras del proyecto EuroInkanet de Erasmus Mundus, Geraldine y Esther por su apoyo y colaboración en las gestiones relacionadas con el funcionamiento de la beca. Igualmente al proyecto por otorgarme la financiación para la realización del doctorado.

Del mismo modo agradezco a los compañeros del departamento por su compañía, apoyo y motivación durante este tiempo. Especialmente a Pedro, Laura, Amparo, Víctor, Pepe y Paula por compartir los esfuerzos, angustias, alegrías e ilusiones no sólo académicas, sino en ocasiones personales. Lo cual ha hecho enriquecedor el tiempo invertido en estos despachos y pasillos.

Deseo también expresar toda mi gratitud a Ángel porque su confianza y dedicación han supuesto una gran motivación y han hecho más leve este reto. Agradezco a Andrea, Paty, Tania, Carolina, Felipe, Mentxu, Sandra y Patricia por estar dispuestos siempre a escuchar, acompañar y animar cuando ha hecho falta y a todos los que no menciono y que su buena energía ha contribuido a fortalecer el proceso. 



\section{Resumen}

La aparición de múltiples crisis (alimentaria, financiera, energética y climática) desde 2008 ha ocasionado un incremento de la demanda de productos agrícolas alimentarios y no alimentarios. La solución propuesta a estas crisis se enfocó en lograr el incremento de la producción agrícola atrayendo inversión privada hacia los factores productivos, generando así un creciente interés por la compra de tierras a nivel mundial. En este proceso, se han identificado los países con mayor disponibilidad de tierra productiva, entre los cuales aparece Colombia como el cuarto con mayor cantidad de tierras para agricultura en América Latina. En el contexto rural colombiano, caracterizado por una excesiva desigualdad en el acceso a la tierra y un persistente conflicto armado con fuertes raíces en la exclusión socio-económica y política de las comunidades rurales, esta nueva fiebre por la tierra toma unas características específicas, en términos del escenario nacional y local donde tiene lugar.

Es por ello que esta investigación se centra en profundizar en el fenómeno del acaparamiento de tierras en Colombia en las últimas tres décadas, identificando los mecanismos empleados y los factores de tipo legal y político que han facilitado su ocurrencia. A través de un exhaustivo análisis bibliográfico y documental se estudia la influencia que han ejercido las directrices de política internacional en las políticas agrarias y de tierras nacionales en este período. También se analiza el rol que desempeña el estado en el acaparamiento de tierras a través de las modificaciones en el marco legal sobre las tierras baldías de la región de la Altillanura colombiana. El análisis desciende al escenario local a través de 12 estudios de caso específicos, que son reconstruidos a partir de la realización de un análisis sistemático de la literatura científica existente sobre despojo y acaparamiento en el país. Con el análisis comparativo de estos casos se visibilizan los mecanismos utilizados y la trayectoria de las estrategias empleadas para despojar y acaparar la tierra.

Los resultados permiten mostrar en primer lugar que, las directrices de política internacional centradas en la superación de la pobreza, la violencia y el logro del desarrollo agrícola han estimulado la inversión de capitales en la compra de tierras e instalación de agronegocios, sin lograr erradicar las condiciones de pobreza, exclusión y violencia en las zonas rurales. El estado ha desempeñado un rol activo en el acaparamiento de tierras a través de la eliminación de restricciones legales a la inversión y mediante el uso de acciones coercitivas. En el ámbito local, los estudios de caso dejan ver la existencia de tres grandes trayectorias de despojo y acaparamiento que se suceden en el tiempo y van de i) la expulsión del campesinado a la formalización fraudulenta de predios por 
los despojadores, ii) los múltiples traspasos de los predios al establecimiento de los agronegocios y iii) las disputas legales hasta lograr o no la restitución. Todo lo anterior precedido e inserto en un escenario de violencia persistente que desdibuja el logro de la paz.

Palabras clave: Acaparamiento de tierras, baldíos, Colombia, políticas agrarias, estado, marcos legales, violencia, despojo. 


\section{Summary}

The emergence of multiple global crises (food, financial, energy and climate) has increased the international demand for food and non- food agricultural commodities since 2008. The proposed solution to these crises was focused on increasing agricultural production by attracting private investments toward productive factors, thereby generating a greater interest in buying land worldwide. In this process, the identification of countries with the higher availability productive land has been made, being Colombia the fourth with higher availability of productive land in Latin America. In the Colombian rural context, characterized by an excessive inequality in access to land and a persistent armed conflict rooted on the socio-economic and political exclusion of rural communities, this new land rush acquires specific characteristics in terms of the national and local scenarios where it takes place.

That is why this research goes in depth in the phenomenon of land grabbing in the last three decades in Colombia, identifying the implemented mechanisms and the legal and political factors which have facilitated this process. Through an exhaustive bibliographic and documentary analysis, the influence of international policy guidelines on agrarian and land national policies is studied for the same period. Also the role played by the state in land grabbing is analysed through the changes in wastelands legal framework in the Colombian Altillanura region. The analysis also focuses on 12 local case studies, which are reconstructed based on a systematic analysis of the existing scientific literature about dispossession and land grabbing in the country. The comparative analysis allows us to unfold the mechanisms and the trajectories of the strategies used to dispossess and grab the land.

The results show how the international policy guidelines aimed at overcoming poverty, violence and achieving agricultural development, have attracted capital investment in land purchases and agribusiness setting up without eradicating the poverty, exclusion and violence conditions in rural areas. The state has played an active role in land grabbing by removing legal restrictions on investments and with the use of coercive actions. At the local level, the case studies reveal the existence of three main stages of dispossession and land grabbing that take place over time i) from the expulsion of the peasantry to the fraudulent land formalization by the grabbers ii) the multiple land transfers to the agribusiness setting up and iii) the legal conflict until land restitution is achieved or not. All of the above preceded and inserted in a scenario of persistent violence that blurs the achievement of peace. 
Keywords: land grabbing, wasteland, Colombia, agrarian policies, state, legal frameworks, violence, dispossession. 


\section{Resum}

L'aparició de múltiples crisis (alimentària, financera, energètica i climàtica) des de 2008 ha ocasionat un increment de la demanda de productes agrícoles alimentaris i no alimentaris. La sol lució proposada a estes crisis es va enfocar en aconseguir l'increment de la producció agrícola atraient inversió privada cap als factors productius, la qual cosa ha ocasionat un creixent interés per la inversió en terres a nivell mundial. Així, s'han identificat els països amb major disponibilitat de terra productiva, entre els quals apareix Colòmbia com el quart país amb major disponibilitat de terres d'Amèrica Llatina. En el context rural colombià, caracteritzat per una excesiva desigualtat en l'accés a la terra i un persistent conflicte armat amb forts arrels en l'exclusió socio-econòmica $i$ política de les comunitats rurals, esta nova febre per la terra pren unes característiques específiques, en termes de l'escenari nacional i local on té lloc.

És per això que aquesta investigació se centra en profunditzar en el fenòmen $\mathrm{d}$ 'acaparament de terres en Colòmbia en les últimes tres dècades, identificant els mecanismes emprats i els factors de tipus legal i polític que han facilitat la seua ocurrència. Mitjançant un exhaustiu anàlisi bibliogràfic i documental s'aprofunditza en la influència que han exercit les directrius de la política internacional en les polítiques nacionals agràries i de terres en les últimes tres dècades. També s'analitza el rol que exercix l'estat en l'acaparament de terres ermes de la regió de l'Altiplana colombiana. L'anàlisi descendix a l'escenari local mitjançant 12 estudis de cas específics, que són reconstruïts a partir de la realització d'una anàlisi sistemàtica de la literatura científica existent sobre privació i acaparament al país. L'anàlisi comparatiu d'aquestos casos permet fer visible els mecanismes utilitzats i la trajectòria de les estratègies emprades per desposseir i acaparar la terra.

Els resultats permeten mostrar en primer lloc que les directrius de la política internacional centrades en la superació de la pobresa, el desenvolupament agrícola i la superació de la violència han estimulat la inversió de capitals en l'adquisició de terres i la instal lació d'agronegocis sense aconseguir acabar amb les condicions de pobresa, exclusió i violència en les zones rurals. L'estat ha exercit un rol actiu en l'acaparament de terres mitjançant l'eliminació de les restriccions legals a la inversió i l'aplicació d'accions coercitives. A nivell local, els estudis de cas mostren l'existència de tres principals trajectòries de privació i acaparament que se succeïxen en el temps i van de i) l'expulsió dels llauradors a la formalització fraudulenta de predis pels espoliadors; ii) els múltiples traspassos de predis a l'establiment d'agronegocis i, iii) les baralles 
legals fins aconseguir o no la restitució. Tot l'anterior precedit i inserit en un escenari de violència persistent que desdibuixa l'assoliment de la pau.

Palabras clave: Acaparament de terras, Colombia, polítiques agraries, estat, marc llegal, violència, espoliament. 


\section{Índice}

Capítulo 1. Introducción ....................................................................................................1

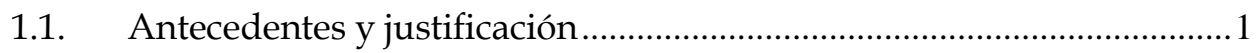

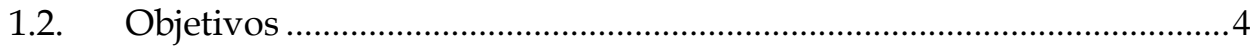

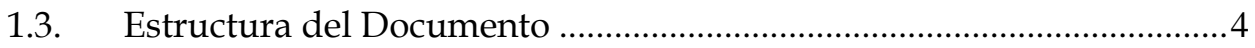

Capítulo 2. Los procesos de acaparamiento de tierras: Marco conceptual y papel del estado ...................................................................................................................

2.1. El abordaje del problema agrario y la cuestión de la tierra en la era del neoliberalismo.

2.2. Los análisis iniciales sobre acaparamiento de tierras ..................................11

2.3. El concepto de acaparamiento de tierras y la escala de medición.............13

2.4. Características del acaparamiento de tierras en América Latina...............16

2.5. Mecanismos para el acaparamiento de tierras: el papel del estado ..........18

2.6. Los elementos a profundizar en el acaparamiento de tierras ....................22

Capítulo 3. Metodología y fuentes

3.1. Análisis bibliográfico y documental para el estudio de políticas públicas

3.2. Revisión sistemática de literatura para la selección de estudios de caso 29

3.2.1. Protocolo para la recolección de datos ....................................................... 31

3.2.2. Selección y construcción de estudios de caso..........................................34

Capítulo 4. Agricultura y violencia en Colombia: Una primera aproximación

4.1. La estructura de la tenencia de la tierra en Colombia ...................................38

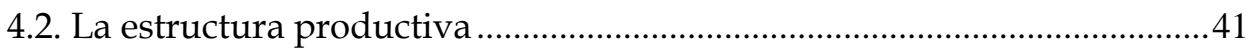

4.3. Importancia del sector agropecuario .......................................................4

4.4. Población rural y grupos étnicos..................................................................45

4.5. Violencia guerrillera y paramilitar...............................................................

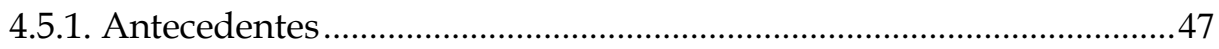

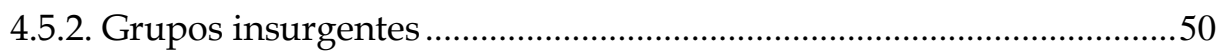

4.5.3. Paramilitares y narcotraficantes …………………………………….....51 
Capítulo 5. Evolución de las políticas agrarias y de tierras en Colombia: La influencia de los organismos internacionales

5.1. Las primeras directrices del Banco Mundial y los intentos de políticas agrarias redistributivas.

5.2. El Desarrollo Rural Integrado. Narcotráfico y reconcentración de la tierra .64

5.3. Liberalización de la economía. El mercado de tierras 66

5.4. Las políticas neoliberales: Alianzas productivas para lograr la paz y el desarrollo.

5.5. Enfoque y financiación del proceso de paz por el BM y el gobierno de Estados Unidos (USAID). El Plan Colombia. 72

5.6. Inicios del siglo XXI: Seguridad Democrática para el modelo

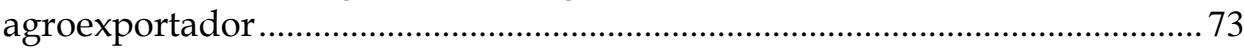

5.7. La participación de la financiación internacional en la atención a la

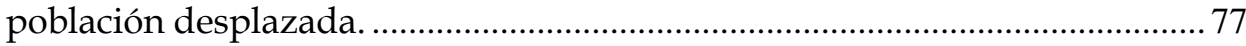

5.8. La Ley de Justicia y Paz Ley 975 de 2005: Desmovilización de los grupos paramilitares 78

5.9. Incremento del apoyo internacional al segundo período de la Seguridad Democrática 2006-2010. 80

5.10. El periodo del proceso de paz, la ley de restitución de tierras y el posconflicto 81

5.11. Los respaldos internacionales a la formalización de los derechos de propiedad sobre la tierra y a la restitución. 84

5.12. Adopción de las recomendaciones de política: Una síntesis por períodos y dimensiones. 86

Capítulo 6. Cambios en el marco legal y acaparamiento de baldíos en la Altillanura colombiana.......................................................................................91

6.1. Marco Normativo de las tierras baldías: Protegiendo el acceso de los campesinos a las tierras públicas .................................................................... 92

6.2. La Altillanura: De tierra marginal a despensa alimentaria ........................ 96

6.3. Los cimientos para el acaparamiento de tierras: Tenencia informal, conflicto armado y desposesión. ..........................................................................99

6.4. Las disputas legales por los baldíos de la Altillanura................................. 101

Capítulo 7. Mecanismos de acaparamiento de tierras en Colombia. Estudios de caso 113

7.1. Una revisión y sistematización de los estudios de caso. 114 
7.1.1. Caso No. 1. Predio Déjala Quieta- Tulapas.

7.1.2. Caso No. 2. Cuencas de los ríos Jiguamiandó y Curvaradó- Bajo Atrato 116

7.1.3. Caso No. 3. Predio Las Pavas................................................................. 119

7.1.4. Caso No. 4. Predio La Alemania............................................................ 121

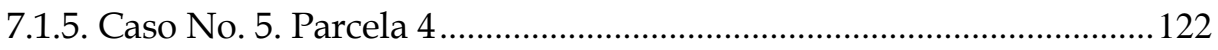

7.1.6. Caso No. 6. Predio Finca La Bellacruz................................................ 124

7.1.7. Caso No. 7. Hato Cabiona (Caserío el Porvenir) ................................. 128

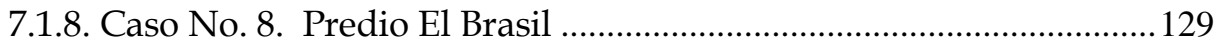

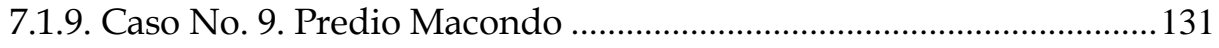

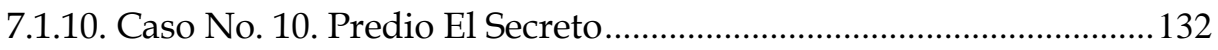

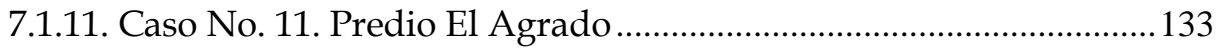

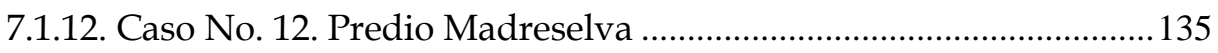

7.2. La categorización de las estrategias de despojo y acaparamiento...........135

7.3. Las trayectorias de despojo y acaparamiento............................................... 141

7.3.1. De la expulsión del campesinado a la formalización fraudulenta .. 141

7.3.2. De los mecanismos irregulares de titulación a las disputas legales 144

7.3.3. Cuatro finales inconclusos ................................................................. 145

7.4. El papel del estado: Entre la facilitación del acaparamiento y la protección de los derechos de las comunidades rurales..................................147

Capítulo 8. Conclusiones ..............................................................................................151

Referencias Bibliográficas ......................................................................................159 


\section{Índice de Tablas}

Tabla 3.1. Criterios de búsqueda para la recolección de datos 32

Tabla 4. 1. Colombia: Distribución del área en uso agropecuario por rango de tamaño. 2014. (Hectáreas)

Tabla 4. 2. Colombia: Área cosechada en cultivos transitorios, quinquenios 1990-2015 (Hectáreas).

Tabla 4. 3. Colombia: Área cosechada en cultivos permanentes, quinquenios 1990-2015 (Hectáreas)

Tabla 4. 4. Colombia: Producto Interno Bruto por ramas de actividad 20002015. Participación porcentual anual.

Tabla 5. 1. Documentos de política: Banco Mundial, USAID y Gobierno de Colombia. 1980-2018

Tabla 5. 2. Influencia de los organismos internacionales en cinco dimensiones de la política Colombiana. 1990-2017

Tabla 6. 1. Total dotación de tierras en Colombia. 1961-2014

Tabla 6. 2. Casos investigados por la CGR de acumulación ilegal de baldíos en la Altillanura colombiana 2014.

Tabla 6. 3. Intentos legales para permitir la acumulación de tierras baldías en Colombia. 2007-2016

\section{Índice de Gráficos y Figuras}

Figura 3. 1. Protocolo de recolección de datos .33

Figura 6. 1. Mapa Subregión de la Altillanura colombiana

Figura 7. 1. Mapa ubicación departamental y municipal de los casos de estudio.

Figura 7. 2. Secuencia de los procesos de acaparamiento en los casos de estudio

Gráfico 4. 1. Colombia: Unidades de Producción Agropecuaria y su área por rango de tamaño 2014

Gráfico 4. 2. Colombia: Área cosechada en cultivos transitorios y permanentes 1990-2015 (Hectáreas).

Gráfico 4. 3. Colombia: Evolución de las importaciones y exportaciones agropecuarias y agroindustriales 1992-2015 


\section{Lista de acrónimos}

ADAM: Áreas de Desarrollo Alternativa Municipal

ANT: Agencia Nacional de Tierras

ANDR: Agencia Nacional de Desarrollo Rural

ART: Agencia para la Renovación del Territorio

ASOCAB: Asociación de Campesinos de Buenos Aires

ASOCOL: Asociación Colombiana Horizonte de Población Desplazada

AUC: Autodefensas Unidas de Colombia

AUCC: Autodefensas Campesinas de Córdoba y Urabá

BACRIM: Bandas Criminales

BID: Banco Interamericano de Desarrollo

BIRF: Banco Internacional de Reconstrucción y Fomento

BM: Banco Mundial

CC: Corte Constitucional

CGR: Contraloría General de la República

CIDH: Comisión Interamericana de Derechos Humanos

CIF: Corporación Financiera Internacional

CMAIPD: Comité Municipal de Atención Integral a Población Desplazada

CNRR: Comisión Nacional para la Reparación y la Reconciliación

DNP: Departamento Nacional de Planeación

DRI: Desarrollo Rural Integrado

EAP: Estrategia de Alianza con el País

EAP: Estrategia de Asistencia al País

ELN: Ejército de Liberación Nacional

EPL: Ejército Popular de Liberación

FARC: Fuerzas Armadas Revolucionarias de Colombia 
FEDEGAN: Federación Colombiana de Ganaderos

FIDA: Fondo Internacional de Desarrollo Agrícola

FIP: Fondo de Inversión para la Paz

FNRV: Fondo Nacional para la Reparación de Víctimas

GMH: Grupo de Memoria Histórica

INCODER: Instituto Colombiano de Desarrollo Rural

INCORA: Instituto Colombiano para la Reforma Agraria

LDRP: Programa de Tierras y Desarrollo Rural

MAT: Mercado Asistido de Tierras

MIDAS: Mas Inversión para el Desarrollo Sostenible

OCDE: Organización para la Cooperación y el Desarrollo Económico

PC: Plan Colombia

PDI: Población Desplazada Internamente

PNCT: Plan Nacional de Consolidación Territorial

PND: Plan Nacional de Desarrollo

PNR: Plan Nacional de Rehabilitación

RRI: Reforma Rural Integral

UAEGRTD: Unidad Administrativa Especial de Gestión de Restitución de Tierras Despojadas

UAF: Unidad Agraria Familiar

UNCTAD: Conferencia de las Naciones Unidas sobre el Comercio y Desarrollo

UPRA: Unidad de Planificación de Tierras Rurales, Adecuación de Tierras y

Usos Agropecuarios

URT: Unidad de Restitución de Tierras

USAID: Agencia de los Estados Unidos para el Desarrollo Internacional

ZIDRES: Zonas de Interés de Desarrollo Rural, Económico y Social. 


\section{Capítulo 1}

\section{Introducción}

\subsection{Antecedentes y justificación}

Las primeras décadas del siglo XXI están experimentando la proliferación de múltiples crisis; alimentaria, financiera, energética y climática. Todas encierran la idea de la escasez que se manifiesta en la insuficiencia de alimentos para una población mundial creciente, la falta de fuentes seguras de inversión, agotamiento de los combustibles fósiles y aumento del calentamiento del planeta. La crisis alimentaria se hizo visible a partir de 2007-2008 con un incremento histórico en los precios de los alimentos. Las medidas de política centraron la atención en el crecimiento de la producción agrícola como solución. El Banco Mundial (BM) en su informe de 2008 estableció la necesidad de atraer mayor inversión para la agricultura. La demanda por los activos productivos, dentro de ellos la tierra, ya estaba creciendo y con los nuevos estímulos, los capitales corporativos nacionales e internacionales fueron los llamados a invertir en las zonas rurales.

Tres años después, el BM también identificó las regiones y países con mayor cantidad de tierras productivas 'disponibles', donde América Latina y el Caribe ocupaba el segundo lugar, con más de 123 millones de hectáreas después del África Sub-Sahariana y donde Colombia era el cuarto país, después de Argentina, Brasil y Bolivia en disponibilidad de tierras (Deininger et al. 2011:78-79). 
Con la creciente fiebre por la tierra, se realizaron a nivel global diversos informes y artículos que trataron de explicar las causas, dimensiones y efectos de las inversiones en las poblaciones locales. Varios de ellos centrados en el problema como un fenómeno coyuntural, sin involucrar las dimensiones de tipo histórico del contexto donde ocurrían, y sin entrar tampoco en el análisis del cambio agrario que estas podrían generar. Las conclusiones de varios de estos reportes y estudios se consideraron apresuradas y sesgadas por carecer de suficiente evidencia empírica, de estudios de caso específicos.

Colombia fue incluida en un estudio ordenado por la FAO para conocer en qué medida en América Latina y el Caribe se presentaba el fenómeno de acaparamiento de tierras. Para el análisis se adoptó una definición limitada del concepto de acaparamiento de tierra, y por ello concluyeron que solo en dos países había acaparamiento de tierras (Brasil y Argentina), y para varios lo que prevalecía era la concentración y extranjerización de la tierra, problemas agrarios de vieja data en varios países de la región.

Sin embargo, en Colombia desde 2011 se habían empezado a publicar en los medios de comunicación, la intención y/o realización de grandes inversiones en tierras en algunas regiones del país para adelantar agronegocios y proyectos de explotación forestal por inversionistas nacionales y extranjeros.

En el contexto agrario colombiano, la excesiva concentración de la tierra es y ha sido fuente de desigualdad, inequidad y pobreza en el campo, continúa alimentando el conflicto armado y la proliferación del narcotráfico, que se mantiene en las zonas rurales generando desplazamiento, despojo de tierras y pobreza. La nueva dinámica de la actual fiebre por la tierra, centrada principalmente por la demanda internacional de cultivos para múltiples usos, toma unas características específicas al enmarcarse dentro de este proceso de violencia y despojo que ya se venía gestando y ejecutando en las últimas tres décadas.

Los trabajos que abordaron el tema del acaparamiento de tierras desde la economía política agraria permitieron ampliar el marco de análisis, iniciando por definir el concepto de acaparamiento de tierras y abogando por la necesidad de contextualizar el espacio local donde se presentaban las transacciones, haciendo énfasis en el papel de los actores implicados en el 
proceso a nivel internacional y nacional. En este sentido, esclarecer el papel e influencia que tienen los organismos internacionales y determinados gobiernos en promover las inversiones en tierras en los países en desarrollo, se convierte en una herramienta fundamental al momento de analizar el porqué de la aplicación de determinadas políticas para el desarrollo y la agricultura en los países receptores de las inversiones.

Este es el primer cometido que aborda este trabajo, establecer esa influencia de los organismos internacionales en las políticas agrarias de Colombia que van delineando el camino para la promoción de inversiones en las zonas rurales.

Otra preocupación planteada y reclamada como necesaria en las investigaciones, es el análisis del papel que desempeña el estado del país receptor. Inicialmente se argumentó que el fenómeno del acaparamiento ocurría en países donde los estados eran actores pasivos y débiles, pero en realidad lo que se demostró es que ocurre en democracias relativamente estables y con instituciones formadas (Borras \& Franco 2013). También que el estado sí tiene un papel activo ante el acaparamiento. En el caso colombiano los trabajos de Grajales (2011, 2013, 2015), Gómez et al. (2015), Ballvé (2012, 2013) ya introducen la participación del estado en procesos de despojo, a partir del estudio de casos específicos. Sin embargo, en esta investigación profundizamos en ese rol del estado, desde el análisis de los cambios en los marcos legales, influenciados por actores externos e internos y que no solo desencadenan reacciones en el nivel nacional, sino que tienen efectos visibles en los espacios locales donde el acaparamiento ocurre.

De igual modo, algunos estudios se han esforzado por reunir evidencia y documentar casos específicos de despojo Gómez et al. (2015); García \& Vargas (2014). También algunos casos fueron documentados por el Grupo de Memoria Histórica (2010) para la región de la costa Atlántica. No obstante, hay un vacío en la recolección, documentación y análisis conjunto de estudios de caso, desde los cuales se puedan definir los mecanismos de acaparamiento de tierras y establecer cómo estos han operado a nivel local. Y es en esta falencia donde esta disertación busca aportar evidencia a partir de la reconstrucción del proceso de despojo y acaparamiento en una serie de casos concretos, visibilizando los mecanismos utilizados, la trayectoria seguida en el tiempo y documentando, hasta donde fue posible, su desenlace. 


\subsection{Objetivos}

El objetivo principal que guía este trabajo es profundizar en el fenómeno del acaparamiento de tierras en Colombia en las últimas tres décadas, identificando los mecanismos empleados y los factores de tipo legal y político que han facilitado su ocurrencia.

Para poder cumplir con esta tarea se han planteado los siguientes objetivos específicos:

- Un primer objetivo específico es identificar y analizar la influencia de las directrices de política internacional en el diseño y aplicación de la política agraria nacional, a través de un estudio minucioso de dichas directrices y la constatación de su aplicación en los planes y programas de gobierno aplicados en los últimos años.

- El segundo objetivo específico es determinar el rol que desempeña el estado en los procesos de acaparamiento de tierras, principalmente a través de la implementación de políticas y de las modificaciones de las leyes agrarias y del marco legal.

- Finalmente, un tercer y último objetivo específico es identificar los mecanismos y estrategias seguidas para despojar y acaparar la tierra en Colombia a través de estudios de caso que tienen como nivel de análisis las transacciones realizadas con los predios.

\subsection{Estructura del Documento}

Luego de este primer capítulo introductorio, el capítulo número dos presenta las consideraciones teóricas desarrolladas previamente a nivel global sobre el acaparamiento de tierras dentro del marco de análisis del problema agrario. Se hace referencia a los análisis iniciales que trataban de explicar las causas y los efectos del fenómeno, así como su magnitud. También a los esfuerzos por la construcción del concepto mismo de acaparamiento de tierras y la identificación de los mecanismos utilizados, profundizando sobre el rol que cumplen los estados en estos procesos, y mediante qué estrategias participan facilitando o no su desarrollo. Se resaltan también en este apartado los vacíos encontrados en la literatura existente que van a guiar el análisis que se aborda en este trabajo. 
El capítulo número tres presenta la metodología y las fuentes utilizadas para alcanzar los objetivos de la investigación. Además de describir los métodos y las estrategias de investigación adoptadas para cada objetivo específico, también sustenta y justifica el porqué de su utilización.

El capítulo número cuatro permite tener una breve y precisa caracterización del país en términos de su problemática sobre la tenencia de la tierra, la estructura productiva y la importancia del sector agrario en términos de su aporte al desarrollo del país. De igual manera se sintetiza la dinámica de la violencia a cargo de los principales grupos armados, introduciendo así su rol y participación en los procesos de despojo y acaparamiento de tierras.

En el capítulo número cinco apunta a identificar de qué forma los organismos internacionales a través de directrices de política y ayuda al desarrollo permean las agendas políticas nacionales en el diseño e implementación de políticas para la agricultura, el problema de la tierra y la política de paz. El análisis de los documentos y recomendaciones específicas sobre la agricultura colombiana emitidas por varios organismos internacionales a lo largo de los últimos 30 años y, en paralelo, su reflejo en planes de desarrollo y legislación colombiana, permiten establecer las principales dimensiones de esa influencia, su evolución en el tiempo y sus repercusiones sobre el contexto en el que el acaparamiento de tierras tiene lugar.

El capítulo número seis profundiza en el rol que desempeña el estado en facilitar el acaparamiento de tierras a través de mecanismos de tipo legal. Este análisis se desarrolla mediante el estudio de la legislación sobre las tierras baldías o tierras del estado, las cuales en años recientes han sido el centro del debate público por la publicación de casos de compras masivas y apropiación indebida de estas tierras en la región de la Altillanura colombiana.

En el capítulo número siete se describen y analizan los mecanismos y estrategias de acaparamiento de tierras a través de una serie de estudios de caso en diferentes regiones del país. Detalla de igual forma cómo se llega a la identificación y construcción de estos casos a partir de la realización de un análisis sistemático de literatura, reforzado con fuentes de información alternativas que permiten la reconstrucción de cada caso. El resultado deja ver 
las trayectorias que siguen los procesos de despojo y acaparamiento, sus relaciones con la violencia desarrollada en el medio rural, los mecanismos que se implementan y los resultados más recientes.

Finalmente, el capítulo número ocho presenta las conclusiones centrales de la investigación, las cuales buscan responder a los objetivos planteados. Se presenta un dialogo inicial de cómo los resultados han permitido corroborar algunos de los planteamientos teóricos iniciales, pero también apuntan a llenar algunos vacíos dentro de los estudios sobre el tema. 


\section{Capítulo 2}

\section{Los procesos de acaparamiento de tierras: Marco conceptual y papel del estado}

Este capítulo presenta una síntesis de los elementos conceptuales básicos en los que se apoya la abundante literatura reciente sobre los procesos de acaparamiento de tierras que se están desarrollando, a nivel global, en estas primeras décadas del siglo XXI. Se aborda la definición del concepto en sí, sus principales características y mecanismos y dentro de estos últimos, se profundiza en el papel que desempeña el estado en los procesos de acaparamiento. No se pretende realizar una revisión detallada y un recorrido general por esa amplia literatura, sino reseñar sobre todo las referencias conceptuales y el análisis de experiencias comparadas que muestren las distintas formas de actuación del estado en relación a esos procesos, lo que constituye el marco teórico en el que inscribir nuestro análisis del caso colombiano.

Dentro de la literatura revisada destacan los estudios realizados desde la óptica de la economía política agraria, que permiten analizar el fenómeno poniendo el acento en el control que está ejerciendo el capital global sobre la tierra y otros 
recursos naturales. Esa literatura se complementa con los análisis que se plantean desde la sociología crítica, profundizando en cómo a través de la gobernanza internacional se ha facilitado el camino para que los estados desempeñen un rol fundamental en permitir y facilitar las transacciones en tierras.

\subsection{El abordaje del problema agrario y la cuestión de la tierra en la era del neoliberalismo}

El tema de la tierra ha sido parte fundamental del análisis de la cuestión agraria, una cuestión que para el siglo XXI ya se creía poco importante y un problema resuelto para los países desarrollados, pues la producción y suministro de alimentos estaba solucionado o por lo menos estable. En este sentido para estos países la tierra también había dejado de ser un factor trascendental desde su dimensión productiva, política y social. Y aunque para la mayoría de los países en desarrollo el tema desapareció también de sus agendas políticas, después de casi 30 años de intentos de reformas agrarias redistributivas, las demandas por un acceso equitativo a la tierra han permanecido en el tiempo ante la persistencia de una estructura de tenencia altamente desigual (Arnalte et al. 2012).

No obstante, la crisis alimentaria de 2007-2008, generada por la subida de los precios de los alimentos, trajo de nuevo el tema de la cuestión agraria y en especial de la tierra en las agendas de las políticas de desarrollo, como lo muestra el reporte sobre desarrollo del Banco Mundial de 2008 dedicado a la agricultura. En este la visión de la agricultura es un asunto de competitividad que se resuelve con llevar inversión privada a las zonas rurales y para la cual los estados deben crear facilidades relajando las barreras de tipo legal y jurídico. Akram-Lodhi et al. (2009) analizan esta visión como una ampliación del enfoque ya establecido y prevaleciente del sistema capitalista, que busca exponer a un número mayor de personas a los imperativos del mercado.

Los análisis sobre los cambios en la cuestión agraria dentro del sistema capitalista y, más exactamente, en la era de la globalización neoliberal de acuerdo con Akram-Lodhi \& Kay (2009), se mantienen sobre los mismos tres elementos clásicos: la producción, la acumulación y la política. Para Bernstein 
(1996/97), citado por Akram Lodhi \& Kay (2009), estos tres elementos son las problemáticas fundamentales de la cuestión agraria. Así, la problemática de la producción encerraba el surgimiento del trabajo asalariado rural generalizado y del capital agrario, incluyendo el análisis de la transformación de la pequeña producción en su mercantilización, la reestructuración de los procesos de trabajo rural, los cambios técnicos y el proceso de diferenciación de la clase campesina. La problemática de la acumulación se refería al potencial que tiene la agricultura para producir excedentes, comprender cómo generarlos, hacia dónde destinarlos y las formas en que son apropiados. Y la problemática de la política que permitía entender las tensiones que existen entre las estructuras de dominación, subordinación y apropiación del excedente y la capacidad de los individuos y clases sociales para actuar a fin de transformar y trascender esas estructuras (2009:19-21).

Para estos tres elementos la tierra continúa siendo central, y el control sobre la misma es determinado ahora por el mercado global, el cual asegura su adjudicación mediante una lógica de productividad y maximización de beneficios. Las transacciones de tierras que antes competían al ámbito nacional entran así a ser una prioridad para la creciente industria agroexportadora global que, a su paso, intensifica una clara diferenciación del espacio agrario: el orientado a las exportaciones y el destinado a la producción campesina (Akram-Lodhi \& Kay 2009).

Akram-Lodhi (2015) relaciona la adquisición de tierras a gran escala por el capital corporativo con el actual sesgo de la producción hacia la exportación, en la medida en que crea la necesidad de producir excedentes comercializables para incrementar la rentabilidad. Esta ampliación de la escala de producción implica un incremento en la escala de capital agrícola (stock de maquinaria y equipo) que a su vez requiere explotaciones cada vez más grandes demandando así más tierra. En este sentido Kay (2015:74) argumenta que para el caso de América Latina si antes la cuestión agraria se ocupaba de la concentración de la tierra ahora "el principal problema agrario es la concentración del capital y el dominio de agronegocio".

Por su parte desde la sociología crítica también se ha profundizado en la relación entre en acaparamiento de tierras y la introducción del neoliberalismo. En esta vía Sassen (2015) analiza cómo bajo el actual régimen las economías se 
contraen y las expulsiones de población crecen como una lógica inherente al sistema neoliberal. Esta autora relaciona el acaparamiento de tierras con los efectos negativos de las políticas de los organismos de la gobernanza internacional (FMI, el Banco Mundial y la OMC) que han impuesto a la mayoría los países del Sur Global la reestructuración de sus economías desde los años 1980s, y bajo el régimen de la deuda, han causado el debilitamiento del poder de sus estados, facilitando así el camino para la entrada de las grandes transacciones en tierras. En esta dirección el interés sobre la tierra está por encima de la población que la habita, lo cual conduce a las expulsiones de población.

Harvey (2005), consideró estas expulsiones de población como el resultado de una práctica más de la acumulación dentro del neoliberalismo, donde se da una redistribución de la riqueza y la renta y no la generación de estas. Esto acurre a través de lo que él denominó: "Acumulación por desposesión"1 donde no se presenta necesariamente una generación de riqueza sino una transferencia de esta desde las esferas públicas y populares al dominio de lo privado. Este concepto de acumulación por desposesión incluye la privatización y mercantilización de los activos públicos, de los derechos (salud, educación) y también de la tierra y de la naturaleza en todas sus formas (2005: 167). Dentro de esta dinámica el estado es principal instrumento para realizar esta redistribución a través de diversos mecanismos que van desde las privatizaciones hasta las medidas tributarias, fiscales y legales, incremento de medidas policiales y de vigilancia y la represión activa (2005: 172).

En esta línea, recurriendo a estos marcos analíticos profundizados a lo largo de este capítulo, se analizan los cambios que está generando la intensificación de la aplicación de políticas de corte neoliberal en las zonas rurales, las implicaciones de la globalización en las nuevas formas de acumulación y concentración de los recursos productivos, en especial de la tierra, y el rol del estado por su acción mediante la aplicación de políticas o inacción en la regulación de los desequilibrios que producen esas nuevas tendencias.

\footnotetext{
1 El concepto encierra cuatro aspectos: la privatización y la mercantilización, la financiarización, la gestión y la manipulación de la crisis y las redistribuciones estatales.
} 


\subsection{Los análisis iniciales sobre acaparamiento de tierras}

Los primeros análisis sobre la actual inversión a gran escala en tierras a nivel mundial estuvieron dirigidos a explicar los detonantes o causas, establecer la escala o cantidad de hectáreas involucradas en las transacciones, identificar el origen de los inversores, los países receptores, el destino o nuevos usos del suelo e identificar sus posibles impactos. La causa de las inversiones se atribuyó a un cambio en la oferta y la demanda de commodities agrícolas (Cotula 2012), evidenciado en la crisis alimentaria de 2007-2008. El precio de los alimentos se disparó por el destino alternativo de algunos cultivos para alimentación, forraje y energía, los denominados flex-crops, se convierten en una inversión rentable y segura en épocas de crisis e inestabilidad económica y financiera. Lo anterior junto con la llamada financiarización de la agricultura, que involucra la inversión de diversos fondos y grupos financieros en la compra de tierras por considerarla un activo seguro y con expectativas de retornos futuros (Cotula 2012), situaron la tierra en los mercados globales.

Las políticas globales también han desempeñado una influencia determinante en la inversión en tierras. El Banco Mundial en 2011, justificando la necesidad de aumentar la productividad para garantizar la seguridad alimentaria mundial, elaboró una tipología de los países con tierras "disponibles" para la producción agrícola -encontró 446 millones de hectáreas, incluyendo Colombia- y los clasificó según su brecha de productividad. Resaltó las oportunidades que pueden traer las inversiones para superar la pobreza rural en dichos países, donde el papel de los estados debía ser la reducción de riesgos que pueden generar las transacciones en tierras, principalmente por la falta de información y definición de los derechos de propiedad, tanto para comunidades locales como para los inversores. Como una medida para guiar la regulación de las inversiones, evitar que causen daño, sean sustentables y ayuden al desarrollo, el Banco propone la aplicación de los principios para la inversión agrícola responsable ${ }^{2}$ (Deininger et al. 2011)

\footnotetext{
${ }^{2}$ En la elaboración de estos siete principios denominados: "Principios para la inversión agrícola responsable que respete los derechos, los medios de vida y los recursos", participaron la FAO, FIDA y la Conferencia de Naciones Unidas sobre el Comercio y Desarrollo (UNCTAD).
} 
Para White et al. (2012) este conjunto de reglas y regulaciones e incentivos por parte de la comunidad internacional, también favorece las inversiones a gran escala, dado el carácter contradictorio de las organizaciones multilaterales, que de un lado previenen sobre los peligros de las grandes inversiones y por otro promueven programas y ayudas que las facilitan. Es así como el Banco Mundial y USAID con el objetivo de promover el desarrollo rural y mejorar los mercados en las zonas rurales han canalizado recursos para crear las condiciones adecuadas a las grandes inversiones (2012: 630-631). Los programas como las alianzas productivas entre pequeños y grandes empresarios, financiadas por estos organismos en Colombia, reflejan de forma clara la dualidad en las políticas internacionales.

Además, a las nuevas oportunidades agrícolas y alimentarias de las inversiones en la tierra, se añadieron otras derivadas de las políticas globales para la mitigación del cambio climático, en especial la promoción de mercados de carbono. Estas políticas crearon un marco propicio que incrementó la presión sobre la demanda de tierras para plantaciones forestales, reservas y parques naturales. A su vez proyectos de turismo y ecoturismo, y en general la demanda de servicios eco-sistémicos se convierte en otra fuente de acumulación a través del denominado 'mercado del medioambiente' (White et al. 2012).

La influencia que tienen las políticas públicas en la promoción de la inversión en tierras, es analizada por Cotula (2012) tanto en los países inversores como en los países receptores. En los primeros, encuentra que los gobiernos (como los Países del Golfo) han respaldado con financiación las inversiones en países con alto potencial agrícola, aunque ello no sea siempre por razones de seguridad alimentaria, sino más bien por oportunidades de negocio (China), macroeconómicas o geopolíticas (China, Libia). En el caso de la Unión Europea y Estados Unidos, su interés también descansa en la política de promoción de energías renovables ${ }^{3}$, justificada en mantener la seguridad energética (2012: 668-669). Por su parte, en los países receptores las políticas nacionales también se adecuan para favorecer la inversión privada en la agricultura y en sectores extractivos, en especial la inversión extranjera a través de beneficios fiscales y

\footnotetext{
${ }^{3}$ Uso de biocombustibles para el transporte y obtención de energía de la biomasa (pellets de madera) para plantas generadoras de energía.
} 
tributarios para los cuales establecen las modificaciones políticas y legales que las inversiones exigen.

Los países receptores de inversiones en tierras identificados inicialmente fueron los países de África Subsahariana, del Sudeste Asiático y Latinoamérica. La procedencia de los inversores se centró en China, Corea del Sur, los Países del Golfo, India, Europa y Norte América (Cotula 2012). Recientemente, (Nolte et al. 2016) presentaron a Malasia, Estado Unidos, Reino Unido, Singapur y Arabia Saudí, como los primeros países de procedencia de las inversiones. Sin embargo, como lo señala Cotula (2012) las fronteras del origen de las inversiones (internacional, regional y nacional) son fluidas y en muchos casos difíciles de establecer pues algunas se canalizan a través de terceros países, mediante compañías de empresas mixtas, se crean en países de tránsito como los paraísos fiscales y en varios casos las compañías extranjeras operan localmente creando compañías subsidiarias.

En cuanto a las inversiones a gran escala en tierras de origen nacional, los análisis documentan que las élites nacionales también están haciendo grandes inversiones en tierras, solas o en alianzas con inversores extranjeros (Deininger et al. 2011; Cotula 2012; Borras et al. 2012)). En el caso de América Latina los inversionistas regionales juegan un papel determinante, en Brasil y Argentina las compañías además de controlar inversiones en países de la región han comprado grandes extensiones de tierras en sus propios países. Para el caso de Colombia las élites económicas y políticas nacionales son responsables de una gran parte de la inversión masiva en tierras, aunque también operan mediante alianzas con compañías del orden regional y global.

\subsection{El concepto de acaparamiento de tierras y la escala de medición}

Los términos utilizados para denominar el presente y creciente interés por la tierra no gozan de un consenso entre los académicos, políticos y activistas; así unos han optado por llamarlo adquisiciones de tierra a gran escala, fiebre global por la tierra, compra masiva de tierras. Sin embargo, el término que posiblemente ha alcanzado mayor popularidad tanto en el ámbito académico como el político, sea el de acaparamiento de tierras (land grabbing), un término que algunos han criticado por encerrar una carga demasiado ideológica. En 
todo caso, independientemente del término utilizado, todos ellos están relacionados con la adquisición o transacción de tierras a gran escala, por encima de 200 ó de 1000 hectáreas (Oya 2013a: 504). Borras et al. (2012) afirman que no se puede dar una definición estándar del término de acaparamiento de tierras, pero dentro de la óptica de la economía política agraria, ese término implica poder y relaciones de poder, por lo que otorga contenido político e histórico a la actual fiebre por la tierra y por ello evitan sustituirlo por otro.

En la construcción de una definición más integral del concepto, Borras et al. (2012) identifican tres características interrelacionadas: la primera, el control de la tierra y de otros recursos naturales, así como del beneficio asociado a ese control; la segunda, la escala de las transacciones en términos de la cantidad de la tierra pero también del capital involucrado y la tercera, la respuesta de la lógica del capital que, ante la aparición de múltiples crisis busca oportunidades de inversión más seguras. Finalmente definen así el proceso:

"Contemporary land grabbing is the capturing of control of relatively vast tracts of land and other natural resources through a variety of mechanisms and forms that involve large-scale capital that often shifts resource use orientation into extractive character, whether for international or domestic purposes, as capital's response to the convergence of food, energy and financial crises, climate change mitigation imperatives, and demands for resources from newer hubs of global capital." (Borras et al., 2012:851)

En los estudios iniciales, la atención estuvo centrada en conocer la escala de las transacciones en términos de la cantidad de tierra involucrada y menos en la escala de capital. Los datos de GRAIN y en mayor medida The Land Matrix ${ }^{4}$, siguen siendo una referencia para analizar la escala de las inversiones a pesar de que ya se han discutido sus imprecisiones conceptuales y metodológicas (Cotula 2012; Oya 2013a) y su utilización en varios trabajos científicos que sin

\footnotetext{
${ }^{4}$ El último reporte de GRAIN (2016), registró 491 transacciones que involucraban 30 millones de hectáreas. Nolte et al, (2016) analizando los datos de Land Matrix, reporta 1.549 transacciones en tierras sobre 85,5 millones de hectáreas, de las cuales solo para 43,6 millones de hectáreas tienen contratos efectivos, las restantes agrupan las que son solo expresiones de interés de compra, las que están bajo negociación, los tratos cancelados y fallidos. De los contratos efectivos para 24,1 millones de hectáreas la intención de uso fue agricultura y el resto para proyectos forestales, turismo, industria, conservación, energía renovable y otros usos.
} 
fundamentación empírica han conducido a diversos sesgos ${ }^{5}$. Uno de los aspectos más controvertidos es el de los efectos de las transacciones en las comunidades locales. A pesar de que se insiste en considerar que estos efectos son negativos, diversos estudios no alcanzan unos resultados tan concluyentes. Así, Hall (2011) muestra que los efectos dependen en gran medida del tipo de transacciones; Borras \& Franco (2013), que no todos los procesos de acaparamiento de tierras generan la expulsión de la población de su tierra, y Oberlack et al. (2016) encuentran mediante configuraciones arquetípicas, bajo qué condiciones las inversiones de tierra a gran escala generan efectos adversos en los medios de vida de la población.

Lo que continúa siendo difícil de cuantificar con exactitud, son las escalas, los datos sobre la cantidad de tierra acaparada siguen siendo aproximados y más aún la escala del capital que es muy difícil de establecer, debido a las complejas transacciones financieras (en el mercado de valores y diversos fondos de inversión) sin control y con poca transparencia (Nolte et al. 2016).

Dentro de los mecanismos de acaparamiento que encierra el concepto arriba mencionado, están las justificaciones de las medidas de política favorables a la inversión en tierras. La mayoría de estas justificaciones de política descansa sobre la utilización del discurso de la existencia de múltiples crisis (alimentaria, energética, climática y financiera), que profundizan la idea de la escasez creciente de recursos. Para hacer frente a dichas crisis, la búsqueda y utilización del potencial productivo de las tierras disponibles, vacías y ociosas en el mundo, a través de grandes inversiones se plantea como solución (Deininger et al. 2011; White et al. 2012).

\footnotetext{
${ }^{5}$ Oya (2013a) apunta ciertos sesgos como los intereses y criterios de actualidad mediáticos, los intereses de las campañas de las ONG para obtener financiación y de las élites políticas nacionales por exaltar el nacionalismo. También por la falta de precisión en el concepto mismo de acaparamiento de tierras, así como por diversas posiciones ideológicas propias de los estudios agrarios, dicotomías no resueltas que llevan a considerar buenos y malos escenarios como: agricultura capitalista vs agricultura familiar, nacional/doméstico vs extranjero, autoempleo vs empleo asalariado agrícola, subsistencia vs orientación al mercado, entre otros.
} 


\subsection{Características del acaparamiento de tierras en América Latina}

El fenómeno del acaparamiento de tierras se ha agudizado en la región en las últimas dos décadas con la llegada de las políticas de liberalización, basadas en la apertura de las economías hacia los mercados globales que también incluye la agricultura, el mercado de capitales y la mano de obra. La agricultura se ha venido enfocando en la producción de cultivos exportables: soja, caña de azúcar y palma de aceite, entre otros. Esta dinámica ha desencadenado nuevos procesos en las zonas rurales, en especial la reconcentración de la tierra y el incremento de casos de acaparamiento de la misma. A su vez el cambio hacia los productos exportables no tradicionales -estimulados por la proliferación de tratados de libre comercio- ha sido realizado en buena parte por empresarios y emprendedores de otros sectores como el minero, industrial, comercial y financiero, algunos asociados a inversores extranjeros (Kay 2015:75).

El primer estudio de la FAO, editado por Soto \& Gómez (2012), para verificar la existencia de acaparamiento de tierra en la región, realizado para 17 países concluye que solo en dos -Brasil y Argentina- se podía hablar de acaparamiento. Frente a estos resultados, Borras et al. (2012) -desde la definición de acaparamiento de tierras que proponen- concluyen que el proceso ocurre por lo menos en una docena de países, cuando el análisis se aborda desde factores más allá de la crisis alimentaria. Dentro de esta visión, resaltan la importancia de diferenciar extranjerización y concentración de acaparamiento de tierras, puesto que la inversión masiva en tierras no sólo ocurre por actores foráneos, los capitales locales también están participando en el acaparamiento, por lo que no siempre la extranjerización corresponde o es sinónimo de acaparamiento. Es más, la concentración de la tierra se ha incrementado en la región en las últimas 3 décadas, con anterioridad a la formulación del concepto de acaparamiento de tierras, por lo que se hace necesario examinar la cuestión de la tierra a la luz de las dinámicas del capital. Estos procesos se iniciaron en la región antes de la crisis alimentaria de 20072008, jalonados por las políticas de liberalización que facilitaron el ingreso de capitales y la transformación de la agricultura (Borras et al. 2012:408).

La otra característica es que en la región las grandes inversiones extranjeras en tierra son realizadas por el capital regional, denominado por Soto y Gómez (2012) empresas trans-latinas, las cuales en algunos casos establecen alianzas 
con capitales internacionales, y en otros, son recursos provenientes de paraísos fiscales, lo que dificulta establecer el origen y escala del capital. Los países que involucran capital nacional en el acaparamiento de tierras son Brasil, Argentina, Chile, Colombia, Panamá, México y Costa Rica. Y a su vez existe un acaparamiento de tierras intrarregional, sobre todo por países como Brasil, Argentina y Chile. La concentración, acaparamiento y extranjerización de tierras se dan mediante diferentes formas: compras directas de tierras, arrendamientos por períodos de 99 años y más, diferentes arreglos de rentas. Lo que subyace aquí como importante es que el capital toma el control de la tierra y los recursos y utiliza diversas formas para lograrlo.

Otra parte central en el análisis es el rol de los estados -considerados estados de una democracia liberal estable- que por un lado intentan tener legitimidad a través de ciertas políticas y leyes en contra de la extranjerización de tierras, pero que, de otro, son activos promotores del acaparamiento de tierras facilitando las transacciones en tierras y las alianzas entre inversores nacionales y extranjeros (Borras et al. 2012).

En el intento de responder, por qué los estados permiten este tipo de transacciones, Sassen (2015) afirma que las políticas de ajuste estructural, a las que se sometieron en su mayoría los países del Sur Global, han hecho reducir de forma drástica su gasto público en servicios esenciales para el desarrollo (educación, salud, infraestructura) al priorizarse el pago de la deuda. Al mismo tiempo, se les ha forzado a liberalizar sus economías para competir en el mercado internacional en situación de desventaja. De esta forma los gobiernos nacionales se han debilitado siendo más proclives a la corrupción, permitiendo y facilitando las transacciones en tierras a favor de las élites locales, de gobiernos y empresas extranjeras. Resalta así que el problema no es solo de carácter endógeno, de debilidad y corrupción de los estados nacionales, sino que está relacionado también con los efectos de las reglas y condiciones que los organismos internacionales (FMI, BM, OMC) impusieron a los gobiernos nacionales si querían lograr el crecimiento económico y el desarrollo (2015: 99).

Para el caso colombiano, el capítulo cinco de esta investigación profundiza precisamente en las medidas de política que estos organismos han adelantado en el país como requisito para los préstamos y la ayuda al desarrollo, 
principalmente en lo han denominado política agraria y de tierras, superación del conflicto armado y de la pobreza.

\subsection{Mecanismos para el acaparamiento de tierras: el papel del estado}

En el estudio de los mecanismos de política utilizados para favorecer el acaparamiento de tierras, se ha dado especial relevancia a las políticas de tipo global, pero también se hace necesario profundizar en las políticas nacionales que tienen efectos directos en los territorios donde sucede el acaparamiento de tierras. Y en este sentido, estudiar el papel de los estados es crucial, pues no es un actor pasivo en el proceso. Por el contrario, a través de las políticas y la instrumentalización de las mismas y por medio de los marcos legales favorece principalmente el acaparamiento de tierra.

Siguiendo las políticas globales, los estados han identificado tierras denominadas 'ociosas' o 'marginales' y las han promocionado como disponibles para atraer e implementar agronegocios. Aparte de promover esta forma de privatización de la tierra, en los casos en que el estado es el poseedor de la tierra, se observa la implementación de figuras de derechos de explotación para operadores privados, como la declaratoria de zonas especiales para el desarrollo económico nacional o de utilidad pública, en tierras generalmente de poca densidad poblacional pero que han sido habitadas ancestralmente por comunidades campesinas e indígenas. De esta forma Cotula (2012) y Wolford et al. (2013) sostienen que los estados, aunque no se consideren un factor causante del actual acaparamiento de las tierras, sí cumplen un rol importante al facilitarlo cuando otorgan o limitan los derechos de uso sobre los recursos que controlan.

La denominación de tierras marginales, aisladas, vacías u ociosas, es cierta solo en la retórica, forma parte de la justificación de las crisis que pide poner estas tierras en producción. Por el contrario, la evidencia muestra que las inversiones están mayoritariamente en lugares con un alto potencial hídrico y un suelo fértil, así como abundancia de recursos naturales y acceso a infraestructuras (Cotula 2012:655-656), por lo que los inversionistas van a por las mejores tierras (White et al 2012). Tampoco las tierras están vacías, han sido en la mayoría de 
los casos el territorio del cual diversas comunidades rurales han generado sus medios de vida. Por lo tanto, si los gobiernos facilitan la compra de las tierras de los pequeños productores rurales por los grandes inversionistas, puede generarse una reforma rural global regresiva y en este sentido se hace necesario comprender los cambios que se pueden generar en la agricultura y en los espacios rurales (White et al 2012).

Borras \& Franco (2013) describen seis tipos de medidas (políticas y administrativas) que adoptan los estados para ejercer control o capturar las tierras marginales y convertirlas en un bien de inversión: i) La creación o justificación de la necesidad de realizar inversiones de tierras a gran escala; ii) la definición, reclasificación y cuantificación de qué tierra es marginal, subutilizada o vacía; iii) la identificación de esos tipos particulares de tierras; iv) la afirmación de que el estado tiene la absoluta propiedad sobre estas tierras; v) la adquisición y apropiación de las tierras; y vi) la reasignación o disposición de las tierras para los inversores.

La nueva institucionalidad creada para la planificación agropecuaria en Colombia $^{6}$ en el gobierno a partir de 2011, tiene como misión varias de estas medidas que preparan el camino para facilitar el ingreso de tierras de frontera a la agricultura comercial a gran escala.

Dentro de las medidas que implementan los estados para dar paso al acaparamiento de tierras, Borras \& Franco (2013) describen tres acciones principales que pueden darse de forma interrelacionada:

- Un proceso de simplificación del estado: esto incluye la creación de catastros, registros de las tierras y títulos, que le permiten al estado simplificar las relaciones sociales basadas en la tierra para facilitar su administración. Pero también a su vez justificar la tierra que no está titulada para apropiarla, la que no está censada considerarla vacía y la que no está formalmente explotada catalogarla como subutilizada.

\footnotetext{
${ }^{6}$ En 2011 se crea la Unidad de Planificación de Tierras Rurales, Adecuación de Tierras y Usos Agropecuarios UPRA, que tiene entre varias funciones elaborar los criterios técnicos para la toma de decisiones sobre el ordenamiento social de la propiedad de la tierra rural, el uso eficiente del suelo para fines agropecuarios, entre otros (MADR 2011).
} 
- La afirmación de la autoridad y soberanía sobre el territorio: las transacciones de tierras son vistas como un componente esencial del proceso de construcción del estado, como una forma de extender la autoridad y la soberanía a espacios donde no ha hecho presencia.

- La coacción y la violencia para hacer cumplir la ley a través de la fuerza pública (policía, militares o paramilitares) y los tribunales, forma parte de la construcción del estado y de la forma de hacer cumplir los procesos de simplificación.

Otra forma que utilizan los estados para facilitar la apropiación de tierras es la creación de las Zonas Económicas Especiales (SEZs por sus siglas en inglés) y los corredores de infraestructura. Las SEZs son áreas geográficas dentro de las fronteras de un país, con reglas especiales para la inversión, el comercio, los impuestos, las aduanas y otras regulaciones (empleo), diferentes al resto del territorio nacional. El propósito es que sean zonas más libres de las políticas del país y con mayor eficacia administrativa (World Bank 2011).

Las SEZ ejercen su poder de expropiar cuando se consideran zonas de interés público, como el caso de la India estudiado por (Levien 2012) donde mediante la Ley SEZs de 2005, se establecieron las condiciones para construir grandes enclaves económicos industriales. Allí el estado, muchas veces a través de mecanismos de coerción, compró las tierras a los pequeños agricultores y las puso a disposición de inversores privados, con el propósito de atraer inversión, desarrollar infraestructura y generar empleo, pero finalmente lejos de lograr una absorción significativa de la mano de obra rural, lo que ha sucedido en las villas es la desposesión y 'commodificación' de la tierra (Levien 2012:949). El estado se ha convertido en el principal comisionista de tierras para el capital, en la medida en que, para facilitar la acumulación, acude a medidas por fuera del mercado como la expropiación de tierras con "propósitos públicos"(Levien 2012:964).

Camboya es otro ejemplo analizado por Touch \& Neef (2015) donde el estado convierte la tierra que posee (entre $75-85 \%$ del territorio del país) en tierra privada a través de la Ley de Tierras de 2001, adjudicando la mayoría de estas a inversores nacionales e internacionales a través de las Concesiones Económicas de Tierra (ELCs, por sus siglas en inglés), las cuales han generado 
fuertes enfrentamientos entre los campesinos y la fuerza pública cuando los primeros se resisten a los desalojos.

Por su parte, los corredores de Infraestructura son: "zonas donde se focaliza una gran inversión en infraestructuras con el objetivo de interconectar zonas de fronteras extractivas con las áreas metropolitanas y los mercados externos...son superautopistas que conectan áreas no explotadas de los países en desarrollo a la inversión extranjera privada, a los agronegocios y la extracción de recursos naturales" (White 2012:629).

En Brasil, el estado, con el objetivo de frenar la ocupación ilegal de tierras en el estado del Amazonas en las zonas de transición con el Cerrado ${ }^{7}$, implementó el programa de regularización de tierras mediante la titulación, denominado Terra Legal. Esta medida, de acuerdo con el análisis de Oliveira (2013) permitió estructurar el acaparamiento de tierras, no exactamente por el proceso de titulación en sí, sino porque facilitó el uso de la zona de transición para la expansión de agronegocios a lo largo del corredor de transporte entre la zona del Cerrado y el Amazonas.

Las acciones adoptadas por los estados son descritas por Jonathan Fox (1993) citado por Borras \& Franco (2013), como dos tareas contradictorias; de un lado facilitan la acumulación del capital y de otra, deben mantener un mínimo nivel de legitimidad. Ambas acciones son parte del problema y también de la solución, en la medida en que los casos de despojo y desposesión atentan contra la legitimidad del estado, este debe actuar frenando o estableciendo regulaciones.

En este sentido, el estudio de las estrategias de tipo legal utilizadas por los estados cobra gran importancia, en la medida en que al tiempo que facilitan las transacciones de tierras también abren puertas para la defensa o reacciones políticas de los afectados. Edelman et al. (2013:1524) exponen cómo a nivel internacional, los estados y los inversionistas defienden las leyes sobre comercio internacional y la inversión que son ampliamente aplicadas debido a la presión de las élites. Por su parte, los activistas y comunidades agrarias

\footnotetext{
${ }^{7}$ El cerrado es la región en la que el estado de Brasil ha permitido y facilitado la inversión económica nacional e internacional en los agronegocios y la economía extractiva.
} 
priorizan las leyes basadas en los Derechos Humanos para defender sus derechos sobre la tierra y la seguridad alimentaria, pero son aplicadas selectivamente y de forma desigual en las convenciones regionales y las leyes.

Para el caso colombiano Grajales (2015) describe muy bien la importancia del uso de los mecanismos e instancias legales para la protección de los Derechos Humanos que han favorecido las demandas de los campesinos para recuperar las tierras despojadas por medios violentos en la región del Bajo Atrato Colombiano. Allí, las instancias judiciales nacionales, apoyadas en leyes e instancias internacionales, han emitido sentencias de protección y recuperación de los derechos sobre las tierras ante las demandas de las comunidades organizadas.

Así pues, son dos los aspectos a profundizar en esta investigación. Por un lado, la influencia y adopción de directrices de organismos internacionales en las políticas nacionales en los últimos 30 años y su influencia en la profundización de la inversión privada en las zonas rurales, especialmente en la adquisición de tierras y la transformación de la agricultura. Por otro, la implementación y modificación de marcos legales para imponer dichas políticas, en un contexto particular de concentración histórica y despojo de la tierra causante del conflicto armado y de la persistencia del narcotráfico que se reproduce gracias a estos factores y que a su vez los fortalece.

Las acciones del estado, descritas arriba por Borras \& Franco (2013), para el caso colombiano han incluido la adopción de procesos de simplificación llevados a cabo con mayor premura en la última década, la coerción y la violencia que ha sido parte integral de la política de recuperación (o apropiación) del territorio, llegando hasta el establecimiento de alianzas con grupos paramilitares para ejercer control territorial y social y dar paso al acaparamiento de tierras (Grajales 2013, 2015).

\subsection{Los elementos a profundizar en el acaparamiento de tierras}

A pesar de la abundante literatura sobre acaparamiento de tierras en la última década, aún existen vacíos y dimensiones para profundizar en los estudios que se hacen sobre el tema. 
Los factores internos de los países que son receptores de grandes inversiones en tierras, son de carácter determinante tanto en la forma en que ocurre el proceso como en los efectos que estas causan. En esta dirección Cotula (2012), llama la atención sobre la necesidad de profundizar las dinámicas locales de los actores nacionales y locales, dentro de estos la participación de las élites en la compra de tierras y también el rol que cumplen los mercados internos en las estrategias de inversión.

Los antecedentes históricos también los relaciona Edelman (2016) como importantes para explicar la historia actual del acaparamiento. Los elementos históricos incluyen las formas históricas de lucha por la tierra, las condiciones preexistentes de tenencia de la tierra y de la organización social y colectiva de las comunidades donde ocurre el fenómeno. $\mathrm{Y}$ en gran medida de estos factores va a depender el impacto del acaparamiento como también la respuesta de resistencia o no de los afectados.

La respuesta de las comunidades o población local afectada por el acaparamiento, la abordan Hall et al. (2015) como las reacciones políticas 'desde abajo ${ }^{18}$ que incluyen diversos tipos de resistencia o su inexistencia. Lo que va a depender en parte del tipo de uso que el inversionista de a la tierra acaparada. Si necesita la tierra y no la mano de obra los pobladores son expulsados de sus tierras, si necesita la mano de obra se da la oportunidad de que sean incorporados a los proyectos productivos y las demandas se centraran en exigir unos mejores términos de incorporación. Pero también depende del tipo de comunidades, pues no son homogéneas y no tienen el mismo interés y concepción sobre la tierra.

Por lo anterior, los estudios del proceso en el nivel local, los estudios de caso específicos, son considerados necesarios y relevantes, pues los efectos de las adquisiciones masivas de tierras, aunque obedezcan a los mismos detonantes

\footnotetext{
${ }^{8}$ Las reacciones políticas desde abajo son respuestas que van más allá de la resistencia, incluyen un rango amplio de movilizaciones que buscan desde la compensación de los expulsados de sus tierras (demandas para ser contratados -incorporados- en los proyectos productivos como granjeros o trabajadores, o cambiar los términos y condiciones de esos contratos, de los arreglos de tenencia, de los sistemas de producción y de las cadenas de valor en las que participan) hasta participar en movilizaciones en contra de aquellos que se resisten a los tratos en tierras (Hall et al. 2015).
} 
comentados anteriormente, ocurren bajo contextos diferentes no solo de los territorios sino también al interior de las comunidades. Los estudios de caso, también permiten conocer el proceso construcción del estado en lo local.

El análisis de la implementación de las políticas y los marcos normativos muestran la actuación del estado en el nivel nacional, pero su actuación en lo local a través de sus instituciones, permite ver además de su construcción en el territorio, cómo y mediante cuáles mecanismos ejerce su soberanía y autoridad para facilitar o frenar el acaparamiento de tierras. De igual manera los estudios de caso permiten conocer el rol de los diferentes actores en lo local, los empresarios, las élites políticas y económicas, la fuerza pública, los grupos armados al margen de la ley y los narcotraficantes, que para el caso colombiano han creado un poder "sub-nacional" (Grajales 2015) que ha participado en la desposesión y el despojo y que hace más difícil el acceso a la tierra para las comunidades rurales. 


\section{Capítulo 3}

\section{Metodología y fuentes}

El presente capitulo describe las bases metodológicas y la selección y uso de las fuentes de información utilizadas para elaborar esta investigación. En un primer apartado se describe el uso de recursos bibliográficos y la realización de un análisis documental variado y exhaustivo de diferentes tipos de textos sobre las políticas públicas centradas en el tema agrario. En segundo lugar, la realización de una revisión sistemática de literatura (Systematic Literature Review) sobre acaparamiento de tierras en Colombia, con el propósito de identificar casos de estudio y realizar un estudio comparado de los mismos.

\subsection{Análisis bibliográfico y documental para el estudio de políticas públicas}

La búsqueda, recopilación y análisis de bibliografía ha sido utilizada desde el primer momento de la investigación con el fin de conocer los trabajos previos llevados a cabo sobre acaparamiento de tierras a nivel global. Dentro de ellos, los desarrollos desde la economía política agraria (el análisis de los cambios agrarios con la introducción del neoliberalismo) son unos de los pioneros en abordar conceptual y teóricamente el fenómeno reciente de acaparamiento de tierras. La lectura y análisis del contenido de estos trabajos científicos, 
abordados anteriormente en el capítulo sobre las consideraciones teóricas, permitieron guiar tanto la estructura de la investigación como la selección de los métodos a utilizar para lograr los objetivos propuestos de la siguiente manera:

- En primer lugar, se presenta en el capítulo número cuatro una breve contextualización sobre la tenencia de la tierra, la estructura productiva y la importancia del sector agropecuario en Colombia. Para los cual se acudió principalmente a las estadísticas disponibles en el último Censo Nacional Agropecuario de 2014 y a los datos del sitio Web del Ministerio de Agricultura (Agronet). Como otro factor de contexto fundamental, se realiza un apartado sobre la violencia, centrado en la historia y accionar de los grupos armados principales, el cual se elaboró a partir de revisión de literatura científica, documentos del Centro Nacional de Memoria Histórica, el portal periodístico de Verdad Abierta y también prensa nacional.

- En segundo lugar, y ya en relación al primer objetivo de la investigación que se trata en el capítulo 5 de este documento, se aborda la influencia de las políticas internacionales sobre las políticas agrarias y rurales colombianas, en especial en relación a la cuestión de la tierra. Se contrasta así, para el caso de Colombia, la idea planteada por algunos autores (por ejemplo, Cotula (2012) o White et al. (2012)) que enfatizan el papel de los gobiernos de los países desarrollados, los organismos de carácter multilateral y las agencias de cooperación internacional en la promoción de políticas y medidas que incentivan la inversión en tierras y que modelan la estructura productiva hacia un tipo de cultivos determinados.

Teniendo en cuenta que el gobierno internacional con mayor influencia en el país, así como en la mayoría de países latinoamericanos, es Estados Unidos, se acudió a la búsqueda de documentos que dieran cuenta de los programas y proyectos implementados por su agencia de cooperación internacional (USAID) en Colombia. Del mismo modo, dentro de los organismos internacionales el de mayor trayectoria en el país ha sido el Banco Mundial y sus agencias relacionadas, quienes además de fijar directrices de políticas son los que otorgan los préstamos y la financiación para los proyectos de desarrollo del país. 
Por ello el análisis se centra básicamente en estos dos organismos incluyendo los requisitos de la OCDE a Colombia en materia de agricultura, debido a la solicitud del país de entrar a este grupo.

Para el caso de la USAID, la búsqueda se realizó en la base de datos de su sitio web, donde se encontraron algunos de los documentos de los proyectos y programas implementados en Colombia en las dos últimas décadas. Se realizó un primer filtro de los mismos, ubicando aquellos que incluyeran el tema de tierras, política agraria, agricultura y desarrollo rural, pues la mayoría están relacionados a temas de seguridad y lucha contra la insurgencia y anti-narcóticos. Con estos documentos se procedió a realizar un análisis de contenido, identificando las recomendaciones de política que estos hacen y si los objetivos que estos apoyos plantean se han reflejado en los programas ejecutados en los territorios en los cuales han operado. Esto último a través de la búsqueda también de documentos que contienen las evaluaciones de los efectos de estas intervenciones.

Para analizar los documentos del Banco Mundial también se accedió a su sitio web donde tiene la base de datos de los préstamos y proyectos a cada país. Para el caso de Colombia incluye más de 237 documentos con referencias a proyectos. En esta base de datos se buscaron los documentos de proyectos que hicieran referencia a la política agraria y de tierras, agricultura y desarrollo rural, superación de la pobreza y solución al conflicto armado. Además, se analizaron los documentos de recomendaciones de política y las estrategias y planes de financiación que elabora el BM para cada período de gobierno identificando y analizando los apartados que contenían los temas ya mencionados.

Finalmente, para poder identificar en qué grado estas directrices de política se implementaron en el ámbito nacional y territorial, se realizó una revisión de los Planes Nacional de Desarrollo (PND) de las últimas dos décadas. Estos documentos se encontraron en el sitio web del Departamento de Planeación Nacional (DNP).

- En tercer lugar, el objetivo número dos de la investigación se enfocó en identificar el rol del estado en el acaparamiento de tierras 
especialmente a través de los cambios en los marcos legales, considerados por Edelman et al. (2013) como parte del contexto que facilita las transacciones de tierras, y el que a su vez abre espacio para las demandas legales por parte de los afectados.

Uno de los casos colombianos que mejor refleja esta situación es la disputa política y legal desatada por acumulación ilegal de tierras baldías o entregadas en procesos de reforma agraria y cuyo punto de eclosión fueron las compras masivas de tierras en la región de la Altillanura. Situación que desde 2011 hasta 2016 ocupó varios artículos en la prensa nacional, informes de diferentes organizaciones y la acción del estado por modificar la ley agraria. Así en el capítulo número seis se analizó cómo funcionan los mecanismos políticos y legales que han sido empleados en los procesos de acaparamiento de la tierra en Colombia.

Para la elaboración de este apartado se acudió a diversos documentos de tipo legal emitidos por las instituciones de la rama judicial, como las sentencias de la Corte Constitucional, denuncias de casos de acaparamiento por diferentes actores, informes de instituciones de gobierno sobre irregularidades en la adjudicación de tierras, informes y reportes de algunas ONG con casos puntuales.

De igual manera se accedió a plataformas periodísticas especializadas como Verdad Abierta y Rutas del Conflicto. La primera fue creada en 2008 como una iniciativa conjunta entre la fundación nacional Ideas para la Paz y la revista Semana, con el objetivo de aportar a la reconstrucción y difusión de la verdad histórica y judicial sobre el conflicto armado colombiano y de desvelar vulneraciones a los Derechos Humanos ${ }^{9}$. La segunda plataforma, se creó para dar información sobre el conflicto armado, involucrando testimonios de los sobrevivientes, difundiendo la información de entidades judiciales e investigaciones periodísticas y

\footnotetext{
${ }^{9}$ Ver https://verdadabierta.com/quienes-somos/. Consultado última vez en Junio 5 de 2018 .
} 
académicas. Esta plataforma es apoyada por el Centro Nacional de Memoria Histórica, la Universidad del Rosario y Verdad Abierta ${ }^{10}$.

De igual manera se realizó una búsqueda de artículos de prensa, en especial aquellos donde se anunciaban las inversiones en tierras en la Altillanura, el cubrimiento mediático a los procesos de denuncia y publicación de los informes, así como al proceso de los intentos de cambio legal, respaldados por documentos de organismos como la USDA.

Aunque la prensa no se considere una fuente totalmente fidedigna de información científica, para estos casos, su utilización ha sido útil para conocer la posición y el rol desempeñado por los actores implicados en los procesos de acaparamiento. Entre los diarios nacionales consultados están El Espectador, Portafolio, revista Semana y revista Dinero.

\subsection{Revisión sistemática de literatura para la selección de estudios de caso}

El tercer objetivo de la investigación se aborda en el capítulo número siete, y persigue profundizar en los mecanismos utilizados para acaparar la tierra en el país y proponer una tipología de dichos mecanismos a través del análisis comparado de estudios de caso. Con ello se quiere contribuir a llenar los vacíos que aún existen en la investigación sobre acaparamiento de tierras, de un lado, por la carencia de estudios de caso específicos que permitan conocer las particularidades del proceso $\mathrm{y}$, por otro, la necesidad de una mayor profundización en el marco analítico histórico de los espacios donde tiene lugar el acaparamiento (White 2012; Edelman et al. 2013; Borras \& Franco 2013).

Para desarrollar el propósito mencionado, era necesario indagar en qué medida se había abordado el fenómeno del acaparamiento de tierras en Colombia en publicaciones científicas y cuántos de estos trabajos investigaban

\footnotetext{
${ }^{10}$ Ver http://rutasdelconflicto.com/proyecto/. Consultado última vez en Junio 5 de 2018.
} 
casos puntuales a nivel (micro) de predios acaparados o despojados. Para lo anterior se optó por elegir la técnica del análisis sistemático de literatura (Systematic Literature Review), dado que este método permite identificar, evaluar y sintetizar de forma exhaustiva todos los estudios relevantes sobre un tema determinado (Petticrew \& Roberts 2008).

La revisión sistemática se considera una rama del esfuerzo científico que tiene tanta validez como la investigación primaria y su uso ofrece tanto la posibilidad de facilitar la construcción teórica como de ponerla a prueba.

Se aparta de una revisión de literatura convencional porque involucra un proceso riguroso y transparente, que debe ser exhaustivo en cubrir la literatura existente, tomar un enfoque claro y sistemático para sintetizar los datos y tener un cuidado especial con la calidad de la evidencia que se incluye. Cumplir con estas características, es lo que le otorga mayor validez y confiabilidad a los resultados que se obtienen al emplearla y evita los sesgos que se atribuyen a una revisión de literatura convencional.

Dentro del tema de acaparamiento de tierras hay varios trabajos que involucran esta metodología de revisión sistemática, entre otros podemos mencionar a (Oya 2013b) sobre el impacto socioeconómico de los acaparamientos de tierras en África, a Dell'Angelo et al. (2017) quienes tratan el acaparamiento de los bienes comunes y Oberlack et al. (2016) quienes abordan la sostenibilidad de los medios de subsistencia ante la fiebre global por la tierra.

De acuerdo con Petticrew \& Roberts (2008), los pasos para llevar a cabo una revisión sistemática incluyen:

- Definir el alcance: una clara definición de la pregunta o hipótesis de investigación y verificar que la revisión sistemátic

- a planteada no se haya realizado aún.

- Planear: convertir la pregunta de investigación en conceptos individuales para crear los términos de búsqueda. Formular criterios preliminares de inclusión y exclusión y justificarlos

- Búsqueda: Utilización de los términos de búsqueda en las bases electrónicas de datos seleccionadas y repetir el proceso de búsqueda para asegurar que se encontraron todas las publicaciones disponibles. 
- Evaluación: Exportar referencias a un gestor de citas para cotejar los resultados y leer los títulos, resúmenes y palabras clave.

- Elegibilidad: Aplicar los criterios de inclusión y exclusión a fondo

- Diseminación de resultados: Elaborar los resultados o hallazgos de los estudios e implementar la forma de difundirlos.

El siguiente apartado describe cómo se llevaron a cabo cada uno de estos pasos en la presente revisión sistemática.

\subsubsection{Protocolo para la recolección de datos}

Teniendo en cuenta la existencia amplia de literatura sobre la problemática de tierras y violencia en Colombia, tanto de carácter académico como no académico, se optó por incorporar una estrategia variada. Además de la inclusión de artículos académicos, se realizó una búsqueda exhaustiva en los sitios web de organizaciones relacionadas con el tema, donde se encontraron reportes e investigaciones adelantados por estos, así como en las bases de varias instituciones nacionales.

En primer lugar, la selección y recuperación de artículos científicos se guío mediante palabras clave en los buscadores de Scopus, Web of Sciences y Google Scholar. Los dos primeros son las bases de datos bibliográficos más extensas y populares y cubren un gran rango de revistas internacionales con revisión de pares. La búsqueda se restringió a los títulos, los resúmenes y las palabras claves de los artículos. El período de búsqueda fue de 1990-2017. Se seleccionó a partir de la década de los años noventa por considerarse la época en que inició el ascenso de actos violentos (asesinatos y masacres) incrementando las cifras de desplazamiento de población rural. La búsqueda se realizó en idioma inglés y español (Tabla 3.1). 
Tabla 3. 1. Criterios de búsqueda para la recolección de datos

\begin{tabular}{|c|c|c|}
\hline Bases de Datos & Criterios de búsqueda & Resultados \\
\hline $\begin{array}{l}\text { Scopus } \\
\text { Web of Science } \\
\text { Google Scholar }\end{array}$ & $\begin{array}{l}\text { Key words: "Land grab*” AND } \\
\text { "Colombia" } \\
\text { "Land transactions" AND “Colombia" } \\
\text { "Land deals" AND “Colombia" } \\
\text { "large scale investment in land" AND } \\
\text { "Colombia" } \\
\text { "green grab" AND "Colombia" } \\
\text { "water grab" AND" Colombia" } \\
\text { "Land investment" AND "Colombia" } \\
\text { Fecha de publicación: } 1990 \text {-2017 } \\
\text { Fecha de realización: 5-6 May } 2017 \\
\text { Tipo de documento: artículo y revista. }\end{array}$ & $\begin{array}{l}\text { Scopus: } 104 \\
\text { Web of Sciences: } \\
84 \\
\text { Google Scholar: } \\
249 \\
\text { Total: } 437\end{array}$ \\
\hline
\end{tabular}

Fuente: Elaboración propia

El proceso permitió obtener inicialmente 437 referencias académicas, luego de la eliminación de referencias duplicadas, se cargaron 133 artículos a Endnote para continuar con el proceso. Todos los potenciales artículos fueron evaluados considerando aquellos que cumplían algunos de los siguientes criterios de inclusión:

- Recogían información y análisis de casos concretos (fincas o zonas) de acaparamiento de tierras o desposesión de tierras

- Estaban relacionadas con:

- Conflictos por tierras asociados a los derechos de propiedad

- Conflictos por tierras asociados con la implementación de agronegocios, proyectos verdes o agroambientales o de infraestructura.

- Despojo de tierras y restitución.

Estos criterios se aplicaron en dos fases: en primer lugar, a nivel de títulos, palabras clave y resumen, y en segundo lugar, a nivel del contenido íntegro de los documentos. Esto permitió quedarse con un total de 35 artículos académicos. El proceso de recolección de datos se esquematiza en la Figura 3.1. 
Con el objetivo de nutrir la reconstrucción de estudios de caso, identificados a partir de los 35 artículos obtenidos con la revisión sistemática de literatura, fue necesario incluir literatura gris, la cual comprende otros documentos que fueron recuperados de los sitios web de organizaciones nacionales como el Departamento Nacional de Planeación (DNP), Contraloría General de la República, Ministerio de Agricultura y Desarrollo Rural, Corte Constitucional, y Congreso Nacional. También artículos de la prensa nacional. Todo el bloque de literatura fue analizado enfocándose en la evidencia empírica sobre casos de acaparamiento de tierras con diferentes propósitos, también como consecuencia de la implementación del modelo económico o de los actos violentos ejercidos por diferentes actores para controlar la tierra.

Figura 3. 1. Protocolo de recolección de datos

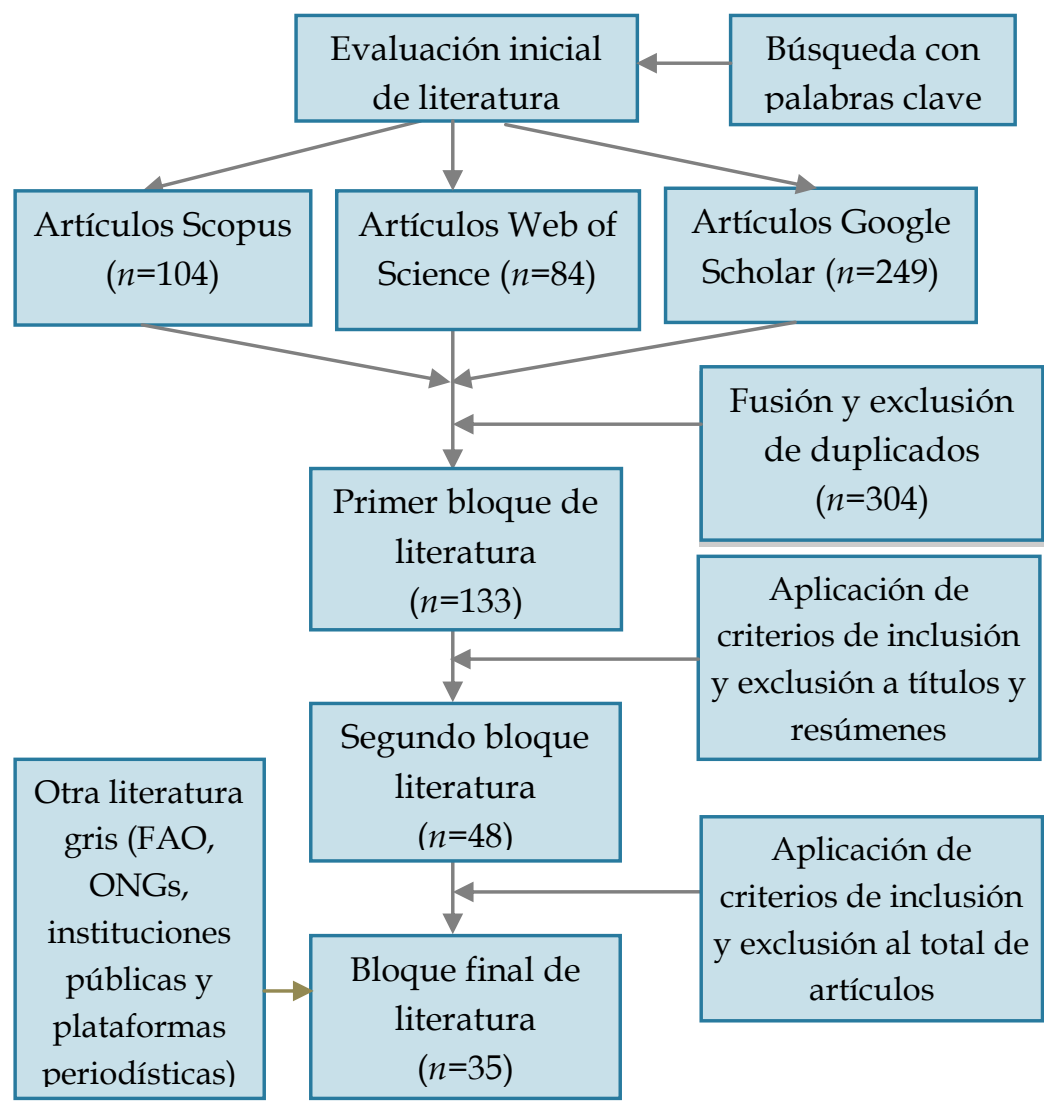

Fuente: Elaboración propia 
Dentro de los contenidos generales de los documentos, 10 abordan el tema del acaparamiento de forma generalizada, es decir no centran su objeto de estudio en una región determinada ni en un predio. Los 25 restantes hacen referencia a las regiones Montes de María (8), Orinoquía (6), Urabá (3), Bajo Atrato (6), al departamento de Sucre (1), al departamento de Magdalena (3) y al departamento de Bolívar (1). La misma región es tratada por varios de los autores o una misma región más de una vez por el mismo autor.

\subsubsection{Selección y construcción de estudios de caso}

La revisión sistemática permitió identificar los casos de estudio y disponer de los elementos necesarios para su caracterización y análisis. Sin embargo, es importante señalar que la descripción y sistematización de los mismos que se recoge en el capítulo siete de esta tesis no deriva de forma directa y biunívoca de una sola fuente bibliográfica. Por el contrario, estos casos aparecen de forma desigual o parcial en varios de los documentos, por lo que ha sido necesaria una reconstrucción a partir de ellos para poder describirlos y sistematizarlos de manera que haya sido posible un análisis comparativo. Cada caso seleccionado se reconstruyó desde el período en que se contaba con información de la situación inicial y fue completándose su trayectoria hasta la última y más reciente información encontrada. Para ello, se ha combinado la información de estos documentos con otra procedente de otras fuentes:

- El portal periodístico especializado Verdad Abierta,

- Documentos legales como sentencias de los juicios sobre restitución de tierras,

Fiscalía General de la Nación, Corte Suprema de Justicia, Juzgados locales y Corte Constitucional.

- Centro de Memoria Histórica

- Prensa nacional.

La combinación de estas fuentes, incluyendo la utilización de documentos de tipo legal, ayudaron a reconfirmar la veracidad de los hechos que se narraban solo en fuentes como los portales periodísticos o la prensa nacional, que pueden contener una mayor carga de sesgo ideológicos. De igual manera los trabajos abordados del Centro de Memoria Histórica, aunque dependa de una 
institución estatal, son un esfuerzo de varios intelectuales en la reconstrucción del conflicto armado y los procesos de despojo. En definitiva, esta triangulación de fuentes académicas y no académicas, incluyendo las oficiales, es la que permite afianzar la fiabilidad y credibilidad de la información utilizada.

El análisis comparativo de los 12 casos que hemos reconstruido se ha basado en la búsqueda de 'patrones' o secuencias de eventos o uso de instrumentos legales en los procesos de despojo y acaparamiento. Para ello, hemos agrupado las etapas similares empleando unas 'etiquetas' comunes que, sintetizadas en una única tabla, han permitido realizar este estudio comparativo. Esto nos permite una visualización de las trayectorias del proceso de despojo y acaparamiento de los predios, y también establecer los patrones y las similitudes en los mismos. Este análisis se contextualiza en el marco de los principales hechos del contexto político y legal en los diferentes períodos, que sin duda influyen en dichas trayectorias.

El desarrollo y aplicación de esta metodología; reconstrucción de casos, definición de etiquetas o categorías en una trayectoria temporal, es un aporte creativo y novedoso que además de permitir reconocer las trayectorias del proceso puede ser utilizado en otros estudios similares. 



\section{Capítulo 4}

\section{Agricultura y violencia en Colombia: Una primera aproximación}

Este capítulo tiene un carácter instrumental, presentando una sucinta aproximación a dos temas cuyo conocimiento en términos básicos es necesario para abordar los análisis que se desarrollan en los tres capítulos siguientes y constituyen el contenido de la investigación. Por una parte, se describen algunos rasgos básicos de la estructura agraria y de la agricultura colombiana y, por otra, se realiza un breve análisis introductorio sobre la conformación y acción de los principales actores alzados en armas (grupos guerrilleros insurgentes y paramilitares) generadores de despojo y acaparamiento de tierras.

La estructura agraria y dentro de ella la tenencia de la tierra determina un rol central en el control que se ejerce sobre esta y sus recursos, así como en la determinación de su uso. Adicionalmente, para el caso colombiano, la estructura agraria desigual e inequitativa se ha constituido en una de las raíces de la violencia rural (Kay 2001; Fajardo 2014). En este capítulo se presenta una breve caracterización de la estructura actual de la tenencia de la tierra, se analiza la estructura productiva de esta agricultura (distribución por 
principales cultivos) y su evolución durante los últimos 25 años, y se aportan asimismo algunos indicadores que reflejan la importancia del sector agropecuario en la economía colombiana. El análisis se apoya en los principales datos del último Censo Nacional Agropecuario (2014), así como en información estadística proporcionada por el Ministerio de Agricultura y Desarrollo Rural.

Esa breve visión de la agricultura colombiana se complementa con una referencia al volumen y estructura de la población rural y al peso que en la misma tienen los distintos grupos étnicos, con una mención asimismo a los derechos sobre la tierra de las comunidades tradicionales.

En la parte final del capítulo (apartado 4.5.), sin pretender profundizar aquí en el análisis de la relación entre concentración de la tierra y violencia, se sintetiza la compleja y extensa historia de los actores armados principales que durante las últimas décadas han participado de forma activa en los procesos de despojo y acaparamiento de tierras, utilizando de forma sistemática métodos violentos. Como introducción a ese análisis se hace una breve referencia a los antecedentes históricos que muestran la transformación de las relaciones de producción en el campo colombiano, la conformación del campesinado y el origen de las movilizaciones y luchas campesinas ya importantes en la primera mitad del siglo XX.

\subsection{La estructura de la tenencia de la tierra en Colombia}

La estructura agraria de Colombia se ha caracterizado por ser bimodal; de un lado grandes extensiones de tierra, latifundios en su mayoría con un bajo o ningún uso productivo y de otro, numerosas explotaciones cada vez más fragmentadas (mini y microfundios). El último censo agropecuario ${ }^{11}$ de 2014 muestra que la situación no ha cambiado y que por el contrario la alta desigualdad continúa.

\footnotetext{
${ }^{11} \mathrm{El}$ anterior censo nacional agropecuario se había realizado en 1970. En el censo de 2014 el total del área rural dispersa censada fue de 111,5 millones de hectáreas de las cuales $56,7 \%$ se dedicó a Bosques Naturales, 38,6\% a uso agropecuario y 4,7\% a otros usos.
} 
Como se puede observar en el Gráfico 4.1, del total de 2.370.099 Unidades de Producción Agropecuarias (UPA) ${ }^{12}$ censadas, el $70,4 \%$ son menores de 5 hectáreas y tiene apenas el 2\% del área (2.160.347 ha), con respecto al área total productiva censada (108.993.334 ha). Y como contraste las UPA mayores a 500 hectáreas concentran el 77,3\% (84.227.529 ha) del total de área productiva. La mediana propiedad (entre 20-50 ha) es mínima, menos del 10\%. Con lo cual es clara la alta concentración de la tierra productiva en el país.

\section{Gráfico 4. 1 Colombia: Unidades de Producción Agropecuaria y su área por rango de tamaño 2014}

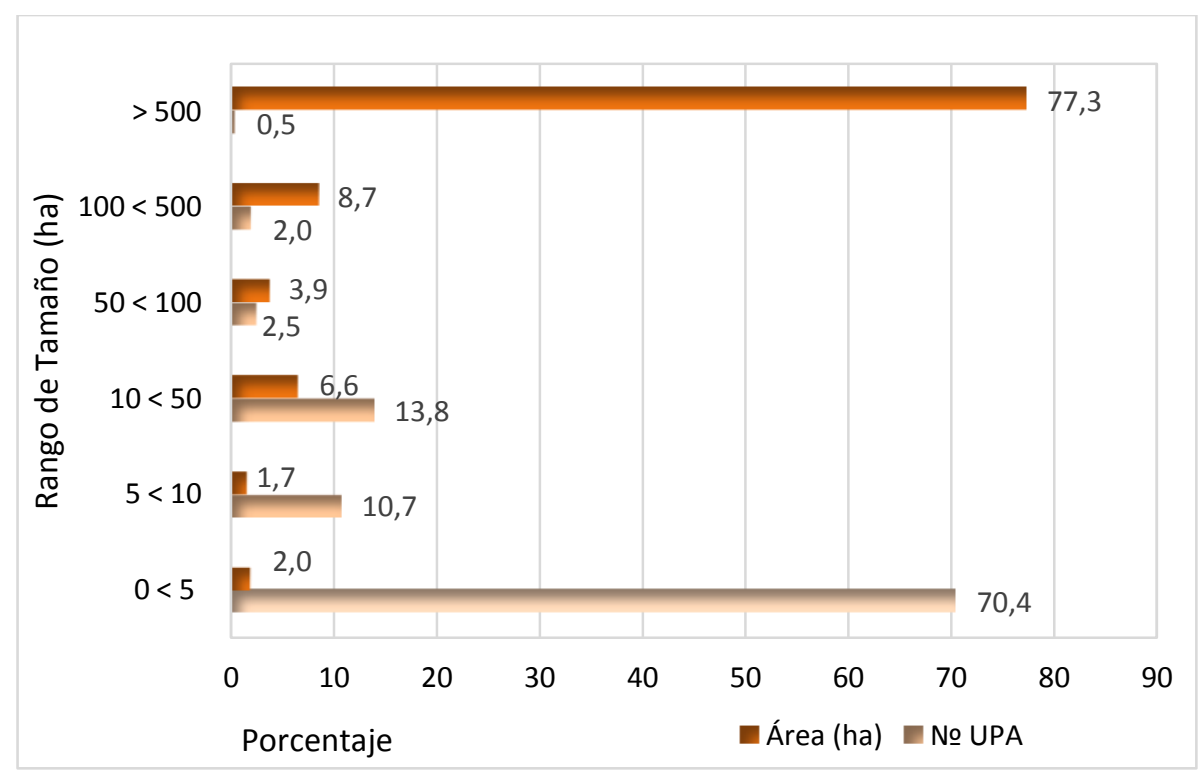

Fuente: Elaboración propia. Datos DANE-CNA 2014.

Los datos también muestran el uso de la tierra agropecuaria. En primer lugar, la característica sobresaliente es la masiva orientación de esa superficie hacia el uso como "pastos y rastrojos" (80\% del total) frente a un escaso $20 \%$ de uso agrícola. Según los datos, las UPA menores de 10 ha son las que mayor área

\footnotetext{
${ }^{12}$ La UPA está definida como la unidad de organización de la producción agropecuaria que puede estar formada por una parte de un predio, un predio completo, un conjunto de predios o partes de predios continuos o separados en uno o más municipios, independientemente del tamaño, la tenencia de la tierra y el número de predios que la integran (Censo Nacional Agropecuario 2014).
} 
dedican a la agricultura (más del $45 \%$ ), mientras que las grandes extensiones destinan menos del $13 \%$ a este uso y más del $85 \%$ de su superficie está en pastos y rastrojos (Tabla 4.1).

Tabla 4. 1 Colombia: Distribución del área en uso agropecuario por rango de tamaño. 2014. (Hectáreas)

\begin{tabular}{cccccccc}
\hline $\begin{array}{c}\text { Rangos } \\
\text { de } \\
\text { tamaño }\end{array}$ & $\begin{array}{c}\text { Área agro- } \\
\text { pecuaria } \\
\text { Total }\end{array}$ & $\begin{array}{c}\text { Pastos y } \\
\text { rastrojo }\end{array}$ & $\begin{array}{c}\text { \% } \\
\text { Pastos y } \\
\text { rastrojos }\end{array}$ & $\begin{array}{c}\text { Área } \\
\text { agrícola }\end{array}$ & $\begin{array}{c}\text { \% } \\
\text { Área } \\
\text { agrícola }\end{array}$ & $\begin{array}{c}\text { Área en } \\
(\mathbf{I A})\end{array}$ & $\begin{array}{c}\text { \% en } \\
\text { IA }\end{array}$ \\
\hline $0<5$ & $1.830 .262,4$ & $992.767,8$ & 54,2 & $827.374,8$ & 45,2 & $10.119,7$ & 0,55 \\
$5<10$ & $1.473 .834,5$ & $784.241,7$ & 53,2 & $683.356,9$ & 46,4 & $6.235,8$ & 0,42 \\
$10<50$ & $5.509 .611,3$ & $3.573 .729,4$ & 64,9 & $1.915 .785,7$ & 34,8 & $20.096,3$ & 0,36 \\
$50<100$ & $3.040 .528,3$ & $2.321 .887,4$ & 76,4 & $707.816,9$ & 23,3 & $10.824,1$ & 0,36 \\
$100<500$ & $6.565 .379,2$ & $5.374 .683,7$ & 81,9 & $1.167 .273,9$ & 17,8 & $23.421,6$ & 0,36 \\
$>500$ & $24.605 .123,9$ & $21.379 .311,4$ & 86,9 & 3.175 .103 & 12,9 & $50.709,4$ & 0,21 \\
\hline $\begin{array}{c}\text { Total } \\
\text { Nacional }\end{array}$ & $\mathbf{4 3 . 0 2 4 . 7 3 9 , 6}$ & $\mathbf{3 4 . 4 2 6 . 6 2 1 , 4}$ & $\mathbf{8 0 , 0}$ & $\mathbf{8 . 4 7 6 . 7 1 1 , 2}$ & $\mathbf{1 9 , 7}$ & $\mathbf{1 2 1 . 4 0 6 , 9}$ & $\mathbf{0 , 3}$ \\
\hline
\end{tabular}

*Infraestructura agropecuaria. Fuente: Elaboración propia. Datos DANE-CNA 2014.

Lo anterior contrasta con la vocación de uso del suelo y su uso efectivo. El IGAC (2012) identificó que la tierra adecuada para explotación agrícola alcanza 22 millones de hectáreas, mientras que el uso ganadero solamente estaría recomendado en 15,2 millones de hectáreas. Las diferencias de esos datos con los usos efectivos que muestra la Tabla 4.1 son evidentes. Sumado a lo anterior, el inventario bovino que reportó el censo fue de 21.502.811 cabezas de ganado, es decir que hay una cabeza de ganado por cada 1,6 ha de tierra dedicada a "pastos y rastrojos", lo que evidencia el carácter muy extensivo de ese aprovechamiento ganadero. Por otra parte, en las UPA menores de 5 hectáreas el área total productiva es de 1,3 ha/ UPA.

En cuanto al régimen de tenencia de las UPA, el censo mostró que el 72,7\% son propias, solo el $9,6 \%$ está en arrendamiento, un $4,5 \%$ son de tenencia mixta y que aún existe un $1,5 \%$ en régimen de aparcería, junto a un $11,7 \%$ bajo otras formas de tenencia (usufructo, comodato, ocupación de hecho, propiedad colectiva).

El total de productores suma 2,7 millones de los cuales solo $26,7 \%$ son residentes en las áreas rurales dispersas. De los residentes en las áreas rurales 
dispersas, solo el 29\% tiene maquinaria, un $28 \%$ cuenta con infraestructura para desarrollar sus actividades agropecuarias y cerca del $43 \%$ dedica un área de su UPA para la producción de autoconsumo.

El nivel de asistencia técnica es bastante deficiente pues solo el 16,5\% de las UPA del área rural dispersa recibieron asistencia técnica. En cuestión de oportunidades de financiación el censo reportó que solo el 10,7\% de los productores de las UPA solicitó créditos de los cuales se aprobaron el 88,4\%.

En cuando a acceso al agua, en un $12,6 \%$ de las UPA los productores declararon no tener acceso al agua para sus actividades agropecuarias. En las UPA mayores a 500 ha solo el 5,7 declaró no tener acceso al agua, mientras que en las UPA menores de 5 ha el porcentaje es del $14,7 \%$.

\subsection{La estructura productiva}

De acuerdo con los datos del Censo Nacional Agropecuario del total del área en uso agrícola (8,4 millones de hectáreas), 7,1 millones está dedicada a cultivos. Los cultivos agroindustriales (café, cacao, caña de azúcar, caucho, palma africana y otros), tubérculos y plátanos participaban con el 57,3\% del área sembrada.

La estructura productiva viene cambiando desde la aplicación de las políticas de la apertura económica. En primer lugar, tal como se puede apreciar en la Tabla 4.2, los cultivos transitorios experimentaron una disminución considerable en el área cosechada en los primeros cinco años de la aplicación de la liberalización comercial sin recuperarse durante los últimos 25 años, en los cuales se han dejado de cultivar más 2 millones de hectáreas. Vale la pena resaltar que este tipo de cultivos forman parte importante de las economías campesinas, que han sido afectadas por el impacto del desplazamiento forzado, causando la pérdida de sus tierras y abandono de los cultivos.

En segundo lugar, los cultivos permanentes (sin incluir el café) en los últimos 25 años han experimentado un incremento en el área cosechada, cercana a 800 mil hectáreas. Entre ellos los que más han incrementado su área cosechada son la Palma Africana (palma de aceite), los frutales y la caña de azúcar, cultivos 
intensivos en tierras y capital. Por su parte el área cultivada en café para el año 2002 fue de 864.140 ha y para el año 2015 de 940.920 ha.

Tabla 4. 2. Colombia: Área cosechada en cultivos transitorios, quinquenios 1990-2015 (Hectáreas).

\begin{tabular}{lrrrrrr}
\hline \multicolumn{1}{c}{$\begin{array}{c}\text { Años } \\
\text { Cultivos }\end{array}$} & \multicolumn{1}{c}{$\mathbf{1 9 9 0}$} & $\mathbf{1 9 9 5}$ & $\mathbf{2 0 0 0}$ & $\mathbf{2 0 0 5}$ & $\mathbf{2 0 1 0}$ & $\mathbf{2 0 1 5}$ \\
\hline Maíz & 836.900 & 665.883 & 571.812 & 593.684 & 495.048 & 514.799 \\
Arroz & 521.100 & 417.778 & 475.914 & 462.338 & 484.119 & 506.809 \\
Sorgo & 273.000 & 180.751 & 68.424 & 67.930 & 18.286 & 3.898 \\
Trigo & 56.700 & 34.977 & 19.842 & 20.930 & 8.695 & 2.751 \\
Cebada & 54.300 & 20.443 & 5.336 & 1.873 & 2.466 & 989 \\
Ajonjolí & 12.450 & 11.887 & 6.398 & 3.517 & 2.668 & 4.460 \\
Algodón & 200.540 & 81.602 & 48.226 & 73.964 & 43.519 & 26.336 \\
Soya & 116.150 & 45.074 & 18.367 & 38.172 & 27.137 & 38.361 \\
Fríjol & 164.600 & 167.012 & 115.739 & 122.896 & 118.154 & 113.115 \\
Maní & 3.350 & 5.382 & 3.141 & 2.105 & 3.604 & 1.679 \\
Hortalizas & 87.600 & 89.805 & 96.134 & 92.067 & 106.377 & 110.569 \\
Papa & 161.350 & 178.482 & 170.719 & 149.239 & 168.826 & 162.801 \\
\hline \multicolumn{1}{c}{ Total } & $\mathbf{2 . 4 8 8 . 0 4 0}$ & $\mathbf{5 9 9 . 6 8 6}$ & $\mathbf{4 6 4 . 0 5 7}$ & $\mathbf{4 8 3 . 8 3 2}$ & $\mathbf{4 7 2 . 7 5 1}$ & $\mathbf{4 5 8 . 3 1 0}$ \\
\hline
\end{tabular}

Fuente: Elaboración propia con datos del Anuario Estadístico MADR 2015.

Tabla 4. 3. Colombia: Área cosechada en cultivos permanentes, quinquenios 1990-2015 (Hectáreas)

\begin{tabular}{|c|c|c|c|c|c|c|}
\hline${ }_{\text {Cultivos }}^{\text {Años }}$ & 1990 & 1995 & 2000 & 2005 & 2010 & 2015 \\
\hline Banano & 32.400 & 43.324 & 41.086 & 43.629 & 45.105 & 47.407 \\
\hline Cacao & 120.712 & 120.154 & 93.492 & 107.137 & 126.680 & 166.637 \\
\hline Caña Azúcar & 112.640 & 188.426 & 224.320 & 189.962 & 176.373 & 203.067 \\
\hline Caña Panela & 197.989 & 210.992 & 213.033 & 206.392 & 198.807 & 200.659 \\
\hline Plátano & 351.803 & 398.015 & 390.794 & 381.453 & 368.393 & 403.491 \\
\hline Tabaco & 19.906 & 13.579 & 14.692 & 18.564 & 10.517 & 11.103 \\
\hline $\begin{array}{l}\text { Palma } \\
\text { Africana }\end{array}$ & 89.671 & 131.067 & 147.439 & 192.970 & 284.241 & 479.193 \\
\hline Otros* & 251.349 & 228.361 & 241.914 & 237.910 & 246.298 & 230.654 \\
\hline Frutales & 70.900 & 124.459 & 162.171 & 212.559 & 236.848 & 294.921 \\
\hline Total & 1.247 .370 & 1.458.376 & $\mathbf{1 . 5 2 8 . 9 3 9}$ & 1.590 .576 & 1.693 .262 & 2.037 .132 \\
\hline
\end{tabular}

*Incluye arracacha, cocotero, fique, yuca y ñame.

Fuente: Elaboración propia con datos del Anuario Estadístico MADR 2015 
La evolución de la estructura productiva en términos de los dos tipos de cultivos se puede observar en el Gráfico 4.2. Solo desde el año 2006 los cultivos permanentes superan en área cosechada a los transitorios, pero sin llegar a recuperar el área dejada por estos.

Gráfico 4. 2. Colombia: Área cosechada en cultivos transitorios y permanentes 1990-2015 (Hectáreas).

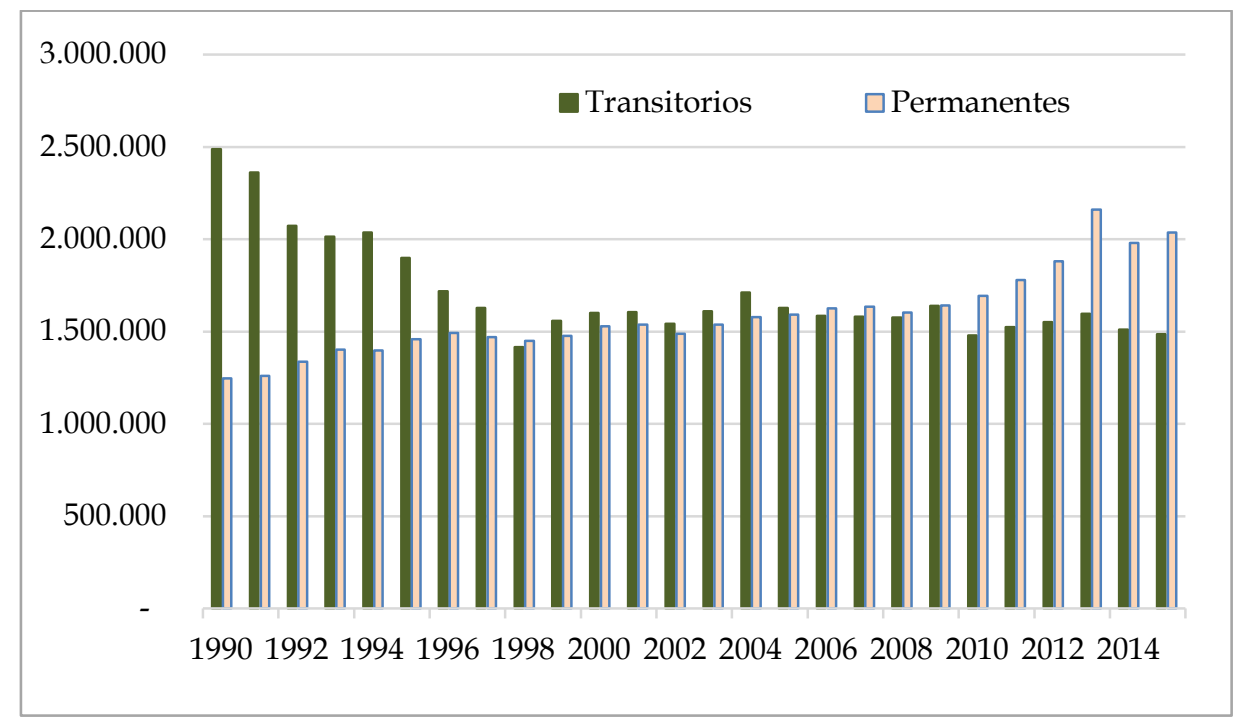

Fuente: Elaboración propia. Datos Anuario estadístico- Agronet Ministerio de Agricultura (2015)

\subsection{Importancia del sector agropecuario}

Como indicadores que dan cuenta de la importancia del sector agropecuario en la economía nacional están, entre otros, su participación en el Producto Interno Bruto del país y en la generación de empleo. Para el primer caso, las cifras de los últimos quince años muestran que su contribución al PIB ha venido decayendo de manera progresiva siendo para 2015 uno de los sectores con menor aporte (Tabla 4.4). 
Tabla 4. 4. Colombia: Producto Interno Bruto por ramas de actividad 20002015. Participación porcentual anual

\begin{tabular}{lrrrr}
\hline Ramas de Actividad Económica & $\mathbf{2 0 0 0}$ & $\mathbf{2 0 0 5}$ & $\mathbf{2 0 1 0}$ & $\mathbf{2 0 1 5}$ \\
\hline Agricultura, ganadería, caza, silvicultura y & & & & \\
pesca & 7,9 & 7,7 & 6,5 & 6,1 \\
Explotación de minas y canteras & 7,9 & 6,3 & 7,0 & 7,0 \\
Industrias manufactureras & 13,6 & 14,1 & 12,7 & 11,1 \\
Suministro de electricidad, gas y agua & 4,1 & 4,0 & 3,7 & 3,5 \\
Construcción & 4,4 & 5,6 & 6,2 & 7,2 \\
Comercio, reparación, restaurantes y hoteles & 11,6 & 11,9 & 12,0 & 12,2 \\
Transporte, almacenamiento y comunicaciones & 6,4 & 6,8 & 7,4 & 7,3 \\
Establecimientos financieros, seguros, & & & & \\
actividades inmobiliarias y servicios a las & & & & \\
empresas & 19,2 & 19,1 & 19,5 & 20,3 \\
Actividades de servicios sociales, comunales y & & & & \\
personales & 16,8 & 15,9 & 15,5 & 15,4 \\
TOTAL IMPUESTOS & 8,0 & 8,5 & 9,2 & 9,5 \\
PRODUCTO INTERNO BRUTO & 100 & 100 & 100 & 100 \\
\hline
\end{tabular}

Fuente: Datos Anuario estadístico- Agronet Ministerio de Agricultura 2015.

Para 1990 el sector agropecuario contaba con una participación en el PIB del 16,24\% (Balcázar et al. 1998), disminuyendo por tanto en los últimos 25 años 10 puntos porcentuales. A pesar de ello, el sector agropecuario continúa siendo una fuente importante de empleo pues para 2002, ocupaba el tercer lugar, participando con un 20,5\% en la ocupación total. Para 2015, continua en el tercer lugar (después del sector comercio y servicios personales, comunales y sociales) con una participación de $16,1 \%$.

En cuanto a la evolución del sector agropecuario y agroindustrial en el mercado exterior, si bien se ha dinamizado desde la apertura económica, cómo se observa en el Gráfico 4.3, las exportaciones no han logrado crecer al ritmo de las importaciones. Mientras que las importaciones agropecuarias y agroindustriales han multiplicado su valor por 9, las exportaciones apenas lo hicieron por 2,5 entre el período de 1992-2015.

Aunque el volumen de las exportaciones continúa superando al de las importaciones, el superávit de la balanza comercial del sector ha registrado una considerable reducción desde los años 1990 hasta la actualidad. Esta reducción se atribuye a un decrecimiento en el desempeño del sector agroindustrial entre 
2000 y 2015, lo que evidencia una pérdida de competitividad de la producción agropecuaria y agroindustrial en sectores distintos al café, flores y banano (Perfetti et al. 2017).

\section{Gráfico 4. 3 Colombia: Evolución de las importaciones y exportaciones agropecuarias y agroindustriales 1992-2015}

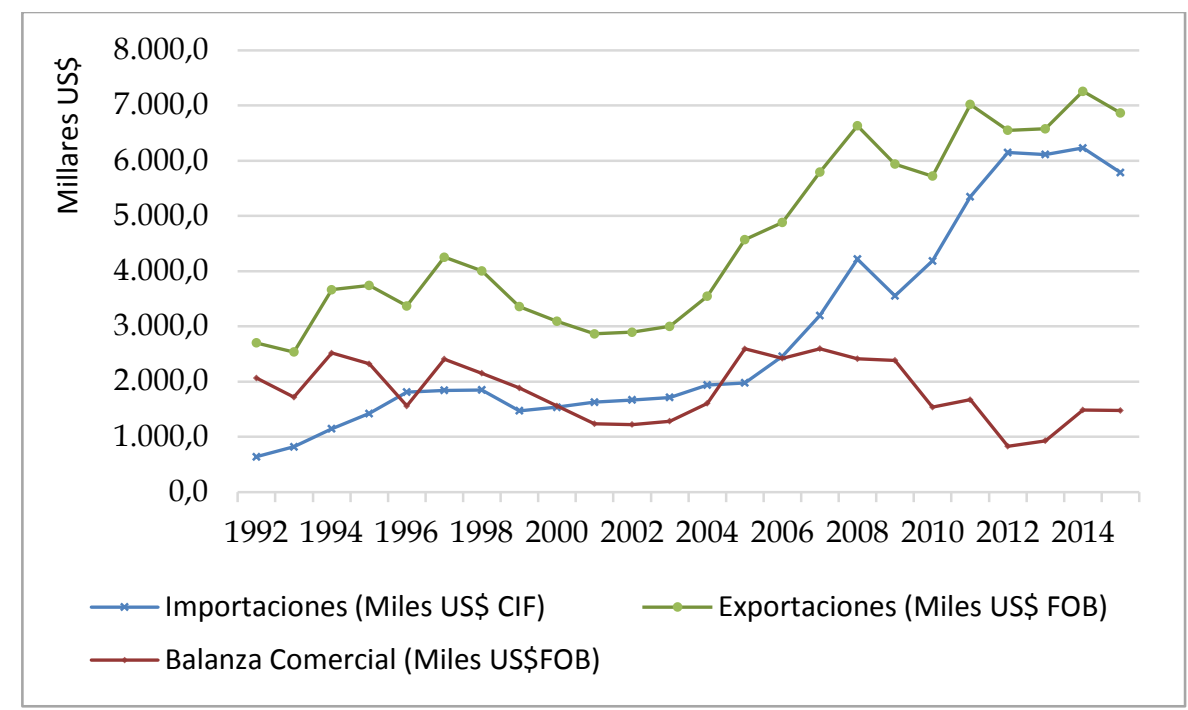

Fuente: Elaboración propia. Datos Anuario estadístico- Agronet Ministerio de Agricultura 2015.

Los datos anteriormente analizados permiten tener una visión actual de la estructura agraria del país que respecto a la tenencia de la tierra se mantiene altamente desigual e inequitativa, una estructura productiva poco diversificada y que tiende en las últimas décadas a centrase en algunos cultivos intensivos en tierra y capital, que no logran insertarse de forma competitiva en el mercado mundial. Las pequeñas explotaciones continúan siendo las que se dedican en mayor proporción a la producción de alimentos.

\subsection{Población rural y grupos étnicos}

De acuerdo con el Censo de Población de 2005 la población total rural era el $24 \%$ (9.958.005 personas) de la población total del país (41.468.384 personas). En cuanto a los grupos étnicos, un 3,43\% de la población (1.392.623 personas) 
pertenecía a algún pueblo indígena, de las cuales el 78,58\% se ubicaba en la zona rural. Por su parte, un 10,52\% (4.273.722) pertenecía a comunidades negras (27,35\% ubicados en zonas rurales) y $0,1 \%$ (42.893) a pueblo raizal (los habitantes de las islas de San Andrés y Providencia de origen anglo-africano) y Rrom gitano (DANE 2005).

Para el año 2014 con el Censo Nacional Agropecuario (CNA) se tiene que la población ubicada en el área rural fue 5,1 millones de personas, de las cuales 1,2 millones reconocen pertenecer a algún grupo étnico (67,8\% indígenas, 32\% afrodescendientes, $0,2 \%$ raizales y $0,01 \%$ Rrom).

Los derechos de propiedad a las tierras que han habitado ancestralmente estas comunidades se consolidaron a partir de la Constitución de 1991. Así el CNA reportó que, de las tierras censadas, estaban ocupadas por los grupos étnicos (comunidades indígenas y comunidades afrodescendientes) un total de 39.854 .772 ha de las cuales el $84,2 \%$ correspondía a territorios de pueblos indígenas, el $15,7 \%$ a comunidades negras y el 0,01\% a territorio ancestral raizal. Los departamentos de Amazonas, Guainía, Vaupés, Chocó y Vichada concentraban el $70 \%$ del área rural correspondiente a grupos étnicos.

Sin embargo, aunque la extensión de tierras donde se han reconocido los derechos de propiedad parece bastante 'generosa', lo cierto es que en su mayoría son tierras con muy poca capacidad productiva y su principal uso o vocación es para conservación. Así, el CNA corroboró que el 90,8\% del territorio ocupado por grupos étnicos estaba dedicado a bosques y solo el 6,9\% a uso agropecuario (CNA, 2014).

Con referencia a las condiciones de pobreza, esta es más elevada en las zonas rurales en comparación con las zonas urbanas, pero más acentuada en los territorios de los grupos étnicos. La incidencia de la pobreza multidimensional (IPM) en el total de la zona rural en 2014 fue del 45,7\%, mientras que en los territorios de grupos étnicos fue del 65,7\%. 


\subsection{Violencia guerrillera y paramilitar}

\subsubsection{Antecedentes}

En Colombia, solo a partir de 1970 se inicia el estudio de la conformación y consolidación de la hacienda y con ello se da lugar a la investigación sobre la formación del campesinado, las relaciones de trabajo en el campo, los movimientos campesinos ${ }^{13}$. La conformación de la hacienda ocurrida a partir de la segunda mitad del siglo XVII, se facilita en parte por la disolución de las instituciones coloniales que liberaron mano de obra indígena y esclava, por el crecimiento de blancos pobres y el mestizaje que se dio alrededor de estas instituciones y fue el origen del campesinado. La mano de obra en las haciendas en sus inicios fue de trabajo esclavo y posteriormente de mestizos pobres bajo unas relaciones serviles (basadas en el monopolio sobre la tierra) que se mantuvieron hasta el siglo XIX (Bejarano 1983).

La expansión de la caficultura, que se realizó a partir de la fragmentación de los viejos latifundios de tipo colonial y a partir de las tierras baldías, es otro hecho importante para comprender las relaciones de trabajo, la conformación del campesinado y de la sociedad rural (Bejarano 1983; 275). Dentro de la hacienda funcionaba la economía parcelaria de los arrendatarios y la economía cafetera, por lo que de acuerdo con Ocampo (1996), la hacienda fue la unidad de explotación y producción agrícola más importante. No solo dominaba la estructura económica en las zonas rurales, sino también la social y la política.

Durante los años veinte y treinta del siglo XX se inicia la crisis de la hacienda en el país. Entre otros factores, debido al incremento de la demanda en mano de obra por la naciente industria nacional que presiona por una mayor movilidad de trabajadores que estaban sujetos bajo formas pre-capitalistas en las haciendas. A su vez los mismos parceleros y arrendatarios reclaman mejores

13 Antes de la década de los años 1970, la historia estaba centrada en el estudio del funcionamiento y la disolución de las instituciones creadas en la colonia (la mita, la encomienda, el concierto agrario, la esclavitud). Se conocían únicamente las relaciones de producción de los encomenderos y los terratenientes, los indígenas y los esclavos, a pesar de que ya existía la hacienda, diferentes formas de trabajo y la diferenciación social (Bejarano 1983). 
condiciones de trabajo y poder sembrar café en sus parcelas. Así, en los años veinte se conforman las primeras organizaciones campesinas que exigían una mayor libertad, recibir el beneficio de su propio trabajo y tener el dominio sobre la tierra que trabajaban. Para 1928 ya se habían conformado organizaciones como: el Partido Agrario Nacional (PAN), la Unión Nacional Izquierdista Revolucionaria y el Partido Socialista Revolucionario, que dio origen al Partido Comunista Colombiano, el cual articuló a su expresión política la organización campesina de base (Alturo et al. 2015).

Adicionalmente, la Gran Depresión afectó la economía de las haciendas (con la disminución de ingresos de exportación, principalmente del café), lo que influyó en el deterioró de los medios de vida de los parceleros y arrendatarios, favoreciendo así el surgimiento de las luchas campesinas, principalmente en Sumapaz, Tequendama y Córdoba. Estos levantamientos fueron apoyados por las ligas campesinas, el sindicato de obreros rurales, y las Unidades de Acción Rural y en el nivel nacional la Confederación Campesina e Indígena.

El declive de la hacienda da paso al fortalecimiento de la economía parcelaria en algunas de las zonas cafeteras. Como una forma de bajar las tensiones en las zonas rurales, el gobierno promulga la Ley 200 de 1936 con la cual se reconocen los derechos de propiedad sobre tierras baldías ocupadas por colonos, se promueven las parcelaciones de las tierras más alejadas de las haciendas creándose un grupo de pequeños propietarios que van a suministrar mano de obra a las haciendas. Esta ley también promovió las colonizaciones, que inicialmente se impulsaron para ampliar la frontera agropecuaria pero que generaron también la invasión por colonos a varias haciendas. Esto ocasionó la expulsión de campesinos de las haciendas por parte de los terratenientes y favoreció la ampliación de la ganadería. Así la diferenciación del campesinado se da de manera desigual, en algunos casos se convierten en pequeños propietarios y en otros se acentúa el proceso de proletarización, en otros perviven las relaciones de sujeción de la mano de obra a través de las aparcerías y arrendamientos y otros continúan el proceso colonizador.

En el período de La Violencia (1948-1953) que tiene como foco principal la pugna bipartidista (entre liberales y conservadores) por el poder del estado, cuya hegemonía no pudo imponerse sino a través de la fuerza, se generó una persecución contra los movimientos sociales (agrario y obrero). La violencia fue 
más aguda en las zonas rurales donde se presentaban fuertes contradicciones sociales, como las zonas cafeteras donde se expresó en la lucha por el control por la tierra. En este periodo se crearon las guerrillas liberales ${ }^{14}$ de oposición al gobierno conservador y que se alinean en un primer momento con las luchas campesinas. Transitan así de una guerra civil a una lucha de clases y a la conformación de un proyecto político por parte del campesinado. Tal amenaza, causó la reunificación de las clases dominantes bajo la dictadura militar de 1953 a 1957, así se enfrentó militarmente la resistencia armada y también se implementó un proceso de amnistía para la entrega de los alzados en armas, con lo cual desmovilizaron a gran parte del movimiento campesino armado. Las operaciones militares continuaron contra campesinos organizados (liberales y comunistas) en Tolima, Sumapaz y los Llanos Orientales.

Entre 1957-1964 con la caída de la dictadura, los bloques populares que no encuentran representación en el bipartidismo, continúan siendo enfrentados por la fuerza pública y van a transitar hacia la constitución de las guerrillas en los años sesenta.

En cuando a las organizaciones campesinas que daban soporte a las luchas agrarias, para 1956 estaban casi destruidas, solo prevalecía la Federación agraria Nacional (Fanal) fundada en 1946 y que fue la más importante hasta la fundación de la Asociación Nacional de Usuarios Campesinos (ANUC) en 1967 (Alturo et al. 2015)

La continuación de la pobreza, la exclusión del campesinado y la concentración de la tierra que siguieron al periodo de la Violencia generaron en los años setenta grandes movilizaciones y recuperaciones de tierra por la vía de hecho. En 1972 las clases terratenientes pactan acabar con los intentos de reforma agraria. Se divide y se debilita la ANUC, tomando un carácter más regional y luego en la década de los años ochenta, gran parte de sus líderes se convirtieron en objetivo militar del paramilitarismo.

\footnotetext{
${ }^{14}$ Las guerrillas liberales surgen por la represión impuesta por el gobierno conservador a los liberales en el período de la violencia. Entre los jefes más reconocidos estaban Guadalupe Salcedo, Dumar Aljure y Bernardo Giraldo.
} 


\subsubsection{Grupos insurgentes}

Son varios los grupos guerrilleros que se conformaron después de la mitad del Siglo XX pero los de mayor influencia y trayectoria han sido las FARC y el ELN ambos de corte marxista. Las FARC tienen su origen en la época de La Violencia de los años cincuenta, cuando se conformaron las autodefensas campesinas de corte comunista, bajo el mando de Pedro Antonio Marín, conocido como Manuel Marulanda Vélez alias "Tirofijo". Su zona de influencia inicialmente fue el sur del Tolima y el Cauca, donde al tener enfrentamientos con las guerrillas liberales y el gobierno, Marulanda da la orden al movimiento campesino armado de replegarse hacia el departamento del Meta y Caquetá en lo que se conoció como las 'Columnas en marcha' o la 'colonización armada' (Fajardo \& Mondragón 1997). Las FARC se fundan en 1964, justo después del ataque del ejército contra ellas conocido como la 'Operación Marquetalia', en el Sur del Tolima, el cual hacia parte del Plan LASO (Latin American Security Operation), que buscaba frenar el crecimiento del comunismo en la región Latinoamericana. El Ejército de Liberación Nacional (ELN) se funda en el mismo año por un grupo de estudiantes y académicos también de corte comunista (Thomson 2011).

El accionar de las FARC estuvo ligado a las luchas de las organizaciones campesinas y obreras y en torno a su propio proyecto político de tomar el poder. Sus métodos de guerra fueron el secuestro, la extorsión, el chantaje y el robo a grandes terratenientes y empresarios, así como confrontaciones con el ejército y atentados contra la infraestructura. Con la entrada del narcotráfico, inicialmente se centraron en cobrar impuestos a los comerciantes de coca en las zonas de cultivo, las cuales eran zonas de colonización donde el estado no llegaba y la guerrilla funcionaba como estado. Estos nuevos ingresos le permitieron fortalecerse y expandirse hacia zonas donde se ubicaban los agronegocios, explotaciones petroleras y mineras, en general lugares ricos en recursos estratégicos. También, les permitió ubicar frentes cerca de ciudades y en las nuevas zonas que la colonización cocalera iba abriendo. Finalmente, la entrada de la industria de la coca y la no clara forma de participación de las FARC en ella, en la que también termina participando el ELN, obstruyen y desvanecen el proyecto político por el cual se conformaron estos grupos insurgentes. 
El incremento de acciones de la guerrilla contra las clases terratenientes, las élites regionales y locales, los militares, los empresarios y narcotraficantes, dio lugar a que estos grupos de poder fortalecieran el paramilitarismo.

Las FARC pasaron por tres procesos de paz antes de su desmovilización definitiva en 2017. El primer intento de acuerdo de paz se dio en 1984, en el Gobierno de Belisario Betancourt, donde las FARC crearon su grupo político La Unión Patriótica (UP), cuyos miembros (cerca de tres mil) fueron asesinados por el paramilitarismo y los narcotraficantes. El segundo intento de negociación fue en 1991 con el gobierno de Cesar Gaviria y el tercero en 1999 con el gobierno de Andrés Pastrana.

Las crecientes acciones de los paramilitares desde la década de los años ochenta y del ejército en las regiones donde operaban las FARC, hicieron cambiar la apreciación de las comunidades hacia esta guerrilla, pues ejerció el terror en varios lugares, cometió varias masacres y asesinatos de población civil, acusándolos de ser colaboradores del ejército o de los paramilitares.

\subsubsection{Paramilitares y narcotraficantes}

La historia del paramilitarismo en Colombia no es reciente, tienen su origen en la creación del ejército privado La Chulavita, o los llamados 'pájaros', que surgió de una alianza entre el partido conservador y la élite terrateniente, para eliminar a los miembros del partido liberal, en el período de La Violencia. De igual manera los grupos paramilitares se legitimaron mediante la doctrina contrainsurgente, contenida en el plan LASO, promovido por Estados Unidos bajo su política de seguridad nacional, siendo Colombia pionera en adoptar dicha doctrina y recibir ayuda y entrenamiento militar en el contexto de la Guerra Fría en los años sesenta. Más tarde en los años ochenta con el surgimiento del narcotráfico y la escalada de las acciones guerrilleras, el paramilitarismo contemporáneo toma otra dimensión en términos de magnitud e impacto, tanto sobre los cambios en las zonas rurales, como sobre la economía y la política nacional.

Dentro de la lucha contrainsurgente, el estado, los militares, narcotraficantes, empresarios y élites rurales comparten un mismo objetivo: combatir las guerrillas. Los paramilitares resurgieron así, como grupos de autodefensa 
privada y protección de estos grupos de poder para defenderse de los ataques y las extorsiones de las guerrillas y se convirtieron en aliados de las fuerzas militares en la lucha contrainsurgente.

En 1994 el presidente Ernesto Samper autorizó la creación de Cooperativas de Vigilancia y Seguridad privada para la autodefensa agraria (CONVIVIR $)^{15}$, por medio de las cuales en compañía del ejército se pretendía dar seguridad a las regiones. Así surgieron cientos de grupos de autodefensa por todo el país y, al mismo tiempo, el gobierno les otorgó legalidad a los ejércitos privados ya creados. Debido a innumerables denuncias por los abusos que cometían y a la violación de Derechos Humanos a la Población civil, las CONVIVIR fueron declaradas inexequibles ${ }^{16}$ por la Corte Constitucional en 1999. Sin embargo, estos grupos no entregaron las armas y continuaron actuando para terratenientes y empresarios y compartiendo con el estado la lucha contrainsurgente, que se extendió no solo a las guerrillas sino también a todo el pensamiento de izquierda, por lo que convirtieron a los académicos y periodistas, sindicalistas y líderes sociales en objetivos militares (Velásquez 2007).

Entre 1985 y 1995 se da un auge en la compra de tierras en el país por los narcotraficantes y por capitales provenientes de la explotación y comercialización de esmeraldas, lo que hace crecer el paramilitarismo, pues la adquisición de propiedades requería protección, para lo que crearon y financiaron los grupos de autodefensas (Reyes 2009; Fajardo 2014). Víctor Carranza, el llamado zar de las esmeraldas en Colombia, se hizo con tierras por el centro y oriente del país llegando a acumular más de un millón de hectáreas por medios lícitos e ilícitos. Fue señalado por crear y financiar grupos de autodefensa como Los Carranceros que actuaron en la región del Magdalena Medio y en los departamentos del Meta y Vichada (Semana 2013a).

\footnotetext{
${ }^{15}$ Las CONVIVIR se establecen en el Artículo 42 del Decreto Ley 356 de 1994 y se hacen operativas en 1995.

${ }^{16}$ La inexequibilidad es una sentencia dada por la Corte Constitucional cuando una Ley es contraria a la Constitución Nacional y por tanto debe desaparecer total o parcialmente del orden jurídico. http://www.senado.gov.co/glosario/Glosario-1/I/Inexequibilidad-19/. Consultado 17 de Enero de 2018.
} 
La compra de tierras por narcotraficantes influyó en el cambio del problema agrario, porque los narcos han sustituido en muchas regiones las viejas clases propietarias de la tierra afectando los liderazgos locales, han incrementado la concentración de la tierra, los niveles de violencia y desplazamiento forzado y a nivel productivo han hecho que más tierra se destine a la ganadería extensiva (Reyes 2009). También los paramilitares se convirtieron en el brazo armado de multinacionales, para fragmentar y desmantelar los procesos sindicales y la organización social en las regiones donde operaban (Richani 2005).

Dentro de los objetivos o propósitos que Reyes (2009) identifica en los paramilitares están: cortar el vínculo de la población con la guerrilla y fortalecer el suyo creando base social, apoderarse de las tierras (sobre todo por y para los jefes) controlar los territorios, los flujos de droga y armas e influir en el mercado de tierras.

Los paramilitares más grandes e influyentes fueron los de la Casa Castaño, principalmente los tres hermanos Fidel, Carlos y Vicente Castaño. Fidel creó un grupo de autodefensas en su finca Las Tangas y lo denominó 'Los Tangueros', con el cual cometió múltiples crímenes (Gutiérrez 2014). Fidel se hizo rico a través del narcotráfico y el acaparamiento de tierras. Estuvo estrechamente relacionado con Pablo Escobar hasta que este lo traiciona y decide unirse a la búsqueda que el gobierno había iniciado para capturar al narcotraficante. La primera masacre de Fidel la cometió en el municipio de Segovia, Antioquia en 1988, lo hace como venganza a la población por elegir como alcalde a un candidato de la Unión Patriótica, el partido creado por las FARC.

En 1991 cuando se desmoviliza el Ejército Popular de Liberación (EPL) ${ }^{17}$, Fidel Castaño desmoviliza 300 hombres y crea la Fundación para la Paz de Córdoba (Funpazcor), aportando $15 \mathrm{mil}$ hectáreas de tierra de las que se había apropiado. Una vez muerto Escobar en 1993, los Castaño regresan a Córdoba y Urabá y recuperan las tierras que habían entregado durante la desmovilización y acogen y entrenan a desmovilizados del EPL en sus filas. Fidel Castaño muere en 1994, el mando lo asume Carlos Castaño y crean las Autodefensas Campesinas

${ }^{17}$ El EPL se funda en 1967, de ideología marxista-leninista. Operó en la región de Urabá y Bajo Cauca, Córdoba, Sucre y Magdalena Medio. Se desmovilizó en 1991, pero una disidencia sigue operativa en la región del Catatumbo, Norte de Santander y sur del Cesar. 
de Córdoba y Urabá AUCC, junto a Salvatore Mancuso ${ }^{18}$, un ganadero de Córdoba. Las AUCC funcionaron en Bloques, que operaban en varias regiones del territorio, entre ellos el Bloque Bananero, que opero en Urabá al mando de Ever Velosa García alias 'HH' y el empresario bananero Raúl Hasbún, alias 'Pedro Bonito', financiados por las grandes multinacionales del banano. El Bloque Elmer Cárdenas (BEC), que también se tomó el Bajo Atrato y Urabá al mando de Freddy Rendón Herrera alias 'El Alemán', considerado uno de los mayores despojadores de tierra y al que se le atribuyen 8 masacres y 3.269 víctimas (Centro de Memoria Histórica 2012); Verdad Abierta 2008). El Bloque Montes de María ${ }^{19}$ se creó en 1996 como resultado de un acuerdo entre los hermanos Castaño, Mancuso, varios políticos y empresarios de la región. Allí, realizan alianzas con los Carranceros, que hacían ya presencia en la zona. Mancuso le entrega la comandancia de este Bloque a Cobo Téllez alias ‘Diego Vecino'.

En 1997 pasan a denominarse las Autodefensas Unidas de Colombia (AUC), constituyéndose en una confederación paramilitar, pues los Castaño buscaron con esto reunir a todos los grupos de autodefensas que operaban en el país. Carlos Castaño envía a Salvatore Mancuso para ampliar la cobertura de las AUC en todo el Norte del país a través de la conformación y entrenamiento de los miembros de las CONVIVIR, ya creadas por ganaderos y terratenientes de la región. Deciden también ingresar en el sur del país, iniciando por los Llanos Orientales, cuya incursión la marcó la masacre de Mapiripán en el Meta, las acciones violentas de alto impacto se incrementaron en todas las regiones donde operaban.

Mancuso convoca para 2001, lo que se denominó el Pacto de Ralito, donde empresarios, élites locales, terratenientes, ganaderos y funcionarios del estado se reunieron y pactaron la consolidación de un movimiento político que les permitiera ocupar espacios en el Congreso y frenar las posibles negociaciones de paz del gobierno con las FARC que se estaban adelantando. Buscaban

\footnotetext{
18 En las confesiones hechas por Mancuso, al relatar su historia de incursión en el paramilitarismo afirma que fue reclutado y entrenado por el mismo estado dentro de su política de 'seguridad nacional' madre del paramilitarismo de estado (CMH, 2012:39).

19 La región de Montes de María está localizada al norte de Colombia, comprende 15 municipios en dos departamentos; siete en el departamento de Bolívar y ocho en el departamento de Sucre.
} 
refundar la patria a través de la creación de una nueva Colombia y de esta forma también obtener el control sobre instituciones públicas, los procesos electorales y la política regional e incidir en la nacional (Centro de Memoria Histórica 2012:128).

Para las elecciones presidenciales de 2002, los paramilitares tenían sus bloques haciendo presencia en la mayor parte del país, lo cual les facilitó influenciar, presionar y coaccionar las elecciones locales y también las nacionales a su favor. La prueba de su influencia en la política nacional se hace visible en el escándalo de lo que se denominó "la parapolítica" en el 2006, cuándo se muestra que políticos, empresarios, terratenientes, religiosos, organismos de seguridad del estado y el $40 \%$ de los Senadores tenían vínculos con paramilitares. Con el gobierno de Álvaro Uribe Vélez (2002-2010), negocian el proceso de desmovilización mediante la implementación de la Ley de Justicia y Paz en 2005.

En 2004 los paramilitares del BEC (Bloque Elmer Cárdenas) habían formulado el Proyecto de Alternatividad Social (PASO) para su desmovilización, en el que plantearon la participación conjunta de paramilitares desmovilizados, campesinos sin tierra, desplazados, y el sector agroindustrial, en un proyecto de base comunitaria para la reconciliación y como una condición para la desmovilización de este Bloque. Este tipo de proyectos se implementó en tierras donadas por los jefes paramilitares (Centro de Memoria Histórica 2012). El propósito era continuar con los proyectos agroindustriales que tenían los paramilitares después de la desmovilización (Ballvé 2013). Claramente las tierras aportadas eran fruto del despojo cometido por ellos mismos y en varios casos los despojados estarían en el proyecto trabajando como obreros en su propia tierra.

En 2008 son extraditados 13 de los comandantes paramilitares por narcotráfico. Para el Centro de Memoria Histórica (2012) está acción acaba con la posibilidad de identificar los actores intelectuales y responsables del desplazamiento y el despojo. Además de contribuir a la impunidad, dificulta la resolución de los procesos de restitución de tierras, que se podrían clarificar con las confesiones libres de estos miembros del paramilitarismo. 
En las confesiones de los paramilitares, como la de Mancuso, se confirmó que la casa Castaño en sus inicios adquirió tierras en Tulapas, Urabá a través de un comisionista para montar un campamento paramilitar. Estos comisionistas se encargaban de comprar los predios a bajos precios y bajo presión a los campesinos. También confiesa que diseñaron estrategias para infiltrase en todas las entidades del estado para facilitar la titulación de los predios, así como el uso del testaferrato, que fue la modalidad elegida para ocultar la identidad de los despojadores (Centro de Memoria Histórica 2012). También alias ‘Pedro Bonito' describe cómo las tierras se convirtieron para ellos en el "Botín de Guerra", pues cuando entraban a los territorios y despojaban a algún propietario, se quedaban con las propiedades y los bienes de este.

En 2011 los paramilitares en prisión enviaron una carta el Presidente, donde manifestaron que si en verdad querían conocer las causas de despojo de tierras, no solo deberían juzgar a aquellos que aparecen en la 'punta del Iceberg', las estructuras armadas, sino también a los implicados en parapolítica: políticos, empresarios, funcionarios de alto nivel, grandes contratistas, inversionistas extranjeros y miembros de la fuerza pública (2012: 88-89).

El proceso de desmovilización ha sido altamente cuestionado, dado que la acción de los paramilitares continuó después de 2005. En concreto, referente al tema de despojo de tierras se constató que entre el período de 1998-2008 ocurrió el 79,3\% de casos de despojo registrados, y entre 2009-2010 un 5,4\% (2012:72). Y es que muchos paramilitares no se desmovilizaron y otros se reorganizaron, agrupando también integrantes de las mafias de narcotraficantes. El gobierno los llamó inicialmente Bandas Criminales (BACRIM) y recientemente, Grupos Armados Organizados (GAO). Entre los más grandes están: 'Las Autodefensas Gaitanistas de Colombia, AGC o Clan del Golfo que operan en 22 departamentos y 250 municipios y agrupan cerca de 4 mil integrantes (El Espectador 2017a). Le siguen las 'Águilas Negras', 'Los Rastrojos', 'Los Urabeños', 'El Ejercito Antirestitución', entre otras.

Estas bandas han tomado varias de las regiones cometiendo violaciones a los Derechos Humanos. Sus acciones se han dirigido a continuar con el destierro de los reclamantes de tierras y con el asesinato de líderes sociales, así como el control del narcotráfico y a ocupar territorios con proyectos mineros y megaproyectos. A su vez han tomado el control de varias de las regiones donde 
operaban las FARC. Su proliferación y acciones ponen en jaque todo el proceso de paz, pues están en contra de la restitución de tierras a los campesinos despojados, de los programas de sustitución de cultivos ilícitos y de permitir que campesinos y grupos étnicos ejerzan su derecho a vivir en paz en sus territorios.

En síntesis, este capítulo ha puesto de manifiesto la magnitud y la complejidad de una estructura agraria concentradora y excluyente que da paso a un contexto de violencia donde han intervenido múltiples actores. La insurgencia tiene su origen en la alta desigualdad y la exclusión política, económica y social y a la vez, su existencia y acciones justifican el surgimiento de los grupos de autodefensa que se crean para mantener esa exclusión en el tiempo. En el centro de dichas luchas está el control sobre la tierra y sus recursos que aparece como parte de las raíces del conflicto, pero también como el fin último. 



\section{Capítulo 5}

\section{Evolución de las políticas} agrarias y de tierras en Colombia: La influencia

\section{de los organismos internacionales}

Colombia ha mantenido una relación amplia de cooperación con agencias financieras internacionales, no solo para el componente de financiación a través de créditos y donaciones, sino también para el apoyo al diseño e implementación de políticas públicas para el desarrollo. Dentro de las más influyentes respecto a la política agrícola y de tierras está en primer lugar el Banco Mundial (BM) cuyo grupo incluye el Banco Internacional de Reconstrucción y Fomento (BIRF) y la Corporación Financiera Internacional (CFI). En segundo lugar, está la Agencia de Estados Unidos para la Cooperación y el Desarrollo (USAID), cuya intervención se ha intensificado en los últimos años, mediante los lineamientos y soporte al proceso de construcción de paz y la política de lucha contra el narcotráfico. Por último, se incluye la OCDE, que también ha delineado los pasos que Colombia debe cumplir con relación al desarrollo agrícola para poder ser miembro de la organización ${ }^{20}$.

\footnotetext{
20 Dentro de estas agencias multilaterales está también el Fondo Monetario
} Internacional (FMI) el cual colabora conjuntamente con el BM en las intervenciones en 
Capítulo 5. Evolución de las políticas agrarias y de tierras en Colombia: La influencia de los organismos internacionales

Considerando lo anterior, este capítulo presenta el análisis de la influencia de estas instituciones en la determinación, diseño y aplicación de las políticas agrícolas y de tierras en Colombia en los últimos 30 años. Para ello se estudian algunos de los documentos que estos organismos elaboran para el país, junto con los Planes Nacionales de Desarrollo (PND) que recogen las orientaciones básicas de las políticas y programas implementados los diferentes gobiernos en el período mencionado. De este modo se identifican los principales enfoques adoptados por el país, en términos de política agraria y desarrollo rural, poniendo especial atención al tipo de estructura agraria que favorecen, en relación a la distribución y tenencia de la tierra, la estructura productiva y al papel otorgado a los pequeños productores agropecuarios dentro de estos modelos propuestos. Los documentos utilizados para el análisis están contenidos en la siguiente tabla.

\section{Tabla 5.1. Documentos de política: Banco Mundial, USAID y Gobierno de} Colombia. 1980-2018

\begin{tabular}{|c|c|c|c|}
\hline Período & Documentos del BM & USAID & PND \\
\hline $\begin{array}{c}1980- \\
1990\end{array}$ & $\begin{array}{l}\text {-Agricultura Colombiana: } \\
\text { Temas seleccionados y } \\
\text { algunas direcciones para } \\
\text { la estrategia.1983. } \\
\text {-Informe finalización de } \\
\text { proyecto 7234: Tercer } \\
\text { Crédito Agrícola. } 1988 .\end{array}$ & & $\begin{array}{l}\text { 1982-1986. Belisario } \\
\text { Betancourt, PND: } \\
\text { "Cambio con } \\
\text { equidad". } \\
\text { 1986-1990. Virgilio } \\
\text { Barco, PND: "Plan } \\
\text { de economía social". }\end{array}$ \\
\hline $\begin{array}{c}1990- \\
2000\end{array}$ & $\begin{array}{l}\text {-Revisión de la estrategia } \\
\text { de agricultura y desarrollo } \\
\text { rural. } 1996 . \\
\text {-Estrategia de Asistencia } \\
\text { al País (EAP) } 1997 . \\
\text {-Rural Development }\end{array}$ & & $\begin{array}{l}\text { 1990-1994. Cesar } \\
\text { Gaviria, PND: “La } \\
\text { revolución pacífica”. } \\
\text { 1994-1998. Ernesto } \\
\text { Samper, PND: “El }\end{array}$ \\
\hline
\end{tabular}

el país, comparten información sobre monitoreo a la gestión macroeconómica de las reformas estructurales. Conjuntamente con el BM interviene en varios proyectos el Banco Interamericano de Desarrollo (BID) cuyos créditos se focalizan principalmente en la construcción de infraestructuras. 
Capítulo 5. Evolución de las políticas agrarias y de tierras en Colombia: La influencia de los organismos internacionales

\begin{tabular}{|c|c|c|c|}
\hline Período & Documentos del BM & USAID & PND \\
\hline & Investment Program. 1997. & & salto social". \\
\hline $\begin{array}{l}2000- \\
2010\end{array}$ & $\begin{array}{l}\text {-Proyecto de apoyo a } \\
\text { alianzas productivas. } 2001 . \\
\text {-Estrategia de Asistencia } \\
\text { al País (EAP) } 2002 . \\
\text {-Notas de Política: } \\
\text { Fundamentos económicos } \\
\text { para la paz.2003. } \\
\text {-Estudio - “Colombia: } \\
\text { Competitividad rural y } \\
\text { agrícola”.2003. } \\
\text {-Estudio- “Colombia: } \\
\text { Política de tierras en } \\
\text { transición”. 2004. } \\
\text {-Notas de Política. } \\
\text { Colombia 2006-2010: Una } \\
\text { ventana de } \\
\text { oportunidades.2007. } \\
\text {-Alianza estratégica con el } \\
\text { País (AEP) 2008-2011. }\end{array}$ & $\begin{array}{l}\text {-Colombia: Derechos } \\
\text { de propiedad y } \\
\text { gobernanza de } \\
\text { recursos. } 2010 . \\
\text {-Auditoria al programa } \\
\text { de desarrollo } \\
\text { alternativo } \\
\text { USAID/Colombia. } \\
2010 .\end{array}$ & $\begin{array}{l}\text { 1998-2002. Andrés } \\
\text { Pastrana, } \\
\text { PND:"Cambio para } \\
\text { construir la paz". } \\
\text { 2002-2006. Álvaro } \\
\text { Uribe, PND: “Hacia } \\
\text { un estado } \\
\text { comunitario”. } \\
\text { 2006-2010. Álvaro } \\
\text { Uribe, PND: “Estado } \\
\text { comunitario: } \\
\text { Desarrollo para } \\
\text { todos” }\end{array}$ \\
\hline $\begin{array}{l}2010- \\
2018\end{array}$ & $\begin{array}{l}\text {-Alianza estratégica con el } \\
\text { país (AEP) 2012-2016. } \\
\text {-Notas de política: Hacia } \\
\text { la paz sostenible y la } \\
\text { erradicación de la } \\
\text { pobreza. }\end{array}$ & $\begin{array}{l}\text {-Programa de } \\
\text { Desarrollo Rural y de } \\
\text { tierras. Reporte Annual } \\
2015 . \\
\text {-U.S. Overseas, loans } \\
\text { and grants 2016. }\end{array}$ & $\begin{array}{l}\text { 2010-2014. Juan } \\
\text { Manuel Santos, PND } \\
\text { "Prosperidad para } \\
\text { todos". } \\
\text { 2014-2018. Juan } \\
\text { Manuel Santos, } \\
\text { PND: “Todos por un } \\
\text { nuevo país" }\end{array}$ \\
\hline
\end{tabular}

Fuente: Elaboración propia

Dentro del material analizado del Banco Mundial están: i) Las Notas de Política que recogen un diagnóstico de los desafíos actuales y recomendaciones de política para cada período de gobierno, ii) la Estrategia de Alianza con el País $(E A P)$ que contiene el programa del grupo del BM para asistir al país en la implementación de las prioridades planteadas durante cada período y que 
Capítulo 5. Evolución de las políticas agrarias y de tierras en Colombia: La influencia de los organismos internacionales

cambia a Alianza Estratégica con el País (AEP) a partir de 2008 cuando Colombia entra en la clasificación de los países con ingreso medio.

Del mismo modo se han analizado estudios específicos realizados por el BM sobre la competitividad rural y agrícola del país, el proceso de construcción de paz y la política de tierras. De la USAID se han analizado los documentos de los proyectos con los que se iniciaron las intervenciones dentro del Plan Colombia y recientemente el programa de tierras y desarrollo rural que apoya el proceso de restitución de tierras. Y finalmente se hace referencia a las recomendaciones realizadas por la OCDE para el desarrollo agrícola de Colombia.

\subsection{Las primeras directrices del Banco Mundial y los intentos de políticas agrarias redistributivas.}

Poco después del final de la Segunda Guerra Mundial, el BM empieza a tener injerencia directa en las directrices de política en Colombia, cuando con la primera misión, encargada a Lauchlin Currie en 1950, se evalúan los problemas prioritarios del país para definir la asignación de los créditos para el desarrollo, los cuales empezaron a llegar principalmente para implementación de infraestructuras y vías de comunicación ${ }^{21}$. Desde esta primera misión se reconoce la elevada concentración de la tierra, aunque la mayor preocupación de Currie fue la baja productividad, pues el informe señalaba que había muchos campesinos con agricultura de subsistencia en zonas de ladera con tecnologías atrasadas, poco productivos y ocasionando erosión de los suelos, mientras que en las zonas de sabana había grandes latifundios, algunos con ganado y muy baja productividad. Propuso que la acción del estado debería centrarse en el estímulo a la agricultura de exportación, aprovechar las grandes escalas de producción en ganadería y algunos cultivos como algodón, azúcar y palma de aceite. Es así como los primeros préstamos del BM, se dirigen todos a la agricultura de exportación (caña de azúcar, arroz, algodón y sésamo), la mecanización y la ganadería. En cuanto a los campesinos, Currie propuso que

${ }^{21}$ Entre 1966 y 1979, el BM ya había otorgado 10 créditos a Colombia para el desarrollo agrícola; proyectos de irrigación, la colonización en el departamento del Caquetá y desarrollo agrícola en el norte del país (Project Completation Report 7234, 1988) 
estos debían migrar a sectores urbanos más productivos ((Kalmanovitz \& López 2006:171). Aunque lo que finalmente ocurrió fue que, en las zonas urbanas, el crecimiento de la población dobló el crecimiento del empleo (Thompson 2011).

Los cambios en este período estuvieron marcados por la modernización de las haciendas y a su vez los intentos de implementar reformas agrarias redistributivas, promovidas por la Alianza para el Progreso, como la contraparte social de la estrategia militar del gobierno de Estados Unidos para frenar la expansión del comunismo en la región. Así, la primera Ley de Reforma Agraria fue la Ley 135 de 1961, que surge para frenar el movimiento campesino que se exacerbó tras el período de la violencia bipartidista de los años 1950s -denominado 'La Violencia' - y la proliferación de las guerrillas de base campesina que reivindicaban su lucha por la tierra. Esta Ley se fundamentó en el concepto de la función social de la propiedad, que exigía que la tierra estuviese siendo explotada económicamente, por lo que se permitía expropiar o comprar tierras que no lo estuvieran.

En la Ley se estableció la extinción de dominio a favor de la nación en el caso de que la tierra no se explotara por 10 años continuos, se creó el Instituto Colombiano para la Reforma Agraria (INCORA), limitó la adjudicación de tierras baldías en una extensión máxima de 450 hectáreas y ordenó adjudicar la tierra en Unidades Agrícolas Familiares (UAF) que era la extensión de tierra suficiente para permitir la subsistencia de una familia campesina.

Durante este período, se promovió la expropiación de tierras explotadas mediante el arriendo y la aparcería para dárselos a quienes la trabajaban, con lo cual muchos propietarios expulsaron los campesinos que estaban en sus fincas para evitar ser expropiados. Inicia así una etapa de expulsiones de los campesinos arrendatarios y aparceros por parte de terratenientes, y de numerosas invasiones en varias haciendas por el campesinado. Las expropiaciones realizadas fueron mínimas, pues las clases conservadoras terratenientes lograron frenarlas y evitar cualquier intento de redistribución de la tierra, mientras que el movimiento campesino fue frenado por la acción violenta de la fuerza pública (Thompson 2011). 
Capítulo 5. Evolución de las políticas agrarias y de tierras en Colombia: La influencia de los organismos internacionales

Con un cambio de gobierno en 1972, las élites políticas (liberales y conservadoras) y económicas pactan acabar con la reforma agraria redistributiva (El Pacto de Chicoral), y acuerdan otorgar apoyo financiero e institucional para las grandes explotaciones. Esto se va a concretar en 1973, con la expedición de la Ley $4^{\mathrm{a}}$ que protege nuevamente a los terratenientes de ser expropiados, e impide así la distribución de la tierra al interior de la frontera agraria. El acceso para los campesinos sin tierra se limitó a la titulación de baldíos, es decir a las colonizaciones. Y para asegurar la mano de obra en las explotaciones estableció la Ley $6^{\text {a }}$ de 1975, que permitía el sistema de aparcería.

Los procesos de expropiación fueron restringidos y la única forma de distribución de la tierra se hizo a través de adjudicación de baldíos y colonizaciones hacia las zonas de la frontera agropecuaria, sin afectar la concentración de propiedad de la tierra (Machado 2013; Fajardo 2002, 2014). La colonización realizada de manera desordenada y con una casi nula inversión del estado, facilitó la incursión de las guerrillas en estas zonas de ampliación de frontera y posteriormente la proliferación de los cultivos ilícitos (Fajardo 2002).

\subsection{El Desarrollo Rural Integrado. Narcotráfico y reconcentración de la tierra}

A la entrada de la década de los años 1980s la economía colombiana experimentaba precios bajos en los productos agrícolas, el crecimiento del PIB había caído a 1,5\% para 1982, en comparación con un promedio de 6,1\% entre 1970-1978 (Thompson 2011:430), los precios de insumos se habían incrementado y los costos de la tierra también. El narcotráfico se expandía y con él la nueva clase social de narcotraficantes que empezaron a adquirir tierras por todo el país, haciendo uso de los grupos armados para su protección y fomentando así el paramilitarismo. El narcotráfico también permitió el fortalecimiento de la guerrilla con lo cual se incrementó la violencia y el ataque a la población rural, elevando las cifras de población desplazada.

La visión global sobre la reforma agraria se sustituyó por el denominado Desarrollo Rural, así lo refleja el BM en las directrices dadas para la agricultura 
colombiana en 1983, cuando recomienda la necesidad del crecimiento económico, a través de la promoción de las exportaciones y sustitución de importaciones y de la generación de empleo bajo la promoción del desarrollo agrícola y rural (Banco Mundial 1983). Los programas de Desarrollo Rural Integrado $(\mathrm{DRI})^{22}$ se proponen como alternativa a la distribución de la tierra. $\mathrm{Y}$ aquí las agencias internacionales (BM, FAO, BID) se dieron a la tarea de apoyar su implementación en Colombia. El objetivo principal era mejorar la productividad de la agricultura y ampliar la provisión de servicios en las zonas rurales. Los productores campesinos eran los llamados a cubrir la demanda de alimentos mediante el incremento de la producción a través de la adopción de nuevas tecnologías, financiadas a través de créditos. El objetivo de mejorar la productividad se cumplió en algunas zonas, así como también el de desviar cualquier intento de distribución de la tierra (Thompson 2011; Fajardo 2014)

De esta manera se abandona la reforma agraria, las escasas asignaciones de tierras fueron en zonas de conflicto, atendiendo las demandas de tierras de los primeros procesos de negociación de paz con la guerrilla bajo el gobierno de Belisario Betancourt 1982-1986 ${ }^{23}$. Para esto se creó el Plan Nacional de Rehabilitación (PNR) que proporcionaba ayuda a las zonas con violencia guerrillera. En los años noventa, el PNR se enfocó a prestar asistencia social y económica a los municipios pobres y con violencia, especialmente a comunidades campesinas e indígenas. Financió infraestructuras; vías, puentes y saneamiento básico y desarrollo comunitario. Estos programas enfocados a proveer servicios sociales a los pequeños productores y a llevar el estado a las comunidades más pobres, no tuvieron gran impacto, fueron una forma más de apaciguar las organizaciones campesinas que reclamaban tierra y permitir de una forma más calmada que la concentración de la tierra y la entrada de las

\footnotetext{
${ }^{22}$ El DRI se introdujo en la política colombiana desde mediados de los años setenta, primero adscrito al Departamento Nacional de Planeación y en 1983 pasa al Ministerio de Agricultura, se desmontó en los años noventa con la entrada de la apertura económica.

${ }^{23}$ La estrategia para el desarrollo agrícola del gobierno fue reducir las disparidades entre los ingresos rurales y urbanos mediante el mejoramiento de las condiciones de vida y nutrición y asegurar mayores ganancias de las exportaciones. La distribución de la tierra no era una prioridad, se llevaría a cabo en áreas con alta presión sobre la tierra, pero no estaba considerada como un medio principal para reducir la pobreza rural. El BM apoyaba la estrategia financiando los beneficiarios de la reforma agraria y la colonización que tenían limitado acceso a crédito y a la asistencia técnica (Banco Mundial 1988).
} 
Capítulo 5. Evolución de las políticas agrarias y de tierras en Colombia: La influencia de los organismos internacionales

grandes explotaciones comerciales pudiesen continuar sin mayores problemas (Thompson 2011).

En 1988 se expide la Ley 30, que buscó poner otra vez en primer plano la función social de la propiedad permitiendo la expropiación de cualquier inmueble rural improductivo. Lo que no tuvo mayor impacto, dado que el creciente desplazamiento de la población campesina ayudó a la fragmentación de sus organizaciones disminuyendo su capacidad reivindicativa. A la vez, el proceso de apertura comercial estaba iniciando para concretarse en los años noventa.

El narcotráfico llega a Colombia en los años setenta, encuentra un gran potencial para instalarse en las zonas de colonización, donde los campesinos expulsados del centro del país se establecieron en busca de tierras, con la ausencia casi total del estado. Aquí los narcotraficantes encuentran tierras y mano de obra barata, que junto a las condiciones de pobreza y aislamiento hacen que los cultivos ilícitos sean la opción económica más rentable para la población. Los narcotraficantes fueron ganando poder y estableciendo relaciones con las clases de terratenientes locales, lo cual les sirvió para ganar control e influencia y lavar el dinero del narcotráfico mediante la compra de tierras y la ganadería principalmente. Reyes (1997) encontró que entre 1975 y 1995 los narcotraficantes habían realizado compras en 400 municipios del país, con lo que duplicaron la extensión de predios mayores a 500 hectáreas. La concentración de la tierra también la evidenciaron Kalmanovitz \& López (2006), cuando muestran que en 1984 el porcentaje de propietarios con predios mayores a 200 hectáreas era 1,6\% y poseían el $47,1 \%$ de la tierra agrícola, mientras que para el año 2000 eran el 1,4\% y tenían apropiado el 68\% de la tierra.

\subsection{Liberalización de la economía. El mercado de tierras}

En los años noventa se inicia el proceso de internacionalización de la economía, recomendado y soportado en los estudios y préstamos del BM, con el que se deja al mercado la regulación de la economía y se resta intervención al estado. Las reformas de ajuste estructural que se emprendieron se dirigieron al comercio internacional, apertura a la inversión extranjera directa y del mercado 
de capitales, autonomía del banco central, reforma financiera, descentralización fiscal, apertura de la inversión privada en infraestructura, reformas al sistema de seguridad social y remoción de las rigideces del mercado laboral.

En el contexto político nacional, en 1991 se promulga la nueva Constitución Nacional, la cual amplia el alcance de los derechos mediante instrumentos legales para la participación de la sociedad civil, fortaleció la independencia judicial y la rendición de cuentas del gobierno y reformó el sistema electoral.

Dentro de las políticas para el desarrollo agrícola y rural, el BM identificó como el mayor desafío para Colombia enfrentar la pobreza rural (la incidencia de la pobreza rural era 3,6 veces mayor que la incidencia de la pobreza urbana, para 1992 la pobreza extrema rural fue del 31\%). Para lo cual se debía crear empleo en el sector rural, y lograr que el mercado de tierras y de trabajo funcionara de manera más efectiva, además de reforzar la apertura comercial, pues un régimen comercial más libre ayudaría al crecimiento económico (Banco Mundial 1996). De igual modo reconoció que dentro de las fallas que había tenido el DRI estaba el haber omitido el acceso de los pequeños productores a la tierra y al capital (Banco Mundial 1997).

La implementación de la nueva política de tierras en la década de 1990, se inició con el proyecto de cooperación internacional PNUD-FAO-COL91/018, cuya asesoría tenía como finalidad introducir el mercado de tierras. El resultado se plasmó en la Ley de Reforma Agraria 160 de 1994, cuyo eje central fue el mercado asistido de tierras, con el objetivo de estimular transacciones comerciales de tierras entre particulares, acelerar la privatización de los derechos de propiedad en tierras públicas, comunales y colectivas y asegurar la propiedad privada, removiendo la informalidad en los derechos de propiedad. Esto permitiría reducir la concentración y el costo de la tierra, haciendo las exportaciones nacionales más competitivas. Además de bajar la intensidad de los movimientos sociales en el campo. Se trataba de que el estado asistiera al mercado, otorgando subsidios a los campesinos para la compra por el 70\% del valor de la UAF.

Para Mendes \& Fajardo (2015) el objetivo real de la política BM fue promover su agenda agraria neoliberal, aduciendo que la liberalización de la mano de obra, la tierra y el crédito habían sido mucho menores que la liberalización 
Capítulo 5. Evolución de las políticas agrarias y de tierras en Colombia: La influencia de los organismos internacionales

macroeconómica y la fiscal. Ahora el BM abordaba la concentración de la tenencia de la tierra, de forma técnica, como un medio de producción, restando la ideología política de las reformas agrarias redistributivas. También porque le interesaba reducir los impactos de las disputas originadas en la propiedad de la tierra, fuente de conflictos políticos, por ello reconoce la tierra como instrumento para establecer acuerdos de paz en las guerras civiles y también su papel dentro de la iniciada lucha internacional contra la pobreza (Mendes \& Fajardo 2015:3).

Los resultados de la reforma agraria asistida por el mercado, fueron muy pobres en términos de desconcentración y acceso a la tierra y en su fin último de dinamizar este mercado; por un lado, se incrementó el precio de la tierra, esto hizo que los recursos destinados a los subsidios no fueran suficientes. Tampoco las tierras más productivas y bien localizadas fueron las que se vendieron. El mercado no pudo ser dinámico pues las propiedades no tenían títulos, los avalúos catastrales estaban desactualizados o no existían y en general no había un sistema de información de precios de la tierra que facilitara las transacciones. Además, los campesinos no contaron con suficientes recursos para invertir en la producción, por lo que la mayoría se dedicó a la agricultura de subsistencia. Así, la meta de financiación para la compra de tierra en los primeros cuatro años (75.000 familias en el periodo 1994-1998) solo se cumplió en un 23\%, un total 17.058 familias subsidiadas (Mendes \& Fajardo, 2015:10). El poco éxito del mercado de tierras, provoco una mayor intervención del BM a través de un proyecto piloto entre 1997-1998, el cual se realizó en 5 municipios aplicando los correctivos que se creía que estaban haciendo fracasar el programa; se exigió la participación de las municipalidades en el programa e introdujeron un mecanismo flexible de préstamos, al inicio el precio de la tierra disminuyó, pero la agricultura continuaba siendo de subsistencia (Borras 2003)

La concentración de la tierra tampoco disminuyó; no hubo transacciones entre pequeños y grandes propietarios, sino entre pequeños y medianos, lo que fragmentó aún más la propiedad (Machado 2009:167). Estos y otros problemas en la estructura legal e institucional sumado al contexto de violencia y el 
narcotráfico incidió en el fracaso de esta política, que reconoció el BM cuando hace su evaluación del programa en el país en $2004^{24}$.

Para el caso colombiano, como en otros países, los análisis concluyen que la reforma agraria asistida por el mercado, liderada por el BM, fue una estrategia en contra de la reforma agraria redistributiva y basada en la expropiación de tierras privadas por el estado, con el objetivo político de ingresar en la agenda neoliberal la política agraria y desestimar las luchas por democratizar la estructura agraria en sociedades altamente desiguales (Mendes y Fajardo 2015:1).

\subsection{Las políticas neoliberales: Alianzas productivas para lograr la paz y el desarrollo}

En 1995 el país era considerado uno de los más violentos del mundo ${ }^{25}$. La lucha del gobierno en esta década se había centrado en combatir los dos carteles de la droga más grandes, cuya articulación con grupos paramilitares y enfrentamientos con las guerrillas había exacerbado la violencia en las zonas rurales y también las urbanas ${ }^{26}$. El BM intervino financiando el proyecto de laboratorio de paz, llamado 'Desarrollo y Paz de la región del Magdalena Medio', una de las regiones más pobres y con mayor violencia, a pesar de ser el epicentro del desarrollo petrolero del país. De igual manera financió programas para los jóvenes y disminuir la violencia urbana (en Medellín, Cali, Bogotá y Pereira).

\footnotetext{
${ }^{24}$ El BM encontró que el subsidio para la compra era muy alto y que no había sido asignado nada para el proyecto productivo, el alto subsidio hacia subir el precio de la tierra. A los terratenientes, les permitía acceder a los dineros del subsidio por la venta de predios e imponer los términos de la negociación. La actuación del INCORA se criticó por su falta de operacionalidad administrativa y la corrupción al interior de la institución, sugiriendo que el hecho de que el sector público administrara los fondos de la reforma hizo que fuera ineficiente (Banco Mundial 2004)

${ }^{25}$ La tasa de asesinatos era 92 por cada 100.000 habitantes, comparado con 20 en Brasil, 10 en los Estados Unidos, 5 en Argentina y 3 en Chile (Banco Mundial 1997:2).

${ }^{26}$ Al finalizar la década de los noventa, la Población Desplazada Internamente (PDI) por la violencia rondaba los 1,9 millones de personas, los datos de la Defensoría del Pueblo mostraban que el $41 \%$ de los desplazamientos eran causados por los paramilitares, el $28 \%$ por la guerrilla y un 13\% por las fuerzas armadas (Banco Mundial 2001)
} 
Capítulo 5. Evolución de las políticas agrarias y de tierras en Colombia: La influencia de los organismos internacionales

La Estrategia de Asistencia al País (EAP) del BM para el período de gobierno del presidente Andrés Pastrana 1998-2000, reconocía que la violencia y el conflicto armado eran uno de los mayores obstáculos para el crecimiento económico, el desarrollo y el progreso social del país. Por ello, el BM contrató una investigación para estudiar la relación entre violencia, desarrollo y pobreza, que concluyó, entre otras cosas, que la violencia en Colombia principalmente era política, económica y social. Dentro de las causas de la violencia política se identificaron tres factores: i) desigual acceso al poder económico (tierra y recursos naturales); ii) exclusión del poder político y iii) la ganancia de recursos a través de drogas ilícitas por la guerrilla y los paramilitares. Las causas de la violencia económica y social se relacionaban con la pobreza, la desigualdad, el crecimiento acelerado, altos niveles de impunidad, falta de oportunidades educativas y de empleo, entre otros (Solimano et al. 1999).

La EAP se focalizó en objetivos encaminados a enfrentar los determinantes socioeconómicos de la violencia: i) reducción de la pobreza y desarrollo social (promoción de la paz y el desarrollo) y ii) crecimiento sostenible (infraestructuras y servicios). Para ello reclamaba un manejo macroeconómico adecuado mediante la reducción del déficit fiscal y la aplicación de las reformas de segunda generación -de liberalización económica- apoyadas con el FMI como la descentralización, reforma presupuestaria y de seguridad social (Banco Mundial 1997)

En cuanto al crecimiento agrícola, al BM le preocupaba el efecto de la violencia en la reducción de los incentivos a la inversión, especialmente en cultivos perennes. Los efectos de la liberalización aplicada a la agricultura en la década de los 90 se reflejaron en la pérdida del área sembrada. Los cultivos transitorios cayeron en 870 mil hectáreas y los permanentes aumentaron solo en $200 \mathrm{mil}$ hectáreas. Por lo que el BM insistió en que la producción agrícola estaba aún por explotar, como la tierra apta para la siembra de palma de aceite, estimada en 2,5 millones de hectáreas, de las que solo se cultivaban un 5\%. Por lo que el desafío de la agricultura era aumentar la competitividad en el mercado, combinando cultivos permanentes con cultivos de subsistencia anuales. De esta manera los productores incrementarían ingresos y reducirían su deuda. La 
financiación de los pequeños productores ${ }^{27}$, carentes de garantías para los créditos, se resolvería con préstamos a intermediarios financieros $y$ financiamiento a través de proveedores de insumos y agronegocios, considerados más flexibles y accesibles (Banco Mundial 2001:4).

Para fortalecer esta alternativa, el BM inicia la financiación del proyecto de alianzas productivas entre organizaciones de pequeños productores $y$ $\operatorname{agronegocios}^{28}$, pues con ello se les permitía a los campesinos el acceso al mercado y a recursos de capital, y a las empresas incrementar su productividad, reducir riesgos. Así se dinamizaría la economía rural, se mejoraría el bienestar de los pobres rurales y se contribuiría al proceso de paz. El marco de la política rural del gobierno para alcanzar la competitividad, la igualdad y sostenibilidad se centró así en demostrar la necesidad de complementariedad entre el sector público y el privado.

Dado el desigual acceso a la tierra, demostrado en un coeficiente Gini de 0.84, el BM reconoce que los intentos de redistribuir la tierra dentro de la frontera agropecuaria no dieron resultado y que los escasos logros en reforma agraria se dieron en zonas de frontera, por medio de la colonización dirigida y espontánea. Sin embargo, la política rural propuesta por el BM se fundamentó en promover la inversión en el sector, el desarrollo de la tecnología agrícola, la sanidad animal y programas de desarrollo rural (bienes públicos y sociales) para intervenciones en los grupos pobres y marginales. Con lo cual, aun reconociendo la persistencia de la desigualdad en el acceso a los recursos y sus relaciones con la violencia, sus propuestas de políticas no abordan la distribución del control (político y económico) sobre esos recursos en las zonas rurales.

\footnotetext{
${ }^{27}$ Los niveles de crédito para pequeños productores habían caído en más de un $80 \%$ para la entrada de la década del 2000 respecto a los niveles de 1996, debido a la quiebra y posterior liquidación en 1998 de la Caja Agraria, entidad encargada de los préstamos a los pequeños productores. Se reemplazó por el Banco Agrario pero este exigía un 100\% de garantías que los campesinos no podían cumplir (Banco Mundial 2001:3).

${ }^{28}$ El proyecto se implementó a partir del 15 de noviembre de 2001 hasta noviembre de 2006, con una financiación total de U\$51,82 Millones (Banco Mundial, 2001).
} 


\subsection{Enfoque y financiación del proceso de paz por el BM y el gobierno de Estados Unidos (USAID). El Plan Colombia.}

La estrategia para alcanzar el desarrollo rural estaba considerada dentro la propuesta del proceso de paz. En 1998 las FARC y el gobierno de Andrés Pastrana acordaron el despeje de 42 mil kilómetros (la zona de despeje o distensión) para adelantar los diálogos de paz, en el departamento del Caquetá. No obstante, al mismo tiempo el gobierno colombiano negoció con el gobierno norteamericano la implementación del plan para la paz, la prosperidad y el fortalecimiento del estado, el denominado 'Plan Colombia' ${ }^{29}$. Su contenido central fue la lucha militar contra la insurgencia y la erradicación de cultivos ilícitos a base de fumigaciones aéreas.

La intervención de Estados Unidos a través de la USAID tiene una historia de más de 50 años en Colombia a través de asistencia económica y militar, principalmente para el control de narcóticos. En sus inicios (finales de los años noventa), el Plan Colombia se centró en combatir el narcotráfico y apoyar el crecimiento del país. La aplicación del Plan, no ha sido efectiva en la eliminación del narcotráfico ni en fomentar el desarrollo en las zonas donde se ha implementado. Por el contrario, ha sido cuestionado por varias ONG, organizaciones campesinas y académicos debido a su impacto en la violación de Derechos Humanos y en la afectación de la economía de los pequeños productores y del medio ambiente (Fajardo, 2014). Para canalizar los recursos del Plan Colombia destinados a financiar aspectos productivos y sociales se creó el Fondo de Inversión para la Paz (FIP). Estos recursos se destinaron a promover las inversiones productivas en las áreas del conflicto armado bajo el enfoque de las 'alianzas productivas'.

\footnotetext{
${ }^{29}$ El Plan Colombia se puso en marcha en diciembre de 1999. Los recursos del plan eran para 4 años un total de US\$7.500 Millones, de los cuales 58\% vendrían del presupuesto nacional y el restante $42 \%$ de la comunidad internacional. De los recursos aportados por el gobierno de Estados Unidos, a través de su Agencia para el Desarrollo Internacional (USAID), cerca del $80 \%$ tenían destinación militar, aunque los objetivos del Plan Colombia eran: promover el proceso de paz, revitalizar la economía, combatir la industria de narcóticos, fortalecer los pilares democráticos de la sociedad colombiana, promover la reforma del sistema de justicia, proteger los derechos humanos y ampliar la democratización y el desarrollo social (Banco Mundial 2001:7).
} 
En el marco de operación del Plan Colombia, para el año 2005, la USAID crea el Programa de Desarrollo Alternativo mediante dos iniciativas: Más Inversión para el Desarrollo Sostenible (MIDAS) y Áreas para el Desarrollo Alternativo Municipal (ADAM). Su objetivo fue apoyar la erradicación de cultivos ilícitos generando medios de vida sostenibles para mediados y pequeños agricultores. Las actividades implementadas con MIDAS estaban dirigidas a la promoción de agronegocios, cultivos forestales comerciales, pequeños y medianos emprendimientos. Por su parte, la iniciativa ADAM incluyó proyectos de agricultura, infraestructura y actividades de gobernanza local. Los cultivos que se favorecieron fueron la palma de aceite, el cacao y el café. La ejecución se realizó conjuntamente con la agencia gubernamental Acción Social y el FIP (USAID 2010a). Estas estrategias se convierten así en la base de la política rural para este período de gobierno cuyas líneas de intervención incluyeron: la política para la atención a población desplazada, un plan de atención especial para las zonas en conflicto y un programa de desarrollo alternativo ligado a la erradicación de cultivos ilícitos (DNP 1998:307).

\subsection{Inicios del siglo XXI: Seguridad Democrática para el modelo agroexportador}

Después de más de una década de aplicación de la apertura económica, el país estaba sumido en un alto grado de ingobernabilidad, los diálogos con la guerrilla de las FARC se habían frustrado y esta se había expandido y ganado un control considerable en varios territorios llegando con operaciones muy cerca de la capital. La agricultura estaba en crisis por la caída de los precios del café y de la producción de varios cultivos, especialmente los de ciclo corto, a causa del incremento de la competencia derivado de la liberalización.

Para este período el BM había preparado su EAP 2002, sobre tres pilares: i) Crecimiento rápido y sostenible, ii) Compartir los frutos del crecimiento y iii) Construir una gobernabilidad eficiente y transparente. El desarrollo rural, contenido en el primer pilar, incluía el fortalecimiento del sector privado en la provisión de servicios a los productores, la creación de oportunidades fuera de la agricultura, el acceso a tierra para pequeños productores a través del mercado de tierras y dotar de servicios básicos e infraestructura a las zonas rurales. Este contenido de la EAP se incluye en el PND 2002-2006 'Hacia un 
Capítulo 5. Evolución de las políticas agrarias y de tierras en Colombia: La influencia de los organismos internacionales

Estado Comunitario', cuyas bases fueron la seguridad democrática, el crecimiento económico sostenible, la generación de empleo, equidad social e incrementar la eficiencia y transparencia del estado.

Para apoyar este plan de gobierno, el BM asignó un préstamo al país de US\$3.300 millones, uno de los más altos otorgados por el Banco, justificado en el ambicioso programa del gobierno de lograr la paz y reducir la pobreza (Banco Mundial 2002:2) ${ }^{30}$. A su vez insistió en la profundización en la aplicación de las políticas de liberalización ${ }^{31}$, justificadas en la necesidad de corregir el desequilibrio financiero del sector público y el problema de la deuda.

El BM resaltaba que el país crecía a pesar del conflicto armado, pero esa prosperidad no había servido para acabar con la guerra. Las reformas realizadas tampoco habían modificado el funcionamiento clientelista del estado y las instituciones que se mantenían bajo las influencias de los grupos de interés a escala regional y nacional, cuyo propósito era obtener rentas y tratamientos preferenciales (Banco Mundial 2003a:437).

En lo referente al sector agropecuario, las Notas de Política (2002-2006) plantearon abrir los mercados al comercio agrícola a través de la reducción de aranceles a las importaciones agrícolas, la relajación de las medidas no arancelarias y la remoción de programas que protegían a los productores. Para la promoción de la productividad y la competitividad era necesaria la diversificación basada en el mercado, que debía guiarse por el sector privado (Banco Mundial 2003a:442). En cuanto a la Ley 160 de 1994, sugirió flexibilizar la UAF, analizar el potencial productivo de los proyectos de reforma agraria y pidió reformar el INCORA. Para las poblaciones en pobreza extrema, como comunidades indígenas, desplazadas, tercera edad y campesinos sin tierra propuso la creación de redes de apoyo (2003a:446).

\footnotetext{
${ }^{30}$ Del progreso en la aplicación de las reformas sectoriales solicitadas por el BM, dependía que el préstamo se mantuviese en el nivel acordado, de lo contrario se realizaría una baja en el monto del préstamo (Banco Mundial 2002:23).

${ }^{31}$ Ajuste fiscal, reformas en el sistema financiero, tributario, las pensiones, reforma laboral, facilitar la inversión privada en la provisión de infraestructuras y continuar con el programa de privatizaciones del sector eléctrico y las telecomunicaciones.
} 
El PND de Uribe, acoge las reformas del BM y retoma el control de la violencia por el estado mediante la intensificación de las operaciones militares en contra de la insurgencia, apoyado en los recursos del Plan Colombia. Estos en su mayoría $(57,5 \%)$ se dirigieron a la lucha contra las drogas ilícitas y el crimen organizado, un $26,6 \%$ al fortalecimiento institucional y solo un $16 \%$ a la reactivación económica y social ${ }^{32}$.

En lo que denominó su manejo social del campo, promovió los esquemas asociativos de los pequeños productores rurales con empresarios agroindustriales, bajo la premisa de que “...lo importante no es la tierra sino su incorporación a una actividad estable y equitativa" (DNP 2002:230). Con ello buscó acelerar el crecimiento agroexportador, intensivo en tierras y capital. A su vez liquidó el INCORA y otras tres entidades del sector, fusionándolas en el Instituto Colombiano de Desarrollo Rural (INCODER), cuya capacidad de actuación y legitimidad fue bastante cuestionada ${ }^{33}$.

Adicionalmente para el año 2003, el BM mediante un estudio muestra que la competitividad rural y agrícola del país era muy baja y que de ello derivaba la expansión continuada de la pobreza rural. Así identifica que los productos con ventajas comparativas eran: granos y soja; frutas y vegetales; café, azúcar, palma de aceite y cacao; yuca, patatas, tabaco y algodón; productos ganaderos y plantaciones forestales comerciales. Por lo tanto, el gasto del sector debía dirigirse hacia estos productos y a programas de asistencia para los pobres rurales (Banco Mundial 2003b)

Para reforzar lo anterior, el BM realiza en 2004 otra propuesta de política agraria ("Colombia: política de tierras en transición") en la que, aparte de reconocer los impactos sociales y económicos de la histórica desigualdad en la distribución de la tierra en la polarización política del país (Banco Mundial

\footnotetext{
${ }^{32}$ Este apoyo a la reactivación económica financió la Red de Apoyo Social (RAS), compuesta por programas de transferencias condicionadas de Familias en Acción, Empleo en Acción y Jóvenes en Acción (DNP \& DJS 2006) que fueron también un requerimiento del BM.

${ }^{33} \mathrm{El}$ instituto se liquidó en 2015 y las funciones en materia de tierras pasaron a la Agencia Nacional de Tierras (ANT) creada en 2015. El INCODER careció de legitimidad entre los pobladores rurales por casos de corrupción y relaciones de algunos de sus funcionarios con la parapolítica. Además de sus problemas estructurales en relación con la visión del desarrollo rural y la inoperancia en procesos agrarios (Machado 2013).
} 
Capítulo 5. Evolución de las políticas agrarias y de tierras en Colombia: La influencia de los organismos internacionales

2004: 1), vuelve a plantear la orientación de la estructura productiva hacia los cultivos perennes, por tener ventajas de productividad y competitividad. Para garantizar la inversión pública y privada se exige la seguridad en la tenencia de la tierra. El acceso a la tierra se planteó para los agricultores más productivos, intensificando el mercado de tierras mediante ventas y arrendamientos. Planteaba mejorar el sistema de tributación para acabar con la acumulación improductiva y la tenencia especulativa de la tierra. Para este año el BM reportó una cifra de 4 millones de hectáreas abandonadas a causa del desplazamiento forzado, por lo que pidió al gobierno vincular el desplazamiento al problema de la tierra (BM 2004:8).

En línea con estas recomendaciones, el gobierno de Uribe Vélez, centró su política de crecimiento económico, además de en la minería, en los cultivos agroexportadores, entre ellos los destinados a la producción de agrocombustibles. Así la palma de aceite o palma africana fue uno de los cultivos que recibió fuertes subsidios, protección y financiamiento nacional ${ }^{34}$, inclusive formó parte de los programas de sustitución de cultivos ilícitos del Plan Colombia y USAID, vinculando organizaciones de pequeños productores con los agronegocios a través de las alianzas productivas (USAID 2010a).

El incremento del cultivo de la palma también se vio favorecido por la demanda mundial de los agrocombustibles, que incrementó su precio en un $229 \%$ por tonelada entre 2000 y 2010 (Hurtado et al. 2017). Aunque el cultivo de palma ya existía desde 1957, su consolidación despega en los años noventa $^{35}$. Varias investigaciones han demostrado su relación con el desplazamiento forzado. En varias regiones del país numerosas alianzas se tejieron entre empresarios y paramilitares para desplazar población, acceder a

\footnotetext{
${ }^{34}$ Entre los mecanismos para la promoción de agrocombustibles están: La Ley 818 de 2003 con los incentivos tributarios, el Decreto 383 de 2007 para las zonas francas especiales, Ley 939 de 2004 para exención de impuestos a biocombustibles, Decreto 2629 de 2007 para establecer mezclas de diesel con biodiesel, Decreto 1970 de 2005 para la exención de impuesto a la renta para cultivos de tardío rendimiento, Documentos CONPES 3477 de 2007 y 3510 de 2008 para biocombustibles y fortalecimiento del sector palmero y su exportación, Decreto 4051 de 2007 que permite construir y dar estímulos para crear zonas francas en los cultivos de palma, entre otros.

${ }^{35}$ Para 1998 existían 139.310 hectáreas de palma, donde el 11,2\% de las explotaciones concentraba el 88,2\% del área sembrada (Kalmanovitz y López, 2006). Para finalizar el 2011 ascienden a 391.187 hectáreas (Fedepalma 2011).
} 
sus tierras y sembrar palma. Los mismos paramilitares participaron estableciendo cultivos apoyados con los programas de alianzas productivas (Osorio 2015; Ballvé 2013; Grajales 2011, 2016; Thompson 2011; Hurtado et al 2017).

\subsection{La participación de la financiación internacional en la atención a la población desplazada.}

A la entrada del siglo XXI la cifra de población desplazada internamente (PDI) por el conflicto armado rondaba los dos millones, y las medidas establecidas para su prevención, atención y restablecimiento contenidas en la Ley 387 de 1997, habían tenido muy poco alcance frente a la magnitud del fenómeno. La denuncia y presión por ONGs nacionales e internacionales hizo que la Corte Constitucional se pronunciara mediante varias sentencias ${ }^{36}$ y exigiera al estado la atención y el restablecimiento de los derechos a la población desplazada. Estos incluyeron el derecho a la protección de sus tierras, mediante el Decreto 2007 de 2001 que dio paso al Proyecto de Protección de Tierras y Patrimonio de la Población Desplazada iniciado en $2003^{37}$. Mediante este se ordena la protección de los bienes patrimoniales de la PDI a través de la realización de un registro de bienes abandonados y se prohíbe la venta o transferencia de bienes en zonas afectadas por el desplazamiento o en riesgo de padecerlo. Se establece la actuación de las diferentes instituciones en la ruta de protección quedando en cabeza los Comités Municipales de Atención Integral a Población Desplazada (CMAIPD), responsables de la protección de tierras ante amenazas o desplazamiento en el territorio.

En 2010 el proyecto entregó su informe final, reportando que 107.088 personas habían solicitado la protección sobre 115.494 predios que comprendían 3.799.386 hectáreas en 855 municipios del país (Acción Social 2010). La

\footnotetext{
${ }^{36}$ Sentencia T-025 de 2004, Auto 218 de 2006; Auto 004, 005, 007 y 008 de 2009; Sentencia T821 de 2007 donde reconoció la restitución como un derecho fundamental de las personas en situación de desplazamiento a causa de la violencia.

${ }^{37}$ Este Proyecto continuo siendo financiado por el Banco Mundial durante sus tres primeras etapas que concluyeron en 2011 y sirvió de sustento para la política de restitución de tierras iniciada en 2011.
} 
Capítulo 5. Evolución de las políticas agrarias y de tierras en Colombia: La influencia de los organismos internacionales

materialización de este proyecto facilitó no solo la protección sino también el camino para la implementación del proceso de restitución.

La financiación para la realización de este proyecto vino del Fondo del Posconflicto del Banco Mundial y el Alto Comisionado de las Naciones Unidas para los Refugiados, luego se sumaron nuevos cooperantes como la Agencia Sueca de Cooperación Internacional para el Desarrollo, Comisión Económica Europea, Agencia Española de Cooperación Internacional para el Desarrollo y USAID (Acción Social 2010).

\subsection{La Ley de Justicia y Paz Ley 975 de 2005: Desmovilización de los grupos paramilitares}

El gobierno de Uribe adelantó un acuerdo con los grupos paramilitares para su desmovilización, los cuales estaban unificados bajo los diferentes frentes de las Autodefensas Unidas de Colombia (AUC). El proceso se inició en 2003 y se materializó mediante el marco normativo de la Ley de Justicia y Paz de 2005. Su objetivo fue contribuir al proceso de paz teniendo en cuenta las necesidades de los excombatientes y las víctimas civiles del conflicto. La aplicación de esta ley se llevó a cabo mediante 3 mecanismos: i) la creación de la Comisión Nacional para la Reparación y la Reconciliación (CNRR), que debía dar a las víctimas un rol en la clarificación de la verdad y en el seguimiento y verificación de la reinserción y las reparaciones, ii) la creación de las Comisiones Regionales para la Restitución de bienes, encargada de manejar las reclamaciones de propiedades y iii) la creación del Fondo para la Reparación de Víctimas (FRV) que se constituyó con los activos restituidos por los desmovilizados, adquiridos ilegalmente más los fondos del presupuesto nacional (Banco Mundial 2008b:47)

La aplicación de esta ley derivó en la desmovilización de 42.000 miembros de las AUC (BM 2008). Sin embargo, no todos los frentes se desmovilizaron y varios se reorganizaron cambiando de nombre. El gobierno los catalogó como Bandas Criminales (BACRIM), para algunos sectores -académicos, ONGs, periodistas- son considerados como neoparamilitares pues varios de sus jefes fueron miembros las AUC y además continuaron ejerciendo el control en varios territorios sobre actividades lícitas e ilícitas. 
El BM en 2008, mediante el estudio "Colombia Programa de Paz I", evalúa el proceso de desmovilización y reinserción de los paramilitares. Entre los logros el BM menciona que durante el proceso hubo una disminución de las muertes y de los actos violentos. No obstante, hasta las fuentes oficiales registraron el mayor número de desplazamientos en el periodo 2002-2009 con más de 2,5 millones de personas desplazadas (Acción Social 2010).

El BM reconoce también que se presentó un rearme de paramilitares desmovilizados y otros que no se desmovilizaron y continuaban controlando territorios en varios departamentos del país, realizando confrontaciones armadas y controlando el narcotráfico. Resaltó que por parte del gobierno no había una estrategia para recuperar la tierra apropiada por los paramilitares desmovilizados y retornarla a las personas desplazadas. Evidenció también como obstáculo una insuficiente capacidad de convocatoria hacia el sector privado, en el sentido de que varios empresarios se ofrecieron a trabajar con desmovilizados en las agroindustrias de palma de aceite, cacao, caucho y café, pero otros no confiaban en el proceso de reintegración, pues creían que este tipo de propuestas eran promovidas por los líderes desmovilizados para continuar trabajando con recursos obtenidos ilegalmente (BM 2008b:37).

En relación al tema de tierras, la Ley incluyó garantizar la reparación de los derechos de las víctimas a la verdad, la justicia y la reparación y la no repetición. Aunque la ley fue criticada por los altos niveles de impunidad que se otorgaron a los desmovilizados ${ }^{38}$, con penas leves a cambio de dar declaraciones libres sobre los delitos cometidos, esto permitió esclarecer en gran medida la participación de los paramilitares en el despojo de tierras y traer de nuevo el tema de la tierra a las agendas pública. Lo que va a permitir un avance para la implementación de la Ley de Víctimas y Restitución de Tierras.

\footnotetext{
${ }^{38}$ La Contraloría General de la República (CGR) en 2017, presentó los precarios resultados de la implementación de la Ley 975: de 4.981 miembros postulados para penas alternativas, la mitad salieron del proceso y solo hubo 195 condenados (un 8,2\%); de los recursos para indemnizar a las víctimas, solo el $6 \%$ fueron aportados por los postulados desmovilizados a la Ley. A su vez, de las 439.517 ha de tierras solicitadas en restitución, los desmovilizados solo entregaron 612 ha (CGR 2017).
} 
Capítulo 5. Evolución de las políticas agrarias y de tierras en Colombia: La influencia de los organismos internacionales

\subsection{Incremento del apoyo internacional al segundo período de la Seguridad Democrática 2006-2010.}

Para el segundo período del gobierno de Uribe Vélez, el Banco Mundial (2007) en las Notas de Política 2006-2010, Colombia una ventana de oportunidades, refleja una continuidad en sus recomendaciones: una economía más abierta para el crecimiento económico, cultivos permanentes exportables y competitivos y un estado proveedor de bienes públicos.

Una vez formulado el Plan Nacional de Desarrollo 2006-2010, el BM elaboró conjuntamente con el gobierno la Alianza Estratégica con el País (AEP) 20082011. Su objetivo principal estaba enfocado a lograr una paz duradera, proporcionando los soportes económicos y sociales necesarios a través de donaciones, estudios y operaciones de crédito para varios sectores. Para esta fecha, Colombia ya se considera como un país de ingreso medio, por lo que en la AEP se reconocía esté mérito al gobierno:

“... la economía colombiana paso de una situación cercana al estancamiento en 2002, a lograr una tasa de crecimiento de $6.6 \%$ en $2007 .$. la reducción de la violencia y la mayor efectividad del gobierno y de la fuerza de la ley, han dado como resultado un aumento de la confianza del consumidor y del inversionista" (Banco Mundial 2008a:1).

El préstamo del BIRF para ese período sería hasta por US\$ 4.000 millones, y de la Corporación Financiera Internacional (CIF) hasta de US\$ 400 millones, más servicios analíticos y donaciones especializadas, siempre que se mantuviera el compromiso por desarrollar una gestión macroeconómica firme y una reducción efectiva de la pobreza. Con referencia a la anterior EAP 2002-2006, el BM duplicó el promedio anual de préstamos y robusteció los servicios de asesoría, consolidando así su relación con Colombia ${ }^{39}$. En cuanto a las líneas de apoyo del BM para la agricultura y las zonas rurales, continuó con las alianzas productivas:

\footnotetext{
${ }^{39}$ El BIRF era el mayor acreedor individual de Colombia, pasó de una participación en el mercado entre las agencias multilaterales del $24 \%$ en 2001 a un $44 \%$ en 2008 (Banco Mundial 2008:19).
} 
“...se aborda la dimensión rural de la competitividad en proyectos del BIRF los cuales se apoyan en la participación de pequeños agricultores en la cadena de producción agrícola, la calidad, y en las mejoras en la tecnología requerida para competir globalmente (por medio de proyectos de asociaciones productivas y de transición agrícola, respectivamente)" (Banco Mundial 2008a:22)

Así mismo, para los más pobres y vulnerables se continuó con los programas de transferencias condicionadas y la atención a población víctima del conflicto. El BM amplio junto con el BID el programa de Familias en Acción (Banco Mundial 2008a:28). En relación al apoyo en la construcción de Paz financió dos estudios: uno para diseñar la política de reparación para las víctimas del conflicto armado y otro para evaluar el proceso de desmovilización y reinserción de excombatientes.

La política de seguridad democrática se consolida para el año 2009, cuando el Plan Colombia cambia de nombre a Plan Nacional de Consolidación Territorial (PNCT) y se expande en regiones estratégicas bajo el propósito de incrementar el desarrollo económico y reducir la acción de los grupos armados. Entre las 10 zonas intervenidas estaban: Montes de María (Sucre y Bolívar), La Macarena (Meta) y Bajo Atrato (Chocó). El 69\% de los municipios donde actúo el PNCT habían sido intervenidos en el pasado con algunos de los programas de desarrollo del estado, lo cual cuestiona la eficacia de las intervenciones territoriales (FIP 2011). El PNCT incluyó un mayor enfoque en el tema de tierras y también en el apoyo al retorno de población desplazada en la región de los Montes de María, financiado con recursos del BM y USAID.

\subsection{El periodo del proceso de paz, la ley de restitución de tierras y el posconflicto}

La Alianza Estratégica con el País (AEP) 2012-2016 del BM apoyó selectivamente algunos puntos del Plan Nacional de Desarrollo 2010-2014, 'Prosperidad para todos', del presidente Juan Manuel Santos. Básicamente continúo financiando el programa de las alianzas productivas que ya venían desarrollándose desde 2002, de las que se habían apoyado un total de 213 alianzas. Se le cambio el nombre de alianzas productivas por 'competitividad de 
Capítulo 5. Evolución de las políticas agrarias y de tierras en Colombia: La influencia de los organismos internacionales

la pequeña agricultura' y se vinculó con los programas de restitución de tierras, innovación agrícola, mitigación y gestión del riesgo en agricultura, pues se esperaba que todo junto ayudara a mejorar la competitividad de la pequeña agricultura (Banco Mundial 2011).

El gobierno de Santos fundamentó su PND en lo que denominó las locomotoras del crecimiento económico, que incluían la minería y el sector agroindustrial, con el objetivo de hacerlas productivas y competitivas. La inversión extranjera se convierte en uno de los pilares del desarrollo, para lo cual las instituciones del estado tendrían que adaptarse y los obstáculos de tipo legal y político deberían ser removidos para dar seguridad económica y jurídica a esa inversión. Además de incrementar los tratados de libre comercio, de los cuales había ya 13 firmados, uno de sus objetivos era ingresar al país como miembro de la OCDE, cuyo proceso de adhesión se inició en 2013.

Puede decirse que en la visión y la dirección de las políticas agrarias se continúa con una profundización del modelo económico del gobierno anterior; una política de seguridad, impulso a la agroindustria, la minería y facilidad para la inversión, principalmente. No obstante, hay dos hechos en los que la administración de Santos se distancia de la anterior relacionados con el problema agrario; el proceso de paz con la guerrilla de las FARC iniciado en 2012 y firmado en 2016 y la implementación de la Ley 1448 de 2011, conocida como Ley de Víctimas y Restitución de Tierras. Los acuerdos con la guerrilla han incluido una Reforma Rural Integral (RRI) que tiene como centro el acceso a la tierra para los trabajadores rurales que carecen de ella o la tienen de forma insuficiente y a su vez busca promover la desconcentración de la misma. La participación de las comunidades rurales en las decisiones sobre el destino y uso de los recursos del territorio que habitan se plantea como una prioridad para el desarrollo territorial en la RRI ${ }^{40}$.

\footnotetext{
${ }^{40}$ La Reforma Rural Integral concibe el territorio rural como un escenario socio-histórico con diversidad social y cultural, en el cual las comunidades desempeñan un papel protagónico en la definición del mejoramiento de sus condiciones de vida así como en el desarrollo del país con una visión de integración urbano-rural. En la RRI se acuerda la creación de un Fondo de Tierras con 3 millones de hectáreas en sus 10 primeros años. Acuerdo Final: Punto 1. Hacia un nuevo campo colombiano. Reforma Rural Integral (Mesa de Conversaciones de Paz 2016).
} 
Por su parte, con la Ley de Víctimas y Restitución de Tierras se busca el reconocimiento de las víctimas del conflicto armado colombiano y sus derechos a la verdad, la justicia y la reparación con garantías de no repetición ${ }^{41}$. De acuerdo con Restrepo y Bernal (2014) en los últimos 25 años, el conflicto armado ha resultado en el despojo de cuatro millones de hectáreas de tierras por abandono forzoso y 2 millones por usurpación violenta. La restitución de tierras ha encontrado, además de los obstáculos de tipo administrativo y legal, fuertes enemigos en los sectores que han acaparado históricamente las tierras. Élites políticas, terratenientes y empresarios regionales, en varios casos aliados con la fuerza pública y en otros casos con estructuras criminales, se oponen a la restitución porque algunos han hecho parte de procesos de despojo y acaparamiento o han comprado predios que fueron adquiridos por medios violentos. Entre los años 2006-2011 fueron asesinados 71 líderes campesinos reclamantes de tierras en 14 departamentos del país (Martínez 2013).

La aplicación de la Ley de Restitución de Tierras también contiene aspectos contradictorios. A pesar de que busca reparar a las víctimas devolviendo las tierras despojadas, en su artículo 99 rinde prioridad a los agronegocios y el extractivismo al contemplar que, cuando existan proyectos agroindustriales productivos en el predio despojado y se haya probado la "buena fe exenta de culpa" $^{\prime 2}$ de quien figure como propietario, el magistrado podría autorizar un acuerdo entre el desplazado y el empresario para no interrumpir el proyecto. Lo cual es una forma de priorizar las alianzas productivas instaladas sobre predios adquiridos por medio del despojo.

\footnotetext{
${ }^{41}$ Dentro de los derechos para las víctimas está la restitución de tierras cuando han sido despojadas de ellas o han tenido que abandonarlas forzosamente. La Ley crea la Unidad de Restitución de Tierras URT, que gestiona el registro de tierras despojadas y lleva en nombre de las víctimas las solicitudes o demandas de restitución ante los jueces y/o magistrados de restitución de tierras.

${ }^{42}$ Se acredita buena fe exenta de culpa demostrando no solo la conciencia de haber obrado correctamente sino también la presencia de un comportamiento encaminado a verificar la regularidad de la situación (CC 2012b). Es decir que la adquisición del predio se hizo por medios legales y que también se verificó que la historia de tenencia del predio ha sido legal y no hubo antecedentes de violencia en la zona.
} 
Capítulo 5. Evolución de las políticas agrarias y de tierras en Colombia: La influencia de los organismos internacionales

\subsection{Los respaldos internacionales a la formalización de los derechos de propiedad sobre la tierra y a la restitución.}

La USAID ha tenido una activa participación en la definición e implementación de la política de tierras que se ha intensificado en las últimas dos décadas. Desde 2010 elaboró un perfil del país sobre gobernanza de recursos y derechos de propiedad, en el cual esboza los asuntos clave sobre la tenencia de la tierra en el país y los derechos de propiedad, identificando como sus principales limitaciones la falta de formalización en la tenencia de la tierra y la definición de los derechos de propiedad (USAID 2010b).

A partir de 2013, USAID implementa conjuntamente con el gobierno el 'Programa de Tierras y Desarrollo Rural' (LDRP por sus siglas en inglés) con el propósito de direccionar los temas de la formalización y la seguridad en la tenencia de la tierra, la cual se consideraba clave para la etapa del posconflicto. Se buscó preparar al gobierno local y regional para implementar la reforma de tierras a través de cuatro componentes: Fortalecimiento institucional en el nivel local para el proceso de restitución de tierras a las víctimas del conflicto, formalización de los derechos de propiedad, identificación y adjudicación de tierras baldías y movilización de recursos para generar bienes públicos en las zonas rurales (USAID 2015).

El total de préstamos y donaciones de la USAID a Colombia desde 1946 hasta el año 2016 comprende US\$ 14.949,4 millones de dólares, de los cuales el 75\% se ha dirigido al control de narcóticos y asistencia militar. Para el año 2016 el apoyo para el tema de tierras y desarrollo rural ocupó el tercer lugar en prioridad para la financiación después del programa antinarcóticos y asistencia militar (USAID 2016).

De otro lado, la OCDE en 2015 entrega la evaluación y las recomendaciones de la política agrícola al gobierno, como parte del proceso de adhesión que debe cumplir el país para ser miembro de la organización. El Documento comienza reconociendo la posición estratégica del país, la riqueza de recursos agrícolas y de agua, la biodiversidad y los recursos minerales. Resalta la importancia del sector agrícola en el PIB y en la generación de empleo y a su vez, expone que las políticas adoptadas para el sector han sido deficientes por lo que afronta grandes desafíos, como la baja productividad que impide la competitividad del 
sector, a lo cual contribuye una infraestructura deficiente, el desigual acceso a la tierra, su utilización improductiva y la debilidad de las cadenas de valor. Reclama la necesidad de reformas estructurales especialmente en el sistema de tenencia de la tierra (catastro, tributación, uso del suelo), instrumentos financieros para pequeños productores y dinamización del mercado de alquiler de la tierra. También solicita dirigir esfuerzos a inversiones estratégicas, dejar instrumentos que distorsionan la producción y el comercio, aumentar inversión en infraestructura de transporte y de riego y ampliar políticas de desarrollo rural, mejorar el marco institucional de la política agrícola y mayor integración a los mercados agrícolas internacionales (OCDE 2015).

Básicamente pide ampliar la liberalización del comercio, y de nuevo prioriza la productividad para la competitividad en los mercados internacionales. Alrededor de esto gira la exigencia de clarificar los derechos de propiedad que faciliten las inversiones, estimular el mercado de arrendamiento de tierras y apoyar los procesos de restitución. Lo anterior se refleja ya en algunas medidas del segundo PND 2014-2018 del Presidente Santos, donde se adelantó una reforma de la institucionalidad del sector, liquidando el INCODER y creando en su lugar tres agencias: la Agencia Nacional de Tierras (ANT), la Agencia Nacional de Desarrollo Rural (ANDR) y la Agencia para la Renovación del Territorio (ART). La primera, la ANT tiene entre sus funciones: el ordenamiento social de la propiedad gestionando el acceso a la tierra como factor productivo, garantizar la seguridad jurídica de la propiedad, administrar las tierras de la nación (baldíos) y administrar el Fondo de Tierras planteado en la RRI. El Ministerio de Agricultura quedó encargado de la formulación de la política (DNP 2014b; MADR 2015).

Sobre las medidas para mejorar la tenencia de la tierra, tal vez lo destacable ha sido la realización del Censo Nacional Agropecuario en 2014, pues abordar el tema del catastro rural no ha sido posible por toda la presión que están ejerciendo las élites empresariales y políticas y los grupos armados para frenar el proceso de restitución de tierras. De esta manera es imposible delimitar la propiedad, hacer inventario de baldíos y recuperar los que están indebidamente apropiados. Tampoco es posible mejorar el sistema de tributación con lo cual los grandes terratenientes continúan pagando pocos impuestos y manteniendo las tierras improductivas. 


\subsection{Adopción de las recomendaciones de política: Una síntesis por períodos y dimensiones.}

Teniendo en cuenta la síntesis anterior sobre al apoyo prestado al país por los organismos internacionales en el diseño e implementación de políticas y su respectiva financiación, puede identificarse un hilo conductor que subyace a lo largo de los períodos estudiados que dejan ver cómo los objetivos de estas continúan siendo los mismos: competitividad, crecimiento, desarrollo, reducción de la pobreza y de la violencia. También es claro que la adopción de los enfoques y políticas que prescriben estos organismos al país se implementan, fundamentalmente, en la medida y en las líneas para los que ellos otorgan los créditos y las donaciones.

De todas maneras, tal como se ha descrito a lo largo del capítulo, aunque de forma más genérica, el gobierno nacional ha ido reflejando estas recomendaciones en las políticas nacionales. La Tabla 5.1, recoge la evolución en el tiempo de los enfoques o políticas recomendadas y lo que ha aplicado el gobierno nacional. Para ello se han agrupado en cinco componentes o dimensiones que interesan e influyen directamente en la política agraria: la visión de desarrollo, el desarrollo agrícola y rural, la construcción de la paz, el acceso a tierras y la reducción de la pobreza.

En cuanto a la visión de desarrollo, responde claramente al sistema económico neoliberal dominante que exige la plena libertad de mercado y para lo cual la política de apertura y liberalización se convierte en un mandato, bajo el supuesto que es la vía para lograr el crecimiento, que a su vez es lo que permite el desarrollo.

El desarrollo rural y agrícola termina centrado en programas enfocados a la productividad, casi exclusivamente de las actividades productivas rentables o exportables y donde la pequeña agricultura tiene acceso a través de las asociaciones con los agronegocios. Para los más pobres de las zonas rurales se ejecutan programas de protección social con un carácter asistencialista.

La construcción de la paz, enfocada inicialmente como las luchas contrainsurgentes y antidrogas, librada en las zonas rurales, continúa teniendo el mismo enfoque a pesar de los acuerdos de paz. La continuación de la 
violencia y el narcotráfico justifica el mantenimiento de este tipo de intervención, aunque los resultados hayan demostrado que no funciona. La parte social y productiva de estos programas se ha sustentado en los mismos programas de alianzas productivas, y con los mismos cultivos exportables, cuya implementación se ha basado en gran parte en el despojo y el acaparamiento violento de la tierra.

En cuanto al acceso a tierras se aplicó la política de liberalización con la implementación del mercado de tierras, que aún sigue vigente, sin resultados positivos. La priorización de la inversión privada e internacional, que también incluye la tierra y los recursos del territorio, generó la preocupación de garantizar la seguridad del capital, con lo cual el enfoque de todos los organismos es pedir la seguridad en los derechos de propiedad de la tierra para generar confianza inversionista. Sobre esto se fundamentan la restitución de tierras y todas las medidas técnicas y jurídicas e institucionales que se vienen aplicando.

En relación a la reducción de la pobreza, desde que se implementó el enfoque de las redes de protección social, los programas de transferencias condicionadas se mantienen en el tiempo y han sido evaluados positivamente, aunque las condiciones de pobreza e informalidad laboral persistan en el país.

Tabla 5. 1. Influencia de los organismos internacionales en cinco dimensiones de la política colombiana. 1990-2017

\begin{tabular}{|c|c|c|c|c|c|}
\hline & $\begin{array}{l}\text { Visión de } \\
\text { Desarrollo }\end{array}$ & $\begin{array}{l}\text { Desarrollo } \\
\text { Rural y } \\
\text { Agrícola }\end{array}$ & $\begin{array}{l}\text { Construcción } \\
\text { de Paz }\end{array}$ & $\begin{array}{l}\text { Acceso a } \\
\text { Tierras }\end{array}$ & $\begin{array}{l}\text { Reducción } \\
\text { de la } \\
\text { pobreza }\end{array}$ \\
\hline 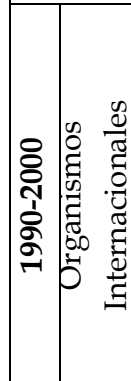 & $\begin{array}{l}\text { Liberalización } \\
\text { de la } \\
\text { Economía. } \\
\text { Competitivi- } \\
\text { dad para el } \\
\text { crecimiento. }\end{array}$ & $\begin{array}{l}\text { Enfoque hacia } \\
\text { la } \\
\text { productividad } \\
\text { Focalización } \\
\text { de recursos } \\
\text { financieros a } \\
\text { cultivos } \\
\text { rentables }\end{array}$ & $\begin{array}{l}\text { Política Anti- } \\
\text { drogas y } \\
\text { anti- } \\
\text { subversiva. }\end{array}$ & $\begin{array}{l}\text { Liberalización } \\
\text { de mercado de } \\
\text { tierras } \\
\text { Aplicación del } \\
\text { mercado } \\
\text { asistido de } \\
\text { tierras (MAT) }\end{array}$ & $\begin{array}{l}\text { Enfoque y } \\
\text { financia- } \\
\text { ción a las } \\
\text { redes de } \\
\text { Protección } \\
\text { Social. }\end{array}$ \\
\hline
\end{tabular}


Capítulo 5. Evolución de las políticas agrarias y de tierras en Colombia: La influencia de los organismos internacionales

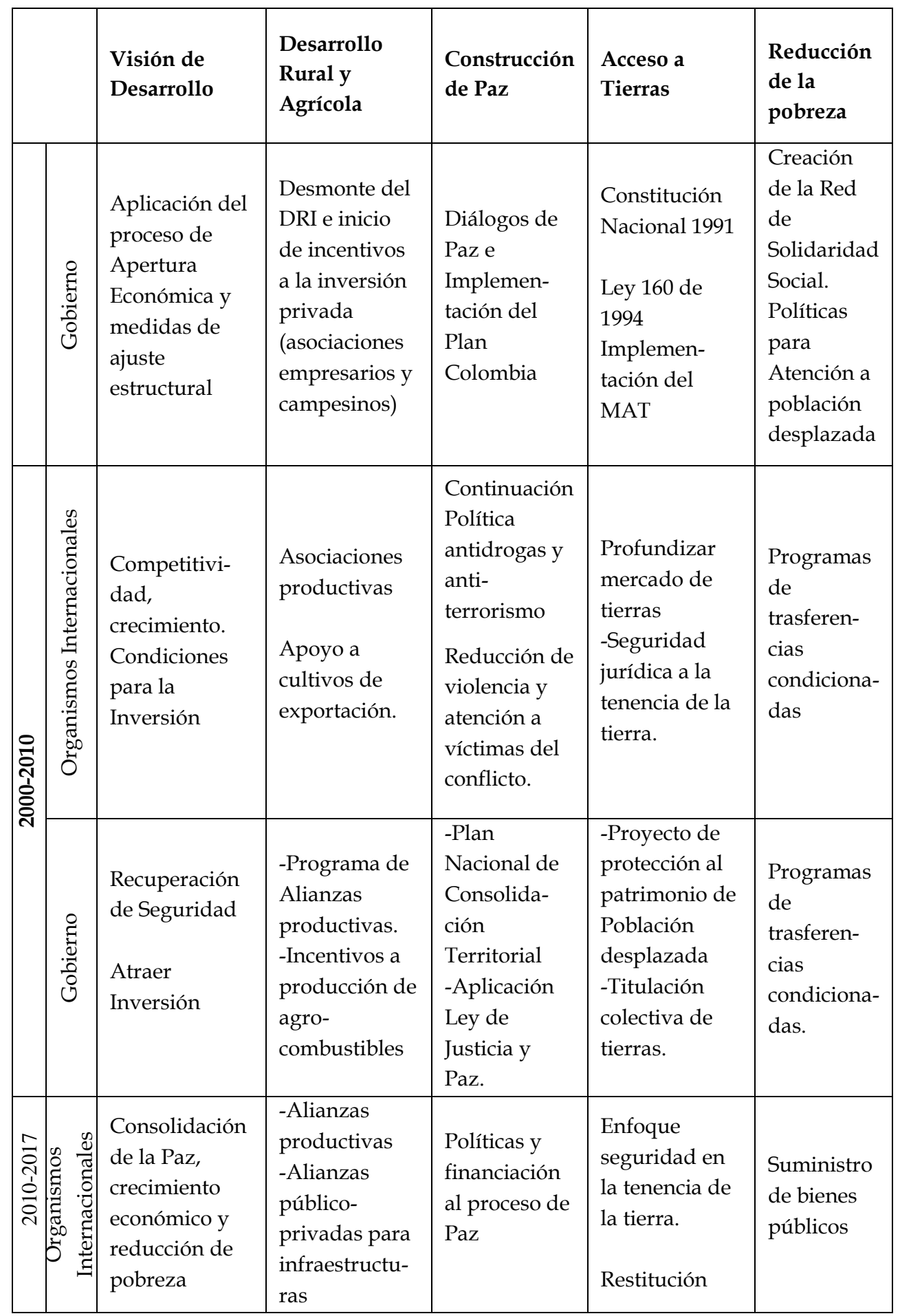




\begin{tabular}{|c|c|c|c|c|c|}
\hline & $\begin{array}{l}\text { Visión de } \\
\text { Desarrollo }\end{array}$ & $\begin{array}{l}\text { Desarrollo } \\
\text { Rural y } \\
\text { Agrícola }\end{array}$ & $\begin{array}{l}\text { Construcción } \\
\text { de Paz }\end{array}$ & $\begin{array}{l}\text { Acceso a } \\
\text { Tierras }\end{array}$ & $\begin{array}{l}\text { Reducción } \\
\text { de la } \\
\text { pobreza }\end{array}$ \\
\hline $\begin{array}{l}\stackrel{0}{0} \\
\stackrel{0}{0} \\
0 \\
0 \\
0\end{array}$ & $\begin{array}{l}\text { Crecimiento } \\
\text { económico } \\
\text { basado en } \\
\text { agro } \\
\text { exportación y } \\
\text { minería. } \\
\text { Firma de TLCs }\end{array}$ & $\begin{array}{l}\text { Continuación } \\
\text { Programa de } \\
\text { alianzas } \\
\text { productivas } \\
\text { Priorización } \\
\text { cultivos } \\
\text { exportables }\end{array}$ & $\begin{array}{l}\text { Acuerdos de } \\
\text { Paz con las } \\
\text { FARC } \\
\text { Continuación } \\
\text { política } \\
\text { antidrogas }\end{array}$ & $\begin{array}{l}\text { Ley de } \\
\text { restitución de } \\
\text { tierras } \\
\text {-Cambio en } \\
\text { las } \\
\text { instituciones } \\
\text { de la política } \\
\text { de tierras } \\
\text {-Cambios en } \\
\text { la Legislación } \\
\text { de tierras }\end{array}$ & $\begin{array}{l}\text { Continua- } \\
\text { ción } \\
\text { programas } \\
\text { transferen- } \\
\text { cias } \\
\text { condiciona- } \\
\text { das. }\end{array}$ \\
\hline
\end{tabular}

Fuente: elaboración propia

Lo expuesto aquí deja ver el marco de políticas agrarias y de desarrollo económico general aplicado en el país en las últimas décadas, el cual como se puede apreciar ha sido muy condicionado y en gran medida co-diseñado por los organismos internacionales. Y es dentro de este marco de políticas que los procesos de acaparamiento de tierras, que analizaremos en los dos capítulos siguientes, tienen lugar. 



\section{Capítulo 6}

\section{Cambios en el marco legal y acaparamiento de baldíos en la Altillanura}

colombiana

Este capítulo presenta el análisis sobre uno de los puntos neurálgicos de la contienda política y legal por los casos de acaparamiento reciente de tierras en Colombia, la apropiación de tierras baldías o con antecedentes de baldíos (aquellas que fueron adjudicadas en procesos de reforma agraria). La Constitución y la legislación agraria determinan que la adjudicación de estas tierras sea prioritariamente para trabajadores rurales pobres sin tierra o con tierra insuficiente. Aunque la situación de acaparamiento de estas tierras ha sucedido en varias partes del país, el análisis aquí presentado se centrará en la subregión de la Altillanura colombiana ${ }^{43}$, por ser la que suscitó la disputa y puso en el debate y conocimiento nacional las compras masivas de tierras en la última década.

La Altillanura con 13,5 millones de hectáreas de tierras planas, encaja muy bien en las condiciones expuestas por el Banco Mundial (Deininger et al. 2011), al

43 La subregión forma parte de la Región de la Orinoquia conformada por los departamentos de Arauca, Casanare, Meta, Vichada, Guaviare y Guainía, los cuales comprenden el 33\% del territorio nacional (38.060.000 ha). 
considerarse una región con tierras marginales, vacías, ociosas o disponibles y por tanto aptas para ingresarlas a la producción agropecuaria.

El interés del estado por ampliar la frontera agropecuaria en esta región es compartido por el Departamento de Agricultura de los Estados Unidos (USDA), cuyo discurso, en sus reportes sobre Red de Información Agrícola Global (GAIN) por sus siglas en inglés) deja ver su posición a favor de la asignación de estas tierras al capital privado. Y en este sentido, se une a la presión para cambiar la legislación y facilitar las compras a gran escala, asumiendo como normales las estrategias usadas por algunas compañías para acaparar las tierras.

Este capítulo conecta dos procesos que han discurrido de forma paralela. Por una parte, detalla los intentos de implementación de estrategias de tipo legal y político por parte del estado, iniciadas hace ya dos décadas para flexibilizar la legislación sobre dichas tierras y facilitar su apropiación y explotación. Por otra parte, relaciona dichos intentos con las reacciones y mecanismos de resistencia desde la sociedad civil que ha defendido y disputado al estado -por vías legales- los derechos constitucionales otorgados a los campesinos y trabajadores rurales pobres sobre los baldíos.

La estructura del presente capitulo incluye en primer lugar la presentación del marco legal sobre las tierras baldías. En segundo lugar, introduce una breve caracterización territorial y socio-productiva de la Altillanura, seguida de una aproximación a su construcción socio-histórica. En tercer lugar, se presentan las condiciones de la tenencia de la propiedad sobre la tierra, de violencia y despojo que preceden a las grandes inversiones. Finalmente, se describen las etapas de la contienda legal entre el estado por favorecer la inversión masiva en tierras y la sociedad civil por evitar que se cambie la legislación agraria.

\subsection{Marco Normativo de las tierras baldías: protegiendo el acceso de los campesinos a las tierras públicas}

Los baldíos están definidos como todas aquellas tierras situadas dentro de los límites territoriales del país que no tienen un dueño particular y por tanto 
pertenecen al estado ${ }^{44}$. Los baldíos han tenido un rol central en la forma en que tanto el estado como la población han controlado y ocupado el territorio. Desde la colonización española, los ocupantes originales de las tierras fueron privados de ellas y pasaron a ser de la Corona. Al iniciar la época Republicana (1819), el $80 \%$ del territorio nacional se consideraba baldío y la tierra se usaba como forma de pago de deudas y para promover la ocupación poblacional y productiva del territorio. Así, el estado entregaba tierras a particulares y empresas -nacionales y extranjeros- a cambio de la construcción de infraestructuras o instalación de empresas, lo que favoreció la formación de un modelo con elevada concentración de la tierra y como señalan Restrepo \& Morales (2014) se negó la territorialidad existente y los derechos de los pobladores originales.

Las políticas que regulan las tierras baldías han venido evolucionando y de ellas ha dependido la distribución, explotación y uso que ha hecho el estado de estos bienes. La regulación de las tierras baldías data de 1873. En efecto, (Villaveces \& Sánchez 2015) identifican más de sesenta disposiciones regulatorias referentes a los baldíos, las más recientes a partir de la Ley 135 de 1961, la cual fijo el límite para su adjudicación ${ }^{45}$ en 450 hectáreas. Este límite puede variar en algunos casos, como en zonas especiales de difícil acceso (hasta 1000 hectáreas) y en la región de Orinoquia o Llanos Orientales (hasta 3000 hectáreas) por considerarse tierras de baja productividad y aisladas. También se prohibió la concentración de predios hasta después de los cinco años siguientes a su adjudicación. Luego, con la Ley 30 de 1988 se prohíbe la concentración de predios colindantes provenientes de adjudicaciones de baldíos.

\footnotetext{
44 Art. 675 del Código Civil Colombiano.

${ }^{45}$ La administración de las tierras baldías inicialmente fue encargada al Instituto Nacional Colombiano para la Reforma Agraria (INCORA) para adjudicarlas, celebrar contratos, constituir reservas o realizar colonizaciones. La propiedad de los baldíos adjudicables solo es posible mediante título traslaticio de dominio otorgado por el estado. Los ocupantes de baldíos no tienen el carácter de poseedores, solo una expectativa de adjudicación si cumplen con los requisitos de la ley: i) No superar una UAF, ii) tener más de 2/3 del predio explotado, iii) haberlo ocupado por más de 5 años, iv) no tener patrimonio mayor a 1000 SMMLV, y v) no ser titular de otros predios rurales (Ley 160 de 1994).
} 
La Constitución Política de 1991, en los artículos 58, 63, 64, 65 y 79, ordena al estado promover el acceso progresivo a la tierra con prioridad para los campesinos y trabajadores agrarios con el objetivo de mejorar su calidad de vida, por lo que se convierten en sujetos de especial protección por parte del estado(CGR 2014b). Siguiendo estos principios, la Ley 160 de 1994, prioriza la adjudicación de los terrenos baldíos a los campesinos de escasos recursos económicos y establece que la extensión máxima de tierra baldía a adjudicar estará medida por la Unidad Agrícola Familiar (UAF) ${ }^{46}$.

La ley prohíbe la concentración de predios con antecedentes de baldíos en extensiones superiores a una UAF y declara nulos los contratos donde se aporten dichas tierras, si se consolida la propiedad en extensiones superiores a la UAF. En suma, la determinación de la UAF llega a ser la principal figura legal para evitar la concentración de la tierra baldía y priorizar su adjudicación a campesinos y pobladores rurales pobres.

La importancia de las tierras baldías radica en que han sido el principal instrumento para la reforma agraria en términos de dotación de tierra. Los otros mecanismos incluyen: la compra directa de tierras por el estado, tierras provenientes de proceso de expropiación o extinción de dominio, de negociaciones voluntarias y el otorgamiento a campesinos de un subsidio monetario para que compren su predio directamente. En la Tabla 6.1 se refleja la magnitud de la política de adjudicación de baldíos y el alcance de las otras medidas para el acceso a tierras.

\footnotetext{
46 La UAF fue creada mediante la Ley 161 de 1935 de reforma agraria para realizar parcelaciones y asignar la tierra. Luego la Ley 160 de 1994, la define como la empresa básica de producción agrícola, pecuaria acuícola o forestal cuya extensión y condiciones permite a la familia remunerar su trabajo y capitalizarse. El tamaño de la UAF es diferente en cada zona, depende de las condiciones agroecológicas del suelo y su capacidad productiva. Las zonas aisladas y con menor potencial productivo, tienen una extensión mayor. Así, en la Altillanura la UAF tiene un tope máximo de 1.725 ha y una extensión mínima de 36 ha.
} 
Tabla 6. 1. Total dotación de tierras en Colombia. 1961-2014 (Hectáreas)

\begin{tabular}{|c|c|c|c|c|}
\hline $\begin{array}{l}\text { Población } \\
\text { beneficiada }\end{array}$ & $\begin{array}{l}\text { Antes de } \\
1961\end{array}$ & $\begin{array}{l}1961-1993 \\
(\text { Ley } 135 \text { de } \\
\text { 1961) }\end{array}$ & $\begin{array}{l}1994-2014 \\
(\text { Ley } 160 \mathrm{de} \\
1994)\end{array}$ & $\begin{array}{l}\text { Total } \\
\text { dotación de } \\
\text { tierra }\end{array}$ \\
\hline $\begin{array}{l}\text { Titulación de baldíos } \\
\text { a campesinos }\end{array}$ & \multirow[t]{2}{*}{4.808 .700} & 12.736 .329 & \multirow[t]{3}{*}{5.511 .723} & 23.056 .638 \\
\hline $\begin{array}{l}\text { Constitución de } \\
\text { resguardos indígenas }\end{array}$ & & 31.590 .540 & & 31.590 .540 \\
\hline $\begin{array}{l}\text { Titulación colectiva } \\
\text { de baldíos a } \\
\text { comunidades negras }\end{array}$ & \multicolumn{2}{|r|}{5.116 .373} & & 5.116 .373 \\
\hline \multicolumn{4}{|c|}{ Total titulación de baldíos + Resguardos indígenas } & 59.763 .575 \\
\hline \multicolumn{5}{|c|}{ Titulación de tierra diferente a baldíos 1962 - 2014} \\
\hline \multicolumn{4}{|c|}{$\begin{array}{l}\text { Tierras adquiridas por el estado: compra directa, expropiaciones, } \\
\text { negociación voluntaria y subsidio integral de tierras. }\end{array}$} & 1.920 .638 \\
\hline
\end{tabular}

Fuente: Elaboración propia. Datos Sider-Incoder ${ }^{47} .2015$.

Se puede observar cómo el estado ha utilizado las tierras baldías para distribuir a poblaciones pobres: para campesinos se adjudicaron un $76 \%$ entre 1961 y 1993 y después de este año un 24\%. A los grupos étnicos (indígenas y afro descendientes) se les reconocieron los derechos sobre los territorios que han ocupado ancestralmente a partir de la Constitución de 1991 y la aprobación de la Ley 70 de 1993 estableció los requisitos para la titulación colectiva en territorios de las comunidades negras. Del total de hectáreas adjudicadas, un $39 \%$ ha tenido lugar en la región de la Orinoquia (especialmente en Arauca, Casanare, Meta y Vichada).

Los otros instrumentos creados para la dotación de tierra, diferentes a la adjudicación de baldíos representa apenas un 3,2\% del total de tierra adjudicada en el país, con lo cual es claro que los baldíos son y han sido el principal instrumento para el acceso a la tierra de las poblaciones rurales pobres. En cuanto a la cantidad de tierras baldías disponibles de la nación no existen datos por la desactualización y/o inexistencia de catastro en varias

\footnotetext{
${ }^{47}$ Los datos no son totalmente fiables, la Contraloría General encontró serias inconsistencias en la generación y manejo de la información como en el mismo proceso de adjudicación, varias titulaciones menores de 1 ha y varias mayores de 500 ha, en zonas donde la UAF está estipulada por encima y por debajo de esta extensión.
} 
regiones, pero la Contraloría General de la República (2014b) estima que existen por lo menos 7 millones de hectáreas disponibles de las cuales un $41 \%$ están en el departamento del Vichada.

\subsection{La Altillanura: De tierra marginal a despensa alimentaria}

La subregión de la Altillanura, ubicada al oriente del país está conformada por siete municipios (Figura 6.1): tres en el departamento del Meta (Puerto López, Puerto Gaitán y Mapiripán) y los cuatro municipios que conforman el Vichada (La Primavera, Cumaribo, Puerto Carreño y Santa Rosalía). Comprende 13,5 millones de hectáreas de tierras planas, equivalentes al 10\% del territorio nacional, de las cuales 4,5 millones tienen alto potencial para la agricultura (DNP 2014a).

\section{Figura 6. 1. Mapa Subregión de la Altillanura colombiana}

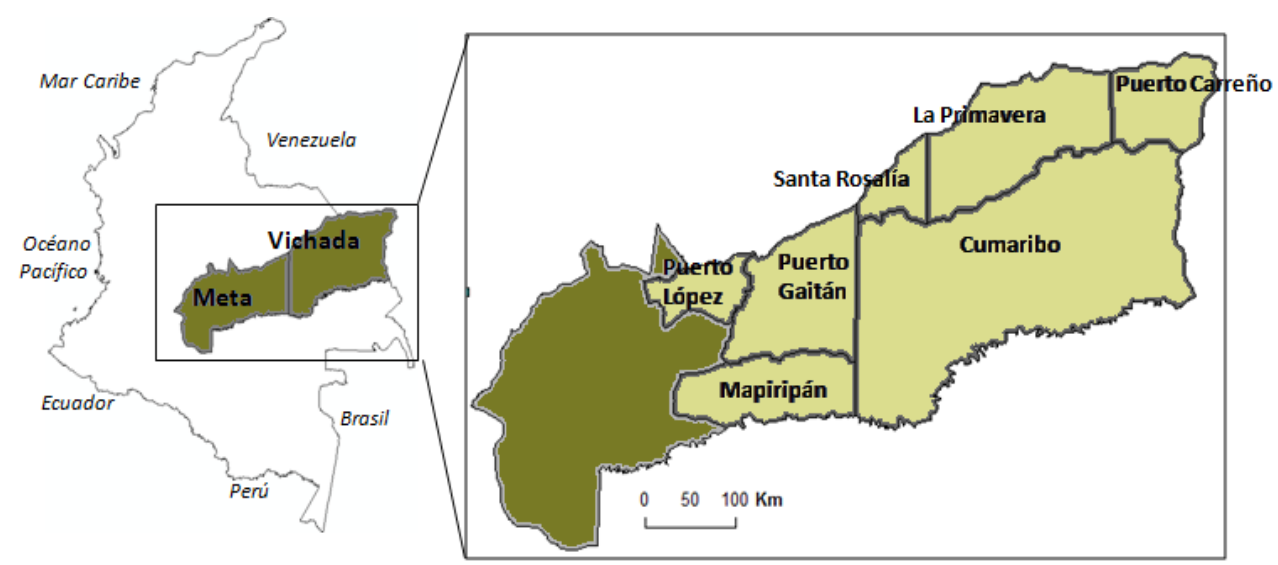

Fuente: elaboración propia

Es una subregión con baja densidad de población, 143.895 personas (1,06 habitantes $/ \mathrm{km}^{2}$ ) aproximadamente, el $30 \%$ son indígenas -existen 46 
resguardos indígenas ${ }^{48}$ y 12 asentamientos indígenas no resguardados- y el resto es población campesina diversa, como poseedores informales, trabajadores rurales estacionales, pobladores urbanos y colonos. Presentaba para 2005 un índice de pobreza multidimensional ${ }^{49}$ del 90,5\% (DNP 2014a)

Las actividades económicas que han predominado recientemente han sido las vinculadas a los enclaves económicos, basadas en la explotación de recursos naturales; la extracción de crudo y gas en el Meta representa un 57\% del PIB departamental y $22 \%$ de la producción nacional, los proyectos de exploración abarcan toda la región. Así mismo la minería (con 38 títulos mineros) cubre 25.594 hectáreas y para 2014 existían 212 solicitudes mineras pendientes de trámite. El departamento de Vichada fue declarado área estratégica minera en 2012, a excepción de las áreas protegidas (DNP 2014a:32).

El área sembrada en productos agrícolas ocupaba 132.595 hectáreas, el 35\% correspondía al cultivo de palma de aceite en los municipios de Puerto López, Puerto Carreño y Mapiripán. Le seguían el caucho y otros forestales con un $28 \%$, caucho con un $15 \%$ y cereales con un $16 \%$ (DANE 2014). Los suelos de la región son ácidos con muy baja materia orgánica y por tanto pobres para la actividad agrícola, hecho que ha servido a gobierno y empresarios para argumentar que la explotación de dichos suelos requiere una inversión elevada para hacerlos productivos, imposible de llevar a cabo por campesinos pobres (Oxfam 2013).

La riqueza medioambiental de la región es elevada; alberga una alta biodiversidad en plantas, aves y ecosistemas hídricos. Posee una alta fragilidad por la estacionalidad del agua y susceptibilidad a la desertificación de los suelos. Según el Estudio Nacional del Agua de 2010, la región presentaba la mayor riqueza hídrica del país, concentrada en los ríos Meta, Vichada y

\footnotetext{
${ }^{48}$ Los resguardos indígenas son una institución sociopolítica legal de origen colonial, La Constitución de 1991, define las tierras comunitarias de los indígenas como resguardo y de propiedad colectiva que se consagra como inalienable, imprescriptible e inembargable (Art. 63 y Art. 329). Existen 639 constituidos y ocupan el 27\% del territorio nacional, el 13\% de los indígenas aún vive en territorios no resguardados (IGAG 2012).

${ }^{49}$ El Índice de Pobreza Multidimensional es una metodología alternativa a la medición de pobreza por ingresos, medida por dimensiones como educación, salud, acceso a servicios y calidad de la vivienda (DANE 2018).
} 
Guaviare, y además, gran capacidad de acumulación de agua subterránea.

La región fue históricamente poblada por los indígenas ${ }^{50}$, principalmente Kurripacos, Puinave y Sikuani, hasta la llegada de los conquistadores, quienes, al no encontrar oro ni tierras muy fértiles, no fundaron ciudades a nombre de la Corona española. En el siglo XVII se le entrega a la iglesia la tierra y el control de los indígenas, ocupando esta el papel del estado por años. Durante la Segunda Guerra Mundial, la demanda de caucho provocó la llegada de colonos y empresas caucheras, quienes emplearon y explotaron a la población indígena en la extracción del látex. La tierra empezó a ser propiedad de los colonos quienes establecieron ganadería y cercaron las propiedades. La violencia de los años 1950s trajo una nueva ola de colonos a la región en busca de refugio y también de tierras, la guerrilla de las FARC se estableció allí desde los años 1960s. Gran parte de los indígenas fueron perseguidos, asesinados o desplazados de sus tierras. En los años 1980s llegan los traficantes y esmeralderos del centro del país que también buscaban tierras en los Llanos Orientales, y aparecen con ellos los paramilitares que, junto a la fuerza pública, darían paso a una nueva ola de violencia -basada en la disputa por el territorio y el control del narcotráfico- durante las siguientes tres décadas (Rutas del Conflicto 2015).

Las características de la región descritas anteriormente responden perfectamente a lo que se ha denominado tierras marginales, en los términos del Banco Mundial, consideradas vacías por su poca densidad poblacional e improductivas pues la economía campesina que allí se desarrolla no entra en los criterios de productividad de los mercados internacionales. Sin embargo, tal como anota White (2012), no son tierras marginales porque concentran importantes recursos hídricos y naturales, en este caso su topografía plana es perfecta para la introducción de grandes explotaciones. Tampoco son tierras vacías pues tienen una historia de población ancestral y reciente de campesinos y colonos que buscan allí generar sus medios de vida.

\footnotetext{
${ }^{50}$ Se reconocen 12 pueblos indígenas en la región, pertenecientes a siete familias lingüísticas (DNP 2014).
} 


\subsection{Los cimientos para el acaparamiento de tierras: Tenencia informal, conflicto armado y desposesión.}

La tenencia de la tierra en Colombia se caracteriza por su alto grado de informalidad ${ }^{51}$. Así en su informe la OCDE (2015) reportaba que más del $40 \%$ de la propiedad de la tierra continuaba siendo informal. Esto es consecuencia de una ocupación histórica del territorio desordenada y espontánea, que nunca ha obedecido a la vocación productiva del suelo, sino a intereses particulares y a una incapacidad del estado en la administración de las tierras (DNP 2015). La tenencia de la tierra ha dado lugar al surgimiento de largos conflictos y ha facilitado los procesos de acumulación, concentración y el despojo al estado y a población vulnerable (Mejía \& Mojica 2015).

La región de la Orinoquia ha sido históricamente zona de colonización por campesinos sin tierra provenientes del centro del país, que buscaban tierras para establecerse, articularse a las economías de enclave o que huían de la violencia bipartidista de los años cincuenta. En esta lógica colonizadora, la legalización o posesión de títulos de propiedad no era importante para los nuevos pobladores, lo que, junto a una ausencia institucional en estas regiones, ha influido en una alta informalidad en la tenencia de la tierra, que afecta a un $75-100 \%$ de los predios en 5 de los 7 municipios de la Altillanura de acuerdo con el (MADR 2015a).

De las tierras baldías adjudicadas en el país, en la subregión en la Altillanura se han titulado entre 1900 y 2014 un total de 4.282.077 ha a campesinos colonos y 3.375.876 ha a resguardos indígenas (INCODER 2014). Esto indica que los cinco millones de hectáreas restantes están en la informalidad. De igual manera no todas las adjudicaciones se encuentran registradas en catastro, que además esta desactualizado para el departamento del Meta y es inexistente para el Vichada.

Con una casi nula presencia del estado, a excepción de la fuerza pública en los últimos años, la región de la Altillanura ha sido el escenario de actuación de

\footnotetext{
${ }^{51}$ Solo en el $6 \%$ (71) de los municipios del país existe un grado de formalidad en los predios mayor al $75 \%$, mientras que el $54 \%$ de los municipios (601) el grado de formalidad en los predios está entre un 25 y $75 \%$ y en el $16 \%$ de los municipios (181) el grado de formalidad es menor al $25 \%$. Además existe un $7 \%$ de municipios (79) sin catastro y un $17 \%$ (190) sin información (MADR 2015).
} 
diferentes grupos armados (paramilitares, guerrilla y bandas criminales) que participan en el narcotráfico, contrabando y minería ilegal. Esto, sumado a bajos niveles de acceso a la justicia, se traduce en una alta vulnerabilidad para la población. Los datos del Registro Único Víctimas (2017) reportaron una cifra de de 59.000 mil personas desplazadas por la violencia entre 1995 y 2016, a su vez el CMH (2012) reportó 18 masacres, 84 asesinatos selectivos y 9 ataques a poblaciones entre 1988 y 2012.

Sobre estas dinámicas de violencia, asociadas a la lucha por la tierra en la cual la desposesión de campesinos, colonos e indígenas ha sido una constante ${ }^{52}$, se presenta la entrada de las inversiones agrícolas a gran escala en la región. Cabe anotar que los cultivos agroindustriales habían iniciado en el departamento del Meta desde la década del noventa, con lo cual el interés de los grandes inversionistas no surge necesariamente en el marco de las crisis (alimentaria, financiera, energética) mencionadas anteriormente, aunque sin duda con estas se intensificó el interés por las tierras:

\section{"When high commodity prices in 2007/08 sparked a food security debate in Colombia,}

The Colombian government increased its focus on the Altillanura's Agricultural potential, the local private sector and foreign investors have been exploring the region's possibilities for at least a decade" (USDA 2009:1).

Así, la incursión de las grandes empresas desde 2007, como la multinacional brasileña, Monica Semillas y los grupos económicos nacionales Aliar y Manuelita, se cuentan como los pioneros más audaces por establecer cultivos a gran escala (soja, palma de aceite y maíz), enfrentando la deficiencia en infraestructuras y la inseguridad en la región junto a la restricción legal de la UAF (Revista Dinero, 2011; USDA, 2009). Este último extremo es señalado de forma explícita por el Reporte GAIN del USDA.

"The UAF, or Family Agricultural Unit, creates the largest barrier to development of commercial, large-scale agriculture in Colombia. [...] One

\footnotetext{
${ }^{52}$ No en vano la Unidad de Restitución de Tierras (URT) reportaba para finales de 2017 un total de 3.104 solicitudes de restitución de tierras en la Altillanura, el 70\% de estas en los tres municipios del Meta. http://restituciondetierras.gov.co/. Consultado por última vez 10 Mayo de 2018.
} 
proposed solution to the UAF issue for the Altillanura is the Business Development Zone, sort of a free-trade zone for agriculture that would provide incentives to investors and be exempt from the UAF (USDA 2009:7)

"The current law states that land provided by the government is not negotiable until 12 years of occupation and any purchase cannot be performed for more than one UAF. This law was conceived to reduce inequalities in the rural area and the uneconomical division; but it is generating conflict with large-scale agricultural projects and investments in the area of biofuels, grains and oilseeds"(USDA 2010:1).

Curiosamente, algunas compañías ya habían encontrado el camino para hacer a un lado esta restricción legal. El mismo reporte de la USDA menciona el caso de la compañía "Monica Semillas", la cual se vio 'forzada' a crear siete compañías para que cada una comprase una UAF (USDA 2009:4).

Estos planteamientos no consideran en ningún momento el rol que la violencia y el despojo de tierras a la población han jugado para hacer posibles estas inversiones.

\subsection{Las disputas legales por los baldíos de la Altillanura}

Los dos últimos gobiernos colombianos (desde 2002) han estado buscando nuevos mecanismos legales para remover la limitación de la UAF, con el objetivo de responder a las demandas de los grandes inversores viabilizando la tierra marginal de la Altillanura hacia la producción agroindustrial. No obstante, la sucesión de intentos por introducir dichos cambios institucionales se ha encontrado con reportes y noticias en diferentes medios de comunicación, mostrando los abusos detrás de estas grandes inversiones y, debido a ello, con la intervención de otras instituciones del estado (Congreso, Contraloría, Corte Constitucional) que han tratado de evitar la introducción de dichas reformas legales.

El primer intento legal por modificar la legislación, fue la creación del Estatuto de Desarrollo Rural -Ley 1152 de 2007-. Con él, el gobierno buscaba facilitar la titulación de tierras abandonadas por desplazamiento forzado a empresarios y 
nuevos poseedores. La opción para los campesinos de acceder a la tierra y a subsidios oficiales estaba sujeta a la conformación de alianzas con los empresarios. Representantes de ONG y organizaciones indígenas y campesinas demandaron la Ley ante la Corte Constitucional, que finalmente lo declaró inconstitucional (CC 2009).

Sin embargo, la presión sobre las tierras baldías o con antecedentes de baldíos continuó. En 2010, el gobierno recibe soporte técnico y financiero del USDA para la restitución, la formalización de tierras y la organización del sector rural en el marco para el programa de gobierno del período 2010-2018, mientras insiste nuevamente en la necesidad de remover los obstáculos legales. "The new administration that took power in August has sent signals that they will consider modifying the current policy in order to increase agricultural production" (USDA 2010:1). En este mismo año 2010, los medios hacen públicas las compras masivas de tierra en la Altillanura, gracias a la denuncia de un partido político (Polo Democrático Alternativo, PDA), que mostró que subsidios del programa Agro Ingreso Seguro (AIS) habían sido asignados a las compañías 'fachada' creadas por la multinacional Mónica Semillas ${ }^{53}$ para evadir la restricción de la UAF. La Superintendencia de Notariado y Registro investigó las compras de la compañía y encontró que todos los predios tenían antecedentes de reforma agraria, es decir que fueron tierras baldías, con historia de ventas ilegales (El Espectador 2012). La empresa fue obligada a devolver el dinero de los subsidios (Superintendencia de Sociedades 2013).

El gobierno responde con un segundo intento para modificar la legislación. Por medio de la Ley 1450 de 2011 introduce la creación de Proyectos Especiales de Desarrollo Agropecuario y Forestal, los cuales podían concentrar tierras provenientes de baldíos y aquellas compradas con subsidio integral de tierras $^{54}$, sin límite de extensión. El mismo partido político (PDA) impugnó los artículos que regulaban esta posibilidad ante la Corte Constitucional, la cual los declaró inconstitucionales (CC 2012a), por considerarlos regresivos respecto

53 El Espectador 2010. http://www.elespectador.com/noticias/judicial/aparece-otroescandalo-agro-ingreso-seguro-articulo-238398. Consultado última vez 17 de Junio de 2016.

${ }^{54}$ La ley 160 de 1994 establece el subsidio integral de tierras para financiar hasta el $100 \%$ del costo de una UAF para un campesino y prohíbe que dichas tierras se puedan vender o arrendar antes de 12 años de haberlas adquirido. 
al derecho a la tierra por trabajadores del campo y por modificar la prioridad de asignación de los baldíos entregándolos sin límites a empresarios nacionales o extranjeros.

A lo largo de 2011 y 2012, surgieron varias noticias mostrando que compañías trasnacionales de Brasil (Monica Semillas), de USA (Cargill), de Israel (Merhav) y Argentina (Ingacot), poseían 113 mil hectáreas de cultivos de soja y maíz y palma de aceite en la Altillanura colombiana. De igual manera $100 \mathrm{mil}$ hectáreas más de plantaciones forestales estaban en manos de otras compañías trasnacionales y fondos de inversión (Portafolio 2013). También grupos económicos nacionales incursionaron con 56 mil hectáreas en los mismos cultivos, apoyados en la transferencia tecnológica hecha por la empresa Embrapa de Brasil para corregir la acidez de los suelos ${ }^{55}$. En declaraciones a la revista Dinero estos empresarios argumentan que para lograr la rentabilidad de estas inversiones requieren extensiones mayores a 10 mil hectáreas y que en este sentido la UAF limita las economías de escala (Dinero 2011).

En mayo de 2013, el Ministerio de Agricultura publica un informe con 13 casos (7 en la Altillanura) de acumulación de UAF con origen de baldíos en 231 predios y 67.951 hectáreas (MADR 2013). Al mismo tiempo el PDA, presenta un informe a la Contraloría General de la Nación (CGN), ${ }^{56}$ describiendo las estrategias jurídicas usadas por multinacionales y grupos económicos nacionales para acaparar tierras en la región.

Precisamente en 2013, Oxfam publica un informe (Oxfam 2013) que tuvo gran impacto mediático, mostrando que Cargill había comprado alrededor de 58 mil hectáreas mediante la creación de 36 empresas subsidiarias $(\mathrm{SAS})^{57}$, comprando

\footnotetext{
55 Los suelos de la región son ácidos con bajo contenido de materia orgánica y resultan pobres para la actividad agrícola. La tecnología empleada para corregirlos se desarrolló en Brasil en la zona llamada "El Cerrado Brasilero" similar a la zona de la Altillanura en su composición edafológica.

${ }^{56}$ Ver:https:/ / detenerelacaparamientodetierras.files.wordpress.com/2011/11/documento_c ontraloria_vr-final1.pdf. Consultado ultima vez 11 Julio de 2016.

57 Las Sociedades por Acciones Simplificadas SAS, se crean en 2008 con el objetivo de facilitar el emprendimiento, por lo que cuentan con una alta flexibilidad y facilidades para su constitución y funcionamiento y pueden constituirse por personas naturales o jurídicas nacionales o extranjeras.
} 
una UAF cada una. La mayoría de estas propiedades habían sido compradas por otras empresas a sus originales dueños y vendidas a Cargill a un precio 33 veces mayor a su precio inicial. Todos estos predios fueron inicialmente baldíos y las compras fragmentadas hicieron posible evadir la restricción legal de la Ley 160. Las empresas contaron con la asesoría jurídica de abogados nacionales, relacionados con círculos políticos y diplomáticos para hacer las compras fraccionadas (Semana 2013b).

A pesar de los diferentes escándalos y denuncias, el gobierno hace un tercer intento para remover la UAF con el Proyecto de Ley 162 de 2013, el cual apuntaba a crear nuevas modalidades de acceso a la tierra y modificar el régimen de baldíos. Prohibía la concentración de UAF solo después de 1994 e incluía la posibilidad de celebrar contratos de arrendamiento por 30 años prorrogables. Los campesinos con baldíos adjudicados podían aportarlos a los proyectos asociativos y no imponía límites a las extensiones de los proyectos (Congreso de la República 2013). El Presidente retiró el proyecto de ley un mes después de su presentación debido a la presión ejercida por diferentes asociaciones de comunidades campesinas, ONG y el partido del PDA, quienes argumentaban que el proyecto de ley buscaba legalizar el acaparamiento de tierras que había sido denunciado ${ }^{58}$.

En 2014, la Contraloría General de la República (CGR), luego de investigar los casos identificados por el Ministerio de Agricultura un año antes, concluyó que la información entregada por el INCODER sobre baldíos adjudicados entre 1901-2012, contenía serias inconsistencias: fechas de adjudicación erradas, inexistencia de datos de beneficiarios, de área adjudicada, beneficiarios con varios registros de adjudicación, y que el $41 \%$ de los terrenos adjudicados habían sido vendidos antes de cumplir los 5 años que señala la Ley. La CGR también comprobó que no hubo verificación de condiciones de elegibilidad antes de la adjudicación (CGR 2014:72). Además, el informe de la CGR confirma 14 casos que involucran acumulación de UAF en la Altillanura, un área de $215.670^{59}$ hectáreas, en los cuales seis empresas recibieron incentivos y

\footnotetext{
58 Ver: http://www.elespectador.com/noticias/politica/gobierno-ordena-minagriculturaretirar-proyecto-de-ley-articulo-459621. Consultado 23 de marzo de 2016.

${ }^{59}$ El informe presenta un total 101.180 hectáreas, pero al realizar la sumatoria de hectáreas de los casos reportados, la cifra es de 215.670,1 hectáreas, por lo que aquí se presenta esta última cifra.
} 
subsidios del estado -entre ellas Cargill- creados para apoyar pequeños productores. La investigación incluyó cinco casos de multinacionales, cuatro empresas nacionales, y el grupo financiero y empresarial más grande del país (Luis Carlos Sarmiento Angulo) así como miembros de la política y servidores públicos. La Tabla 6.2 sintetiza esta información.

Tabla 6. 2 Casos investigados por la CGR de acumulación ilegal de baldíos en la Altillanura colombiana 2014.

\begin{tabular}{|c|c|c|c|}
\hline Casos & Departamentos & $\begin{array}{c}\text { No. } \\
\text { Predios }\end{array}$ & $\begin{array}{c}\text { No. } \\
\text { Hectáreas }\end{array}$ \\
\hline $\begin{array}{l}\text { Multinacionales: Monica, Cargill, } \\
\text { Timberland y Wood Holdings, Poligrow }\end{array}$ & Meta-Vichada & 71 & 105784 \\
\hline $\begin{array}{l}\text { Empresas Nacionales: Riopaila- Castilla, } \\
\text { Grupo Luis Carlos Sarmiento Angulo, } \\
\text { La Fazenda, Indupalma y Manuelita }\end{array}$ & Meta-Vichada & 100 & $91.217,5$ \\
\hline $\begin{array}{l}\text { Particulares: Carlos Aguel Kafruni, } \\
\text { Familia Ministro Aurelio Irragori, } \\
\text { Camilo Pabón. }\end{array}$ & Meta-Vichada & 17 & $18.668,6$ \\
\hline Total & & 188 & $215.670,1$ \\
\hline
\end{tabular}

Fuente: Elaboración propia. Datos Informe CGR 2014.

La CGN concluyó que el INCODER incumplió la Ley 160 de 1994, al permitir la acumulación de terrenos baldíos por particulares sin cumplir los requisitos y al hacer una deficiente gestión para su recuperación. Además, refiriéndose a estrategias usadas para acaparar las tierras, expuso:

"Las herramientas jurídicas que algunos particulares no sujetos de reforma agraria, no campesinos, han empleado para evadir o incumplir los requisitos y restricciones legales sobre los baldios se traduce en una práctica de privatización de estos bienes, aminorando el patrimonio estatal y distorsiona el contenido público de las transacciones de ese tipo de bienes. Entonces quienes han incurrido en estas prácticas no están en capacidad de alegar algún derecho, dado que han violado la ley y esto no merece ninguna protección" (CGR 2014: 106).

LA CGR argumentó también que los intentos del gobierno por cambiar el marco legal estaban más dirigidos al saneamiento de la propiedad privada hacer legales las apropiaciones- que, a la restitución del patrimonio del estado, 
lo que da lugar a la desprotección del derecho del acceso a la tierra para hombres y mujeres de escasos recursos (CGR 2014:134).

No obstante, a pesar de estas denuncias, el gobierno intenta, por cuarta vez, cambiar la legislación con el Proyecto de Ley 133 de 2014, ahora proponiendo la creación de las Zonas de Interés de Desarrollo Rural y Económico (ZIDRES). Estas áreas fueron definidas para zonas geográficas aisladas, con poca infraestructura, suelos poco productivos para las que se requieren grandes inversiones para su explotación y que por lo tanto resultan inapropiadas para la producción campesina y familiar. Estas son precisamente las características de regiones como la Altillanura. El proyecto de ley proponía la concesión o arrendamiento a largo plazo a los empresarios, sin límites en extensión y con la posibilidad de concentrar tierras privadas y públicas. Incluía además la expropiación a campesinos que no explotaran el predio adjudicado de acuerdo a los lineamientos de productividad dados por la UPRA (Congreso de la República 2014).

Algunas organizaciones denunciaron que lo anterior negaba la producción campesina, por anteponer la productividad como prioridad para acceder a la tierra, reclamaron que el proyecto cambiaba el término de campesino por el de trabajador agrario e introducía el término de empresa asociativa como figura bajo la cual los grandes empresarios podían acumular tierras (Oxfam 2014). Estas organizaciones se opusieron al proyecto manifestando que, la ley legalizaba de facto el acaparamiento irregular previo, cuando aún no se habían resuelto los problemas históricos como la formalización en la tenencia, la restitución de tierras en zonas de violencia, ni los casos de acumulación ilegal de UAF con antecedentes de baldíos investigadas por el Ministerio de Agricultura y la CGR. El Ministro del Interior retiró el proyecto en marzo de 2015 -seis meses después de radicado en la Cámara de Representantesargumentando que aún faltaba consenso y discusión con las comunidades ${ }^{60}$.

Sin embargo, solo un mes después, sin realizar consenso alguno con las comunidades, el gobierno inició el quinto intento para reformar el marco legal.

\footnotetext{
${ }^{60}$ Ver detalles en http://www.verdadabierta.com/images/Carta_del_ministro_del_interior_por_el_retiro_de 1_proyecto_de_las_Zidre.jpg. Consultada 16 de Junio de 2016.
} 
Las ZIDRES son propuestas de nuevo con el Proyecto de Ley 223 en abril de 2015, promoviendo la asociación de campesinos con empresarios. Aunque los empresarios no gusten mucho de las asociaciones, como lo ilustra este documento del USDA:

"Requiring firms to work through Colombia's land owning campesinos may be viewed as too uncertain and difficult a proposition for international and Colombian agribusiness firms. Reservations over the stability of an agreement with small Colombian landowners given the country's land rights and title issues, security concerns and the perception of the political leanings of small campesino communities are all considered to be cause for caution." (USDA 2015:4)

Además, en el mismo documento el USDA, expresa sus preferencias por las ZIDRES -en la medida en que pueden priorizar inversiones- y su rechazo a la devolución de las tierras a sus dueños originales.

"The success of the ZIDRE program may provide a less distasteful resolution to the issues of agribusiness land ownership in the Altillanura than simply having land ownership nullified and losing significant investments of time and money." (USDA 2015:5)

Después de intensos debates en el congreso, las ZIDRES son aprobadas mediante la Ley 1776 de 2016, la cual es presentada por el Presidente de la República como una gran victoria para el desarrollo rural:

"Esta es la ley más audaz de nuestra historia para garantizar el desarrollo del campo. Iniciamos el camino para convertirnos en la despensa de alimentos del mundo" (Semana 2016).

"Toda esta altillanura, que por causa del conflicto no ha tenido la inversión ni el desarrollo que ha debido tener, se nos presenta como la gran oportunidad. El director de la FAO sabe perfectamente que el mundo está cada vez más preocupado porque está creciendo y necesita alimentarse (...), hay solamente unos pocos países donde hay un verdadero potencial para aumentar la producción, uno de ellos es Colombia, toda esta zona que podemos convertir en una despensa (El País 2016). 
Los requisitos para constituir una $\mathrm{ZIDRE}^{61}$ se ajustan perfectamente a la región de la Altillanura. Se exige que los proyectos propuestos apunten a la internacionalización de la economía, la alta competitividad, equidad, reciprocidad y conveniencia nacional. Se encarga a la UPRA la delimitación de las ZIDRES y al Ministerio de Agricultura de aprobar los proyectos a implementar. Los criterios para la selección de proyectos son básicamente su productividad y rentabilidad. La participación de los pequeños productores será a través de la asociatividad con los empresarios. Los subsidios y acceso a tecnología se priorizan para los proyectos asociativos. Se establece que los baldíos ubicados en estas zonas pueden darse en concesión o arrendamiento sin límite de tiempo ni extensión.

Después de cinco intentos y más de 20 años, la prohibición de acumular UAF establecida en el Artículo 72 de la Ley 160 de 1994, deja de tener validez para casos previos de concentración ilegal de baldíos. El acaparamiento de baldíos antes de 1994 fue en esta forma legalizado. Así el gobierno colombiano parece haber alcanzado su objetivo para solucionar la situación de ilegalidad en la acumulación de tierras y regularizar la producción a gran escala en la mayor frontera agrícola del país. Los habitantes originales, indígenas y campesinos, son forzados -como única alternativa- a asociarse con los agronegocios sin unas condiciones de participación claras o reguladas por la ley.

Dos partidos políticos de oposición, junto con cuatro ONG nacionales y seis asociaciones de campesinos e indígenas, presentaron una demanda ante la Corte Constitucional, buscando la declaración de inconstitucionalidad de la Ley 1776, argumentando principalmente que:

“...la ley plantea un modelo que introduce importantes modificaciones al modelo agrario en Colombia... por modificar de manera regresiva el régimen de baldios, por promover un modelo de asociatividad en el campo que resta

\footnotetext{
${ }^{61}$ La Ley establece que las ZIDRES se implementen en las zonas que estén aisladas de los centros urbanos, que demanden elevados costos de adaptación por sus características agrológicas y climáticas, que tengan baja densidad poblacional, altos índices de pobreza y que carezcan de infraestructura mínima. Así mismo el Artículo 29 prohíbe establecer ZIDRES en territorios declarados como resguardos indígenas, territorios colectivos titulados o en proceso de titulación de las comunidades negras, zonas de reserva campesina debidamente establecidas por el Incoder o quien haga sus veces. Ley 1776 de 2016.
} 
autonomía a los campesinos...privilegiando de manera desproporcionada la agroindustria en detrimento de la economía campesina"(Carta Demanda 2016).

La CC en febrero de 2017, declaró la Ley ZIDRES Exequible, es decir que se ajusta a la Constitución Nacional. La CC estableció en la sentencia algunos condicionamientos: que las ZIDRES estén articuladas a los planes de desarrollo de los municipios donde se implementen y que los pequeños campesinos no tengan la obligatoriedad de asociarse con los empresarios. Por lo demás da vía libre a su implementación.

A modo de síntesis, la Tabla 6.3 presenta los sucesivos intentos de cambio de la ley agraria para permitir acumulación de tierras procedentes de baldíos asignados en procesos de reforma agraria, así como las respuestas por actores de la sociedad civil y el resultado. 
Tabla 6. 3. Intentos legales para permitir la acumulación de tierras baldías en Colombia. 2007-2016

\begin{tabular}{|c|c|c|c|}
\hline $\begin{array}{c}\text { Modificaciones } \\
\text { Marco Legal }\end{array}$ & Instrumento & Reacción actores & Resultado \\
\hline $\begin{array}{l}\text { 1. Ley } 1152 \text { de } \\
2007 \text { de } \\
\text { Desarrollo } \\
\text { Rural }\end{array}$ & $\begin{array}{l}\text { - Facilita titulación de predios } \\
\text { abandonados por desplazamiento } \\
\text { forzado a nuevos poseedores y } \\
\text { empresarios. } \\
\text { - Crea alianzas productivas entre } \\
\text { campesinos y empresarios. }\end{array}$ & $\begin{array}{l}\text { Demandado ante la } \\
\text { CC por falta de } \\
\text { Consulta Previa } \\
\text { con comunidades } \\
\text { rurales }\end{array}$ & $\begin{array}{l}\text { Declaración de } \\
\text { Inconstitucio- } \\
\text { nalidad de la } \\
\text { Ley por la CC }\end{array}$ \\
\hline $\begin{array}{l}\text { 2. Ley } 1450 \text { de } \\
2011 \text { (Art. 60,61 } \\
\text { y 62) }\end{array}$ & $\begin{array}{l}\text { - Crea Proyectos especiales de } \\
\text { desarrollo agropecuario y forestal } \\
\text { - Permite concentrar tierras } \\
\text { procedentes de baldíos sin límite } \\
\text { de extensión. }\end{array}$ & $\begin{array}{l}\text { Demanda ante la } \\
\text { Corte } \\
\text { Constitucional por } \\
\text { Inconstitucional }\end{array}$ & $\begin{array}{l}\text { CC declara los } \\
\text { artículos } \\
\text { inconstitucio- } \\
\text { nales por } \\
\text { cambiar la } \\
\text { prioridad en la } \\
\text { adjudicación } \\
\text { de los baldíos. }\end{array}$ \\
\hline $\begin{array}{l}\text { 2. Proyecto de } \\
\text { Ley } 162 \text { de } \\
\text { 2013. Modifica } \\
\text { Régimen de } \\
\text { Baldíos }\end{array}$ & $\begin{array}{l}\text { - Aplicar la concentración de UAF } \\
\text { - Contratos de arrendamiento de } \\
\text { baldíos a largo plazo ( } 30 \text { años y } \\
\text { más) } \\
\text { - Asociación de campesinos con } \\
\text { empresarios aportando su tierra. } \\
\text { - Adjudicación sin límite de } \\
\text { extensión. }\end{array}$ & $\begin{array}{l}\text { Presión y rechazo } \\
\text { por sociedad civil: } \\
\text { ONG, asociaciones } \\
\text { de campesinos y de } \\
\text { indígenas. }\end{array}$ & $\begin{array}{l}\text { Retiro del } \\
\text { congreso por } \\
\text { el presidente } \\
\text { de la } \\
\text { República. }\end{array}$ \\
\hline $\begin{array}{l}\text { 4. Proyecto de } \\
\text { Ley } 133 \text { de } \\
\text { 2014. Zonas de } \\
\text { Desarrollo } \\
\text { Rural y } \\
\text { Económico - } \\
\text { Zidres. }\end{array}$ & $\begin{array}{l}\text { - Describe exactamente las } \\
\text { condiciones de la Altillanura para } \\
\text { su creación } \\
\text { - No propone adjudicación, solo } \\
\text { arrendamiento a largo plazo } \\
\text { - Expropiación a campesinos que } \\
\text { no demuestren productividad. }\end{array}$ & $\begin{array}{l}\text { Rechazo por } \\
\text { académicos, } \\
\text { asociaciones } \\
\text { campesinas y } \\
\text { ONG. }\end{array}$ & $\begin{array}{l}\text { Retirado en } \\
\text { marzo de } 2015 \\
\text { por Ministro } \\
\text { del Interior }\end{array}$ \\
\hline $\begin{array}{l}\text { 5. Proyecto de } \\
\text { Ley } 223 \text { de } \\
\text { 2015. Zonas de } \\
\text { Desarrollo } \\
\text { Rural, } \\
\text { Económico y } \\
\text { Social-ZIDRES }\end{array}$ & $\begin{array}{l}\text {-El mismo proyecto } 133 \text { con } \\
\text { diferente nombre. }\end{array}$ & $\begin{array}{l}\text { Rechazo por la } \\
\text { sociedad civil }\end{array}$ & $\begin{array}{l}\text { Aprobado } \\
\text { como Ley } 1776 \\
\text { de 2016-Ley } \\
\text { ZIDRES }\end{array}$ \\
\hline
\end{tabular}

Fuente: Elaboración propia 
Adicionalmente, en 2017 se elaboró el Decreto Ley 902, para cumplir con la implementación de la Reforma Rural Integral (RRI) acordada en el punto uno de los Acuerdos de Paz. Este Decreto Ley establece básicamente: el ordenamiento social y ambiental del territorio, la creación de un fondo de tierras que permita el acceso progresivo de los trabajadores rurales a la tierra, la creación de un registro de beneficiarios de las políticas de reforma rural, y la simplificación de procedimientos administrativos y judiciales para la protección jurídica del acceso, tenencia y propiedad de la tierra. Sin embargo, este Decreto Ley ha sido criticado por varias organizaciones ${ }^{62}$ que consideran que con su aplicación se cambian elementos fundamentales contenidos en la Constitución, en la Ley 160 de 1994 y en los Acuerdos de Paz en los siguientes puntos:

- Se definen tres tipos de sujetos para el acceso y formalización: a título gratuito los que tengan patrimonio menor a 250 SMLMV, a título parcialmente gratuito los que tienen entre 250-700 SMLMV de patrimonio, y los sujetos a título "oneroso", los que tienen patrimonio mayor a 700 SMLMV a los cuales se les formalizaran sus posesiones según los requisitos de ley (pueden tener posesiones o ser ocupantes de predios que superen la UAF). Así se amplía el rango de beneficiarios a aquellos que han ocupado tierras baldías irregularmente superando el límite de la AUF. Por el contrario, la ley permite la entrega de tierra en cantidades inferiores a una UAF cuando no haya disponibilidad de tierras en las zonas solicitadas o que la extensión de tierra entregada sea considerada suficiente para el sostenimiento de familia campesina. Por lo cual, las organizaciones consideran que podría fomentarse una excesiva fragmentación de las explotaciones.

- El Fondo Nacional de Tierras creado no priorizará la inclusión de los baldíos indebidamente apropiados y ocupados. La provisión de tierras para nutrir ese Fondo estaría basada en la venta y arriendo de tierras para reunir fondos y con ellos comprar otras tierras a precios

\footnotetext{
${ }^{62}$ El Centro de Estudios de Derecho, Justicia y Sociedad (Dejusticia) realizó en Junio de 2017 una intervención para la revisión de la constitucionalidad del Decreto Ley 902 de 2017 ante Magistrada de la Corte. Disponible en: https://www.dejusticia.org/wpcontent/uploads/2017/08/Intervencio\%CC\%81n-Reforma-Rural-Integral-.pdf. Consultado última vez el 14 de mayo de 2018.
} 
comerciales, en la utilización de tierras de extinción de dominio, de tierras que se sustraigan de las reservas forestales y de zonas de manejo especial, entre otras. De esta forma confirma el estado su interés por legalizar los baldíos apropiados.

- Para la adjudicación de tierra el Decreto Ley 902 elimina el requisito de ocupación previa de cinco años que garantizaba la vocación agraria de los solicitantes, así las personas solicitantes pueden no tener vínculo alguno con la tierra, con lo cual se desdibuja la caracterización de quién es el sujeto de reforma agraria.

El recorrido realizado, analizando este proceso permite evidenciar el papel activo del estado que, a través del cambio en el marco legal relativo a la tenencia y distribución de la tierra, facilita la legalización de las acumulaciones de UAF por grandes inversores privados (acaparamiento), dejando con menos derechos a la población rural sin tierra, despojada y desplazada. Con esto incumple el estado el mandato constitucional de priorizar en el acceso a la tierra para los trabajadores del campo y también incumple lo pactado en los Acuerdos de Paz, lo que deja ver que la estabilidad política y social del país continua incierta.

Es de resaltar también que las demandas legales de la sociedad civil y de algunos actores (funcionarios del estado, miembros del poder judicial, miembros del congreso), ha sido posible gracias al uso de mecanismos y espacios que deja también la misma legislación (en lo que corresponde a la legitimación del estado) para reclamar los derechos de las comunidades rurales vulnerables y vulneradas. Esta contienda hasta ahora parece ganada por los acaparadores e inversionistas con el visto bueno de organismos internacionales que, bajo la justificación de ampliar la oferta alimentaria mundial, han influido en el estado para lograr la seguridad jurídica de sus inversiones. 


\section{Capítulo 7}

\section{Mecanismos de acaparamiento de tierras en Colombia. Estudios de}

caso

El objetivo de este capítulo es profundizar en el análisis de los mecanismos de acaparamiento de tierras llevado a cabo en Colombia a través del estudio de 12 casos que fueron identificados a partir del análisis sistemático de la literatura (ver capítulo Metodología). La Figura 7.1 muestra la ubicación de los predios analizados, ubicados en once municipios de seis departamentos del país.

El capítulo realiza una síntesis de cada uno de estos casos, que es acompañada por una tabla que persigue identificar y situar en el tiempo los principales eventos y procesos acaecidos en cada uno de ellos. Las mismas tablas incluyen una etiqueta clasificatoria para cada uno de esos eventos o procesos, etiquetas que son explicadas a continuación y que constituyen la base del análisis comparativo que se realiza posteriormente. El capítulo finaliza con una identificación y discusión de los principales patrones secuenciales que atraviesan los estudios de caso y que permite entender, desde el nivel micro, los procesos de despojo y acaparamiento que han tenido lugar en Colombia. 
Figura 7. 1. Mapa ubicación departamental y municipal de los estudios de caso.

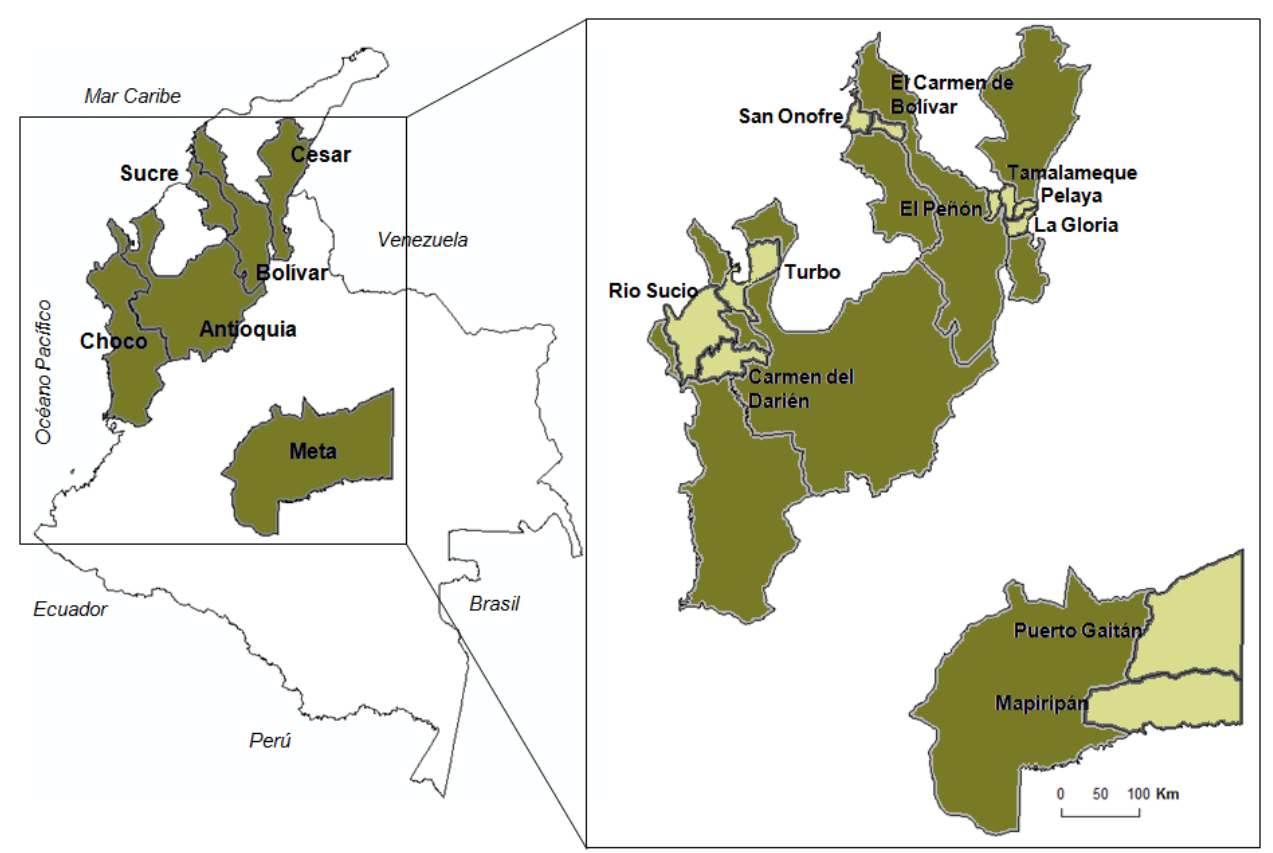

Fuente: Elaboración propia.

\subsection{Una revisión y sistematización de los estudios de caso}

En este epígrafe recogemos los estudios de caso que han sido seleccionados a través del análisis sistemático de la literatura. Para cada uno de ellos, se presenta una ficha inicial de caracterización, un breve resumen y una tabla que persigue identificar los acontecimientos más determinantes de cada proceso, clasificándolos y etiquetándolos con la finalidad de poder realizar a posteriori un análisis comparativo. 


\subsubsection{Caso No. 1. Predio Déjala Quieta- Tulapas.}

\begin{tabular}{ll}
\hline Municipio: Turbo & Extensión Predio: 25 hectáreas \\
\hline \multirow{2}{*}{ Departamento: Antioquia } & Fuentes: (Ballvé 2013), (García \& \\
& Vargas 2014), (Verdad Abierta \\
& $2012 b)$ \\
\hline
\end{tabular}

La región de Urabá fue usada como laboratorio para la apropiación de tierras por los paramilitares y Tulapas (una parte del municipio de Turbo) fue la zona donde se cometió el mayor despojo de tierras en Antioquia. Las guerrillas llegaron desde los años setenta y los paramilitares (las AUCC) entraron a finales de los ochentas, en acuerdos con las élites regionales para atacar la insurgencia y defender a ganaderos y empresarios del banano del ataque y la extorsión de las guerrillas.

Déjala Quieta es un predio que forma parte de las 22.000 hectáreas de las que se apropiaron los paramilitares en la región. La mayoría se habían adjudicado a campesinos por el INCORA desde la década de los ochenta. La violencia paramilitar se intensifica en 1995, por medio de masacres y asesinatos desplazan la población. Después de dos años inician las compras de tierras, por medio de comisionistas y testaferros y cinco años más tarde se da una venta masiva de predios que no se demuestra por la Superintendencia de Notariado y Registro hasta el año 2011. En 2012 el dueño original de Déjala Quieta solicita la restitución del predio, en una primera instancia se falla en contra porque el juez considera que fue un abandono voluntario. El dueño del predio apela y finalmente, la Corte Suprema de Justicia ordena la restitución.

\begin{tabular}{clc}
\hline Período & \multicolumn{1}{c}{ Secuencia del proceso } & \multicolumn{1}{c}{$\begin{array}{c}\text { Etiqueta } \\
\text { (tipo de proceso) }\end{array}$} \\
\hline 1980-1995 & Titulación por INCORA & Titulación legal \\
\hline \multirow{2}{*}{$1995-1997$} & $\begin{array}{l}\text { Incursión paramilitar desplazando la } \\
\text { población, la familia propietaria por miedo } \\
\text { se desplaza y abandona el predio }\end{array}$ & Violencia/desplazamiento \\
\hline \multirow{2}{1997-2001}{} & $\begin{array}{l}\text { Paramilitares envían comisionistas para } \\
\text { forzar la venta de las tierras a bajo precio- } \\
\text { La familia vende el predio por temor a la } \\
\text { violencia }\end{array}$ & Venta irregular \\
\hline
\end{tabular}




\begin{tabular}{|c|c|c|}
\hline $2002-2008$ & $\begin{array}{l}\text { Ventas masivas de tierras por } \\
\text { comisionistas de paramilitares/ } \\
\text { apropiación por paramilitares }\end{array}$ & $\begin{array}{c}\text { Ventas irregulares } \\
\text { Apropiación paramilitar }\end{array}$ \\
\hline 2009 & $\begin{array}{l}\text { El jefe paramilitar Salvatore Mancuso, } \\
\text { declara que recibió orden de los hermanos } \\
\text { Castaño de comprar tierras en esa región } \\
\text { porque querían montar allí un } \\
\text { campamento. }\end{array}$ & Apropiación paramilitar \\
\hline 2011 & $\begin{array}{l}\text { La Superintendencia de Notariado } \\
\text { comprueba ventas masivas a pocos } \\
\text { compradores, casos con irregularidades en } \\
\text { documentos, } 75 \text { de } 103 \text { casos investigados } \\
\text { sucedieron en Tulapas. }\end{array}$ & \\
\hline 2012 & $\begin{array}{l}\text { Los desplazados solicitan la Restitución de } \\
\text { sus fincas }\end{array}$ & Solicitud de restitución \\
\hline 2014 & $\begin{array}{l}\text { Magistrado de Justicia y Paz de Medellín } \\
\text { niega la restitución alegando abandono } \\
\text { voluntario }\end{array}$ & Disputa judicial \\
\hline 2015 & $\begin{array}{l}\text { Corte Suprema de Justicia ordena la } \\
\text { restitución de las tierras por considerar } \\
\text { que la venta fue forzada debido al } \\
\text { desplazamiento y la violencia de la región }\end{array}$ & Restitución \\
\hline
\end{tabular}

\subsubsection{Caso No. 2. Cuencas de los ríos Jiguamiandó y Curvaradó- Bajo Atrato}

Municipio: Riosucio y Carmen del Extensión Predio: 100.457 hectáreas Darién

\section{Departamento: Chocó}

Fuentes: Grajales, 2011:2015 (Baquero 2012); (Osorio 2015);(Verdad Abierta 2014); (Sentencia 054 2014)

Esta región fue ocupada históricamente por 34 comunidades negras, su aislamiento total favoreció la presencia de las guerrillas que controlan la zona desde los años setenta. Los paramilitares entraron apoyando al ejército en su lucha contrainsurgente en 1995, generando masacres y desplazamiento de la población. Las comunidades solicitan en el año 1998 la titulación colectiva de las tierras, acogiéndose a la Ley 70/1993. Los paramilitares que habían vaciado 
gran parte del territorio, establecieron alianzas con empresarios y sembraron palma a través de asociaciones y cooperativas creadas por ellos mismos. La titulación colectiva se realiza en el año 2000 y varias comunidades iniciaron el retorno, pero sus tierras estaban llenas de palma y la violencia contra ellas continúo.

La exacerbación de la violencia y el acaparamiento de tierras quedaron verificados por la Corte Interamericana de Derechos Humanos (CIDH) entre 2001-2002, así como los vínculos entre militares y paramilitares para perpetrar el despojo. La violencia continúa en la región aún después de la desmovilización de los paramilitares, pues sus sucesores continúan atacando la población entre 2005 y 2007. Para este periodo el INCODER y la Defensoría verificaron más de 22 mil hectáreas sembradas de palma en los territorios colectivos. En 2008 los cultivos de palma disminuyen por la enfermedad de la pudrición del cogollo, pero llegan empresas exportadoras de plátano y banano y cultivan plátano y yuca. La CC exige al gobierno agilizar el proceso de restitución para lo cual entre 2012 y 2013, el INCODER revisa la situación jurídica de la zona y encuentra 35.000 ha sembradas de palma, plátano y yuca por empresas, pobladores e invasores de mala fe en las tierras colectivas. Se revocan $80 \%$ de los títulos falsos, los grupos armados impiden la restitución, mientras el gobierno incrementa la fuerza pública en la región.

La Fiscalía en 2013, solicita 22 condenas (a ex paramilitares, empresarios, comisionistas e inversionistas) por participar en la industria de palma con los Castaño y cometer crímenes, desplazamiento y afectación al medio ambiente. En el año siguiente se condenan 16 empresarios por concierto para delinquir, desplazamiento forzado e invasión de áreas de especial protección. En la condena se específica la forma de apropiación de las tierras por los paramilitares; apropiación directa, parcelaciones, documentos falsos y contratos de usufructo con las palmeras.

Para 2017 las comunidades siguen sin poder ejercer su derecho al territorio, mientras las empresas, invasores y repobladores continúan en los territorios colectivos y los líderes reclamantes de tierras son amenazados y algunos asesinados. 


\begin{tabular}{|c|c|c|}
\hline Período & Secuencia del proceso & $\begin{array}{c}\text { Etiqueta } \\
\text { (tipo de proceso) }\end{array}$ \\
\hline $\begin{array}{l}1970- \\
1980\end{array}$ & Incursiona las guerrillas; FARC, EPL y ELN & \\
\hline $\begin{array}{l}1997 \\
1998\end{array}$ & $\begin{array}{l}\text { Violencia y desplazamiento de las AUCC con el } \\
\text { ejército. Comunidades negras solicitan } \\
\text { titulación colectiva de las tierras. }\end{array}$ & $\begin{array}{c}\text { Violencia/desplaza } \\
\text { miento }\end{array}$ \\
\hline 1999 & $\begin{array}{l}\text { Paramilitares crean empresas, asociaciones y } \\
\text { cooperativas y cultivan palma, acceden a } \\
\text { créditos y subsidios. Legalizan compra de la } \\
\text { tierra con ayuda de INCODER con poderes de } \\
\text { compraventa falsos y contratos de usufructo } \\
\text { con empresas. }\end{array}$ & Titulación ilegal \\
\hline 2000 & $\begin{array}{l}\text { Se realiza la titulación colectiva a comunidades } \\
\text { en medio de la violencia }\end{array}$ & Titulación colectiva \\
\hline $\begin{array}{l}2001- \\
2002\end{array}$ & $\begin{array}{l}\text { CIDH y Defensoría del pueblo prueban } \\
\text { vínculos entre ejército y paramilitares para } \\
\text { desplazar la comunidad y sembrar palma }\end{array}$ & $\begin{array}{l}\text { Alianzas para } \\
\text { despojar }\end{array}$ \\
\hline $\begin{array}{l}2004- \\
2005\end{array}$ & $\begin{array}{l}\text { Verificación de } 22.022 \text { hectáreas cultivadas con } \\
\text { Palma. } \\
\text { INCODER declara nulos los contratos de } \\
\text { compraventa y usufructo de las compañías } \\
\text { Urapalma S.A., Palmadó, La Tukeka, e } \\
\text { Inversiones Fregni Ochoa. }\end{array}$ & $\begin{array}{l}\text { Consolidación del } \\
\text { Agronegocio }\end{array}$ \\
\hline 2006 & $\begin{array}{l}\text { Procurador General de la Nación reconoce el } \\
\text { vínculo entre acaparamiento de tierras y } \\
\text { desplazamiento forzado. }\end{array}$ & \\
\hline $\begin{array}{l}2007- \\
2008\end{array}$ & $\begin{array}{l}\text { Defensoría del Pueblo pide no otorgar créditos } \\
\text { agropecuarios y congelar transacciones de } \\
\text { tierras en territorios colectivos. } \\
\text { Tribunal de Chocó exige salida de empresas y } \\
\text { entrega de las tierras a la comunidad }\end{array}$ & Disputa legal \\
\hline $\begin{array}{l}2009- \\
2010\end{array}$ & $\begin{array}{l}\text { CC declara el fracaso del Estado para proteger } \\
\text { los derechos de las comunidades del Bajo } \\
\text { Atrato. } \\
\text { Las empresas palmeras continúan con la tierra } \\
\text { (29.000 ha en palma y ganado). }\end{array}$ & $\begin{array}{l}\text { Consolidación del } \\
\text { agronegocio }\end{array}$ \\
\hline 2010 & $\begin{array}{l}\text { Orden de captura contra } 22 \text { directivos, dueños } \\
\text { y empleados de las firmas palmicultoras }\end{array}$ & \\
\hline $\begin{array}{l}2011- \\
2012\end{array}$ & $\begin{array}{l}\text { El INCODER presenta Informe de situación } \\
\text { jurídica de las tierras colectivas. }\end{array}$ & Disputa legal \\
\hline
\end{tabular}




\begin{tabular}{|c|c|c|}
\hline & $\begin{array}{l}\text { La CC exige al gobierno centrarse en la } \\
\text { restitución de tierras }\end{array}$ & \\
\hline 2013 & $\begin{array}{l}\text { Fiscalía Cuarta Especializada pide condena } \\
\text { para empresarios de palma por crear una } \\
\text { empresa criminal para despojar tierras a } \\
\text { comunidades del Bajo Atrato }\end{array}$ & \\
\hline 2014 & $\begin{array}{l}\text { Juez de Medellín condena a } 16 \text { empresarios por } \\
\text { alianza con paramilitares para cultivar palma, } \\
\text { impedir retorno de las comunidades y causar } \\
\text { daño ambiental. } \\
\text { Se inician trámites para la restitución del } \\
\text { territorio colectivo ante la URT }\end{array}$ & $\begin{array}{l}\text { Judicialización del } \\
\text { despojo }\end{array}$ \\
\hline $\begin{array}{l}2015- \\
2016\end{array}$ & El proceso de restitución de tierras no avanza & \\
\hline 2017 & $\begin{array}{l}\text { Seis líderes reclamantes de tierras del Bajo } \\
\text { Atrato asesinados. La URT aún no realiza } \\
\text { proceso de restitución de tierras. }\end{array}$ & $\begin{array}{c}\text { Bloqueo con } \\
\text { violencia a } \\
\text { restitución material }\end{array}$ \\
\hline
\end{tabular}

\subsubsection{Caso No. 3. Predio Las Pavas}

$$
\text { Municipio: El Peñón }
$$

Departamento: Bolívar

\section{Extensión Predio: 3.000 hectáreas}

Fuentes: (Gómez et al. 2015);

(Verdad Abierta 2017)

En 1997 la finca es abandonada por su dueño (familiar de un narcotraficante), por lo que 123 familias sin tierra, se instalan en la finca y empiezan a cultivarla, se organizan en la Asociación de Campesinos de Buenos Aires (ASOCAB). Seis años después, en 2003 su dueño original, envía paramilitares para que saquen las familias del predio por la fuerza. En el año 2005 con la desmovilización de los paramilitares algunas familias deciden regresar y solicitan la extinción de dominio del predio por inexplotación por parte de su dueño. En 2006 el INCODER al verificar que las familias si explotaban las tierras, inicia proceso de extinción sobre 1.300 ha. En 2007, el dueño aparece nuevamente con paramilitares y desplaza de nuevo la población, además vende las $3 \mathrm{mil}$ hectáreas a dos empresas en partes iguales, C.I. Tequendama y Aportes San Isidro, esta última inicia cultivos de palma. 
Las familias que continúan asentadas en una parte de la hacienda son expulsadas por la policía por orden de la compañía palmera en 2009. Se presume que hay 1.700 ha de la finca que no tienen título, por lo que ASOCAB pide a INCODER un proceso de clarificación sobre estas tierras en 2010. Entre 2011 y 2012 el INCODER visita el predio y comprueba daños a los ecosistemas por el cultivo de palma y la Corte Constitucional le ordena adelantar el proceso de extinción de dominio a favor de las familias de ASOCAB, revocando finalmente los derechos de propiedad de las compañías sobre las 1.300 ha. Para el año 2013 ningún proceso se ha hecho realidad y las familias interpusieron una acción de tutela para que se realizara el proceso de extinción y clarificación, pero a 2017, después de ordenar la CC agilizar los procesos a la ANT, no se ha dado ningún fallo, las familias continúan siendo agredidas y amenazadas por la empresa palmera y esta continua con la explotación de las tierras.

\begin{tabular}{|c|c|c|}
\hline Período & Secuencia del proceso & $\begin{array}{c}\text { Etiqueta } \\
\text { (tipo de proceso) }\end{array}$ \\
\hline 1997 & $\begin{array}{l}\text { Abandono del predio por su dueño. Es ocupado } \\
\text { por } 123 \text { familias campesinas sin tierra, que } \\
\text { constituyen una asociación: Asociación de } \\
\text { Campesinos de Buenos Aires, ASOCAB. }\end{array}$ & $\begin{array}{l}\text { Ocupación } \\
\text { campesina }\end{array}$ \\
\hline 2003 & $\begin{array}{l}\text { El Bloque Central Bolívar de las AUC desplaza a } \\
\text { los campesinos por orden del dueño del predio. }\end{array}$ & $\begin{array}{c}\text { Violencia/Desplaza } \\
\text { miento }\end{array}$ \\
\hline 2005 & $\begin{array}{l}\text { Se desmovilizan los paramilitares y los } \\
\text { campesinos regresan, solicitan al INCODER la } \\
\text { extinción de dominio del predio por } \\
\text { inexplotación económica de las tierras por parte } \\
\text { del dueño. }\end{array}$ & Disputa legal \\
\hline 2006 & $\begin{array}{l}\text { El INCODER confirma que las familias trabajan } \\
\text { la tierra y acepta iniciar el proceso de extinción } \\
\text { de dominio sobre } 1.300 \text { ha. }\end{array}$ & \\
\hline 2007 & $\begin{array}{l}\text { Campesinos denuncian que el dueño apareció } \\
\text { con paramilitares los amenazó y algunos se } \\
\text { desplazaron de nuevo. El dueño vende todo el } \\
\text { predio en partes iguales a C.I. Tequendama y a } \\
\text { Aportes San Isidro, estos últimos inician la } \\
\text { siembra de palma. }\end{array}$ & $\begin{array}{l}\text { Venta irregular } \\
\text { Consolidación del } \\
\text { agronegocio }\end{array}$ \\
\hline $\begin{array}{l}2009- \\
2010\end{array}$ & $\begin{array}{l}\text { Los palmeros con apoyo de la policía desalojan } \\
\text { por la fuerza a los campesinos que se mantenían }\end{array}$ & Disputa legal \\
\hline
\end{tabular}


en las tierras, ASOCAB pide al INCODER que se

haga proceso de clarificación sobre 1.700 ha que

se presumen sin título y por tanto son tierras de

la nación.

\begin{tabular}{|c|c|c|}
\hline $\begin{array}{l}2011- \\
2012\end{array}$ & $\begin{array}{l}\text { INCODER y Ministerio de Ambiente } \\
\text { encontraron afectaciones a los ecosistemas por } \\
\text { cultivos de palma. La CC ordena al INCODER } \\
\text { reapertura del proceso de extinción de dominio a } \\
\text { favor de las familias de ASOCAB. El INCODER } \\
\text { revoca los derechos de propiedad a las } \\
\text { compañías sobre } 1.300 \text { ha. }\end{array}$ & Disputa legal \\
\hline 2013- & $\begin{array}{l}\text { Se interpone una tutela para que se realice el } \\
\text { proceso de extinción y clarificación, solicitado } \\
\text { años antes por los campesinos. }\end{array}$ & Disputa legal \\
\hline $\begin{array}{l}2015- \\
2017\end{array}$ & $\begin{array}{l}\text { Las familias siguen soportando agresiones y } \\
\text { amenazas de la compañía palmera que continúa } \\
\text { la explotación de la tierra. Los procesos de } \\
\text { clarificación de las } 1.700 \text { ha y la extinción de las } \\
1.300 \text { tampoco se ha hecho realidad a pesar de } \\
\text { ser exigido por la CC a la ANT. }\end{array}$ & $\begin{array}{l}\text { No ejecución de } \\
\text { procesos agrarios. }\end{array}$ \\
\hline
\end{tabular}

\subsubsection{Caso No. 4. Predio La Alemania.}

\begin{tabular}{ll}
\hline Municipio: San Onofre & Extensión: 558 hectáreas \\
\hline & Fuentes:(Grupo de Memoria \\
Departamento: Sucre & Histórica 2010); Verdad Abierta, \\
& 2010. \\
\hline
\end{tabular}

La finca pertenecía al INCODER y se entrega para usufructo a 52 familias desplazadas, quienes conforman una sociedad. En 1998 los paramilitares asesinan a un miembro de la comunidad y en los dos años siguientes cometen masacres lo cual hace que cerca del $80 \%$ de las familias se desplacen. Los paramilitares se apoderan de la finca y de todos los bienes que las familias tenían en ella y asesinan a más miembros de la comunidad. Entre 2005 y 2006 con el proceso de desmovilización paramilitar, las familias retornan a la finca, pero aún estaba un miembro de los paramilitares al mando de la finca, y sus bienes y cultivos habían sido destruidos. Para 2010 ya se contaban 12 asesinatos de personas relacionadas con la finca, impidiendo así que los 
campesinos pudiesen ejercer sus derechos al predio y tampoco se había abierto ninguna investigación por el desplazamiento y las víctimas del mismo. Los grupos herederos de los paramilitares aún hacían presencia en la zona, sin permitir el retorno de los campesinos.

\begin{tabular}{|c|c|c|}
\hline Período & Secuencia del proceso & $\begin{array}{c}\text { Etiqueta } \\
\text { (tipo de proceso) }\end{array}$ \\
\hline 1997 & $\begin{array}{l}\text { INCODER adjudica predio a } 52 \text { familias } \\
\text { desplazadas con } 70 \% \text { de financiación. }\end{array}$ & Titulación legal \\
\hline $\begin{array}{l}1998- \\
2000\end{array}$ & $\begin{array}{l}\text { Entran paramilitares, asesinan un miembro } \\
\text { de la comunidad, cometen masacres en la } \\
\text { zona se desplazan cerca del } 80 \% \text { de las } \\
\text { familias de la finca }\end{array}$ & Violencia/desplazamiento \\
\hline $\begin{array}{l}2001- \\
2005\end{array}$ & $\begin{array}{l}\text { Los paramilitares al mando de alias 'Cadena' } \\
\text { de las AUC se apoderan de la finca y los } \\
\text { bienes de las familias. Asesinan más } \\
\text { miembros de la comunidad. Después de la } \\
\text { desmovilización continúan con el control de } \\
\text { la finca }\end{array}$ & Apropiación Paramilitar \\
\hline 2006 & $\begin{array}{l}\text { Los campesinos denuncian el despojo de la } \\
\text { tierra y los asesinatos e inician un proceso de } \\
\text { retorno. Los paramilitares aún controlan la } \\
\text { región e impiden cualquier reclamación de } \\
\text { los campesinos por la finca. }\end{array}$ & Disputa legal \\
\hline $\begin{array}{l}2010- \\
2012\end{array}$ & $\begin{array}{l}\text { Asesinan a campesino que lideró el retorno a } \\
\text { la finca - completando } 15 \text { asesinatos desde } \\
1998 \text { de personas relacionadas con la finca. }\end{array}$ & \\
\hline 2013 & $\begin{array}{l}\text { Los grupos herederos de los paramilitares } \\
\text { continúan amenazando los líderes que tratan } \\
\text { de hacer posible el proceso de restitución de } \\
\text { las tierras. }\end{array}$ & $\begin{array}{l}\text { Bloqueo con violencia a } \\
\text { proceso de retorno }\end{array}$ \\
\hline
\end{tabular}

\subsubsection{Caso No. 5. Predio Parcela 4}

\begin{tabular}{ll}
\hline Municipio: El Carmen de Bolívar & Extensión Predio: 17 hectáreas \\
\hline & Fuentes: (González 2017);(Bargent \\
Departamento: Bolívar & 2012); (Tribunal civil de Cúcuta 2016); \\
& (Verdad Abierta 2016a).
\end{tabular}


Esta parcela forma parte de 10 más que tituló el INCORA a campesinos en 1996 en el municipio del Carmen de Bolívar. Con la escalada de la violencia en el año 2000, el dueño de la parcela 4 se desplaza con su familia a Sincelejo, abandonando el predio. El CMAIPD del Carmen de Bolívar en 2004 declaró la zona en estado desplazamiento forzado por lo cual ningún predio podía venderse. Cuatro años después aparecen comisionistas (en este caso un ex congresista) buscando a los campesinos para comprarles las tierras a bajo precio con la advertencia que no podían regresar debido a la violencia. El dueño de la parcela 4 dice que le ofrecieron 23 millones de pesos y terminó recibiendo solo 14, esta transacción no queda registrada en la matrícula inmobiliaria del predio.

En 2010 aparece una compra registrada de la parcela 4 por 64 millones, el dueño afirma que no conoce a la compradora, pues él para vender la parcela, firmó un poder de compra venta a un miembro del CMAIPD porque no sabe leer ni escribir. El predio aparece transferido por esta nueva dueña al fideicomiso a nombre de Cementos Argos. Esta empresa compró 6.600 ha en la zona, incluyendo la parcela 4 para un proyecto forestal de teca. En 2012 el dueño de la parcela 4 solicita a la URT la restitución de su parcela. Cementos Argos alega que actuó de buena fe y con la intención de ayudar a la población que había padecido el conflicto, en concordancia con la llamada del gobierno a invertir en la región que ya se consideraba en estado de posconflicto. Después de múltiples disputas entre los reclamantes, Argos y el Estado, la URT demuestra que las compras de Argos, aunque fueron de buena fe, no estaban exentas de culpa ${ }^{63}$ y ordena la restitución de las tierras a los campesinos.

\begin{tabular}{llc}
\hline Período & \multicolumn{1}{c}{ Secuencia del proceso } & $\begin{array}{c}\text { Etiqueta } \\
\text { (tipo de proceso) }\end{array}$ \\
\hline 1996 & $\begin{array}{l}\text { Adjudicación por el INCORA en proceso } \\
\text { de reforma agraria }\end{array}$ & Titulación legal \\
\hline 2000 & $\begin{array}{l}\text { Abandono del predio por el propietario } \\
\text { por masacres y violencia en la zona }\end{array}$ & Violencia/desplazamiento \\
\hline
\end{tabular}

\footnotetext{
${ }^{63}$ Es culpable porque las tierras están en zona de violencia y de buena fue porque no se comprobó que la empresa tuviese vínculos con grupos paramilitares, pero varios de los directivos han sido investigados por nexos con paramilitares y uno de los directivos de su empresa subsidiaria, Reforestadora del Caribe, fue un jefe paramilitar (González, 2015; Bargent 2012)
} 


\begin{tabular}{|c|c|c|}
\hline 2004 & $\begin{array}{l}\text { El CMAIPD declaró la zona en estado de } \\
\text { desplazamiento forzado con la } \\
\text { prohibición de comercializar los predios. }\end{array}$ & \\
\hline 2008 & $\begin{array}{l}\text { Los campesinos son contactados por un } \\
\text { comisionista (ex congresista) que les } \\
\text { compró las tierras. Esta operación no } \\
\text { aparece en el folio de la matrícula de la } \\
\text { Parcela } 4 .\end{array}$ & Venta irregular \\
\hline 2010 & $\begin{array}{l}\text { El predio aparece comprado por } 64 \\
\text { millones de pesos. El dueño declara que él } \\
\text { firmó un poder de compraventa a un } \\
\text { miembro del CMAIPD para que hiciera la } \\
\text { venta, pues él no sabe leer ni escribir. } \\
\text { La nueva compradora transfiere el predio } \\
\text { al fideicomiso de Cementos Argos, que } \\
\text { implementa un proyecto forestal (teca) de } \\
6.600 \text { hectáreas, incluyendo la Parcela } 4 .\end{array}$ & $\begin{array}{l}\text { Titulación ilegal } \\
\text { Contrato fiduciario } \\
\text { Consolidación } \\
\text { agronegocio }\end{array}$ \\
\hline 2012 & $\begin{array}{l}\text { El campesino adjudicatario de la parcela } \\
\text { solicita su restitución a la URT. }\end{array}$ & Solicitud Restitución \\
\hline 2016 & $\begin{array}{l}\text { La Unidad de Restitución de Tierras } \\
\text { ordena la restitución de la parcela } 4 \text { a su } \\
\text { original propietario. }\end{array}$ & Restitución \\
\hline
\end{tabular}

\subsubsection{Caso No. 6. Predio Finca La Bellacruz}

Municipio: La Gloria, Tamalameque Extensión: 9.000 hectáreas

y Pelaya

Departamento: Cesar

Fuentes: (Verdad Abierta 2011);

(Uribe \& Rodríguez 2016); (CC

2016b)

Entre las décadas de los años treinta y cuarenta, Alberto Marulanda adquiere 6.000 ha de tierra y mediante medidas violentas y trampas jurídicas (falsos traspasos y escrituras, apropiación de baldíos) logra concentrar hasta 25 mil hectáreas, donde establece ganado. Fue el primer presidente de la Federación de Ganaderos de Colombia (FEDEGAN). En 1970 el INCORA adjudica a los campesinos 9.000 de esas hectáreas. Hasta los años ochenta la finca fue escenario de varios episodios donde las familias sin tierra buscaban 
establecerse en los terrenos baldíos de la hacienda y los Marulanda con ayuda de policía y ejército los expulsaban. Los Marulanda establecieron un frigorífico denominado La Gloria. Un grupo de familias expulsadas se congregaron a un lado de la hacienda y conformaron el municipio de Pelaya, se organizaron en un sindicato agrario para reclamar los terrenos baldíos de la hacienda en 1983.

Entre 1986 y 1989 los campesinos piden al INCORA que les adjudique las tierras baldías de la hacienda que son 1.500 ha, para frenar el proceso los Marulanda piden que se declaren 445 ha como Zona de Reserva Forestal (ZRF) y con esta medida expulsar las familias que se encontraban asentadas allí, ofrecen además vender 2.060 ha al INCORA, para evitar entregar las 1.500 ha de tierras baldías, por ser estas de mejor calidad.

Entre 1991-1995 El INCORA corrobora que hay 1.500 ha de baldíos, pero no hace nada para delimitarlos ni para adjudicarlos a los campesinos reclamantes, en su lugar el INCORA compra las 2.060 ha y las adjudica en gran parte a trabajadores de los Marulanda. En 1996 llegan los paramilitares justo cuando van a entregar los títulos de las adjudicaciones, entran ultrajan y desplazan 170 familias y se instalan en la hacienda en los predios comprados por el INCORA, permanecen allí cometiendo crímenes hasta 2005 ${ }^{64}$. Algunas familias se organizan y van a hacer presión a Bogotá para que les devuelvan las tierras, el gobierno se compromete a dar títulos y garantizar el retorno. Al retornar, los paramilitares asesinan a siete líderes campesinos. Nuevamente regresan a Bogotá y el gobierno les propone reubicarlos en otras tierras (en el Departamento del Tolima), no todos aceptan y continúan con la reclamación de predios baldíos. En 1997 los Marulanda fraccionan la hacienda en siete predios, incluyendo los terrenos baldíos y cambian su delimitación, quedando 5.833 ha. Díez años después, en 2007 engloban los siete predios, con un proceso de blanqueo jurídico, catastral, cartográfico, registral y notarial para ocultar y hacer desaparecer los siete predios que se habían declarado desde 1994 tierras del estado (CC 2016b, 16:32).

Para el 2008 los Marulanda venden su empresa denominada Sociedad MR de Inversiones SA, incluida la hacienda, ahora llamada La Gloria, a una empresa

\footnotetext{
${ }^{64}$ En este año, Francisco Marulanda va a prisión acusado de violencia paramilitar pero es absuelto. Paramilitares y campesinos afirmaron que Francisco Marulanda los había contratado para montar una base de las AUC en la finca Bellacruz (Uribe \& Rodríguez 2016); Verdad Abierta 2013)
} 
creada en Panamá denominada Grupo Industrial La Gloria SA (antes llamada La Dolce Vista Estate Inc, Sucursal Colombia). En 2010 suscriben un fideicomiso denominado La Dolce Vista ${ }^{65}$. Así siembran 5.000 ha de palma. Para el año 2010 ya cuentan con zona franca, mientras que 64 familias se organizan en la Asociación Colombiana Horizonte de Población Desplazada (ASOCOL) e inician otra vez el proceso para reclamar el derecho a las tierras baldías. La disputa de ASOCOL por las tierras ante el Estado, durante los últimos 7 años transcurre entre amenazas e intimidaciones hasta que la CC ordena la recuperación correcta de los baldíos a la ANT en 2016 y así agilizar el proceso de restitución a las familias. Finalmente, ASOCOL presiona para que la ANT realice la titulación, pero lo que se acuerda en 2017, es que unas familias trabajarán en las plantaciones de palma y a otros se les comprarán unos predios en otro lugar, los cuales se pagarán con los excedentes del proyecto agroindustrial. Los baldíos dentro de la hacienda los administrarán las empresas, es decir la Dolce Vista.

\begin{tabular}{|c|c|c|}
\hline Período & Secuencia del proceso & $\begin{array}{c}\text { Etiqueta } \\
\text { (tipo de proceso) }\end{array}$ \\
\hline $\begin{array}{l}1935- \\
1946\end{array}$ & $\begin{array}{l}\text { Terrateniente compra de } 6.000 \text { ha de tierra y logra } \\
\text { concentración hasta } 25.000 \text { ha (mediante despojo y } \\
\text { medidas violentas y jurídicas) y establece ganado. }\end{array}$ & Titulación ilegal \\
\hline 1970 & $\begin{array}{l}\text { El INCORA devuelve a los campesinos } 9.000 \text { ha de } \\
\text { la hacienda parceladas y adjudicadas }\end{array}$ & Titulación Legal \\
\hline $\begin{array}{l}1974- \\
1982\end{array}$ & $\begin{array}{l}\text { Toma baldíos por familias campesinas. Expulsión } \\
\text { violenta con fuerza pública. Consolidan la empresa } \\
\text { ganadera }\end{array}$ & $\begin{array}{c}\text { Ocupación } \\
\text { campesina } \\
\text { Desalojos con } \\
\text { violencia }\end{array}$ \\
\hline 1983 & $\begin{array}{l}\text { Familias expulsadas conforman sindicato agrario } \\
\text { para reclamar las tierras baldías. }\end{array}$ & \\
\hline \multirow[t]{2}{*}{$\begin{array}{l}1986- \\
1989\end{array}$} & $\begin{array}{l}\text { Campesinos ocupan los baldíos y piden al INCORA } \\
\text { su titulación, son desalojados de nuevo por la } \\
\text { fuerza pública. Se declaran } 445 \text { ha como ZRF. }\end{array}$ & $\begin{array}{l}\text { Ocupación } \\
\text { campesina }\end{array}$ \\
\hline & & Disputa legal \\
\hline $\begin{array}{l}1990- \\
1994\end{array}$ & $\begin{array}{l}\text { El INCORA inicia proceso de clarificación, ratifica } \\
\text { la existencia de } 1.500 \text { ha de baldíos. No delimita ni }\end{array}$ & $\begin{array}{l}\text { No ejecución de } \\
\text { procesos agrarios }\end{array}$ \\
\hline
\end{tabular}

\footnotetext{
${ }^{65}$ Esta empresa está integrada por el empresario más grande de palma en el país y miembro honorario de Fedepalma, por el Fondo Elliot y por Efremovich el mayor accionista de la aerolínea Avianca, también forma parte del grupo Sinergy de Brasil.
} 
titula a los campesinos reclamantes.

Los Marulanda ofrecen vender 2.060 ha al INCORA.

Compra de las 2.060 ha a los Marulanda y

adjudicación.

Titulación ilegal

En 1996 incursión paramilitar, desplazan familias y

1995- se toman la hacienda hasta 2005.

1996 Familias desplazadas exigen solución al gobierno.

Violencia/desplaza miento

Retornan y asesinan 7 líderes, se repite el desplazamiento.

Apropiación

Reubicación de algunas familias en otra zona.

paramilitar.

1997 Fraccionamiento en 7 predios la hacienda, cambiando la delimitación a 5.833 ha.

Fraccionamiento

Englobe de los 7 predios para unificar de nuevo la

2007 hacienda cambiando matrícula inmobiliaria e incluyendo los predios baldíos.

Englobe

Venden la hacienda a empresa formada en Panamá.

En 2010 suscribe

Contrato Fiduciario

2008- n contrato de Fideicomiso denominado Dolce Vista.

2010 Siembran 5.000 ha de palma y crean zona franca.

Campesinos forman ASOCOL y tramitan la

Consolidación del

devolución de las tierras baldías.

agronegocio.

ASOCOL interpone una tutela para solicitar de nuevo adjudicación de baldíos

Disputa legal

INCODER declara indebida ocupación de baldíos

por las compañías en 5 de los 7 predios que se

2013 presumían baldíos. La decisión fue demandada ante Disputa legal

el Consejo de Estado por las empresas y la

Fiduciaria.

La CC falla la tutela interpuesta en 2011 a favor de

2016 ASOCOL. Exige a la URT acelerar restitución Disputa legal solicitada por las 52 familias.

ASOCOL interpone otra tutela a la ANT por no

Alianza

2017 adelantar el trámite de titulación.

campesinos/

Acuerdo entre campesinos, ANT y compañía.

empresarios/estado 


\subsubsection{Caso No. 7. Predio Hato Cabiona (Caserío el Porvenir)}

\begin{tabular}{ll}
\hline Municipio: Puerto Gaitán & Extensión: $27.000^{66}$ hectáreas \\
\hline \multirow{2}{*}{ Departamento: Meta } & Fuentes: (Verdad Abierta 2016b)(Rodríguez \\
& 2014), (CC 2016a), (El Espectador 2016) \\
\hline
\end{tabular}

La zona es inicialmente colonizada por campesinos del centro del país. Un ganadero se apropia de 27 mil hectáreas de tierras baldías, instala ganado y deja que se aproveche de forma comunal por otros colonos que llegaron a la región escapando de la violencia de los años 1950s. A su muerte (1979), su viuda vende las tierras (sin títulos legales) a un comerciante de esmeraldas. En los años ochenta llegan paramilitares (Los Carranceros), asesinan a campesinos y se instalan en el Hato. En 1992 el predio es titulado por el INCORA a 27 campesinos procedentes de otra región, relacionados con el esmeraldero Víctor Carranza. Los paramilitares permanecen en la región cometiendo crímenes y desplazando población (colonos e indígenas).

Para el año 2007, se inician transacciones con las tierras englobando la propiedad en 5 haciendas que pasan a 5 nuevos dueños (también relacionados con la familia Carranza). Esto se hace con poderes de compraventa falsos firmados por los 27 adjudicatarios del INCORA (tres de ellos muertos antes de 2007). En 2012 es denunciado en el Congreso el englobe de las 27 mil hectáreas y la adjudicación ilegal. Dos años después se revocan las titulaciones y el englobe, se pide que las tierras sean devueltas al estado, lo que ocurre en 2015. Las familias colonas, interponen una tutela ante la Corte Constitucional pidiendo que les reconozca sus derechos a las tierras habitadas por ellos durante más de 40 años. El Presidente de la República propone implementar un proyecto con empresarios, tipo ZIDRES, pero la CC falla a favor de los campesinos. Sin embargo, para el año 2017 la tierra aún no se titula y permanece en manos del estado.

\footnotetext{
${ }^{66}$ Rodríguez (2014) y Verdad Abierta (2013) Afirman que Víctor Machado se apropió de 25 mil hectáreas, sin embargo en la Sentencia de la Corte Constitucional, SU426 de 2016 se menciona que desde el inicio este colono apropió 27 mil hectáreas, por lo cual se trabaja con el dato de la CC.
} 


\begin{tabular}{|c|c|c|}
\hline Periodo & Secuencia del proceso & $\begin{array}{c}\text { Etiqueta } \\
\text { (tipo de proceso) }\end{array}$ \\
\hline $\begin{array}{l}1930- \\
1980\end{array}$ & $\begin{array}{l}\text { Colonización inicial por campesinos que } \\
\text { huían de la violencia. Un ganadero hace } \\
\text { suyas } 27 \text { mil ha de baldíos. El predio se } \\
\text { vende sin títulos. }\end{array}$ & $\begin{array}{l}\text { Ocupación campesina } \\
\text { Venta informal }\end{array}$ \\
\hline 1986 & Llegada y toma por paramilitares. & Violencia/desplazamiento \\
\hline 1992 & $\begin{array}{l}\text { Adjudicación por INCORA a } 27 \\
\text { campesinos que no son de la región. }\end{array}$ & Titulación ilegal \\
\hline 2007 & $\begin{array}{l}\text { Englobe de predios y concentración de la } \\
\text { tierra en } 5 \text { dueños }\end{array}$ & Englobe \\
\hline 2012 & $\begin{array}{l}\text { Denuncia de englobe y falsas } \\
\text { adjudicaciones por congresista y } \\
\text { organizaciones de Derechos Humanos. }\end{array}$ & Disputa legal \\
\hline 2014 & $\begin{array}{l}\text { Revocación de titulaciones y del englobe, } \\
\text { se pide devolución de las tierras al estado. }\end{array}$ & Disputa legal \\
\hline 2015 & $\begin{array}{l}\text { Los predios regresan al INCODER, al } \\
\text { dominio del estado. Los campesinos } \\
\text { interponen tutela ante la CC, exigiendo su } \\
\text { derecho a la tierra. }\end{array}$ & Apropiación por el estado \\
\hline 2016 & $\begin{array}{l}\text { El Presidente propone implementar un } \\
\text { proyecto productivo con empresarios. La } \\
\text { CC falla a favor de las familias campesinas } \\
\text { y solicita a la ANT adelantar la titulación a } \\
\text { los campesinos. }\end{array}$ & Disputa legal \\
\hline 2017 & La ANT aún no acata órdenes de la CC. & $\begin{array}{l}\text { Apropiación por el } \\
\text { estado. }\end{array}$ \\
\hline
\end{tabular}

\subsubsection{Caso No. 8. Predio El Brasil}

\begin{tabular}{ll}
\hline Municipio: Puerto Gaitán & Extensión: 16.000 hectáreas \\
\hline \multirow{2}{*}{ Departamento: Meta } & Fuentes:(Rodríguez 2014); (Verdad \\
& Abierta 2013b) \\
\hline
\end{tabular}

Sus habitantes originales han sido los indígenas Sikuani o Guahíbos, desplazados por colonos desde la época de la violencia. En la década de los años ochenta, el INCORA divide una gran hacienda y la adjudica a 16 campesinos. El grupo paramilitar 'Los Carranceros' llegan desde 1983. Los 
paramilitares hacen del Brasil su centro de operaciones para entrenamiento, asesinatos, torturas y fosas comunes en 1994. Allí reciben y se integran a las AUC, que vienen de Urabá de la Casa Castaño a cometer la masacre de Mapiripán y permanecen en el predio hasta 2005 cuando se desmovilizan. En 2007 inician los cambios en la propiedad del predio.

Se crea la empresa Agualinda de propiedad de la familia Carranza, cuyo capital son los 16 predios que un abogado con un poder de compraventa firmado por los 16 campesinos, entrega a la constitución de la empresa. Agualinda engloba los predios con el nombre de El Brasil y firma un contrato de compraventa con 10 empresas. Estas empresas crearon un encargo fiduciario con un banco para que comprara El Brasil y lo administrara. Bajo este fideicomiso se firma un contrato de comodato con el grupo empresarial Aliar (creador de las 10 empresas), para la explotación del predio, así Aliar no aparece como propietario de la tierra sino como un comodatario.

En 2012 se denunció en el congreso al grupo Aliar por acumulación ilegal de baldíos, en 2013 el INCODER y la Contraloría General de la República (CGR) confirman la acumulación ilegal de Unidades Agrícolas Familiares (UAF). No hay ninguna acción judicial para que Aliar devuelva las tierras al estado. Al contrario, explotan las tierras cultivadas con maíz y soja y han desarrollado la agroindustria denominada La Fazenda.

\begin{tabular}{|c|c|c|}
\hline Periodo & Secuencia del proceso & $\begin{array}{c}\text { Etiqueta } \\
\text { (tipo de proceso) }\end{array}$ \\
\hline $\begin{array}{l}1980- \\
1990\end{array}$ & $\begin{array}{l}\text { Parcelación y adjudicación por el INCORA a } 16 \\
\text { campesinos. Llegada de los paramilitares llamados } \\
\text { “Los Carranceros”. }\end{array}$ & Titulación ilegal \\
\hline 1994 & $\begin{array}{l}\text { Los paramilitares (Carranceros) establecer su base } \\
\text { de operaciones y crímenes }\end{array}$ & $\begin{array}{l}\text { Apropiación } \\
\text { paramilitar }\end{array}$ \\
\hline $\begin{array}{l}1997- \\
2005\end{array}$ & $\begin{array}{l}\text { Llegan los paramilitares de las AUC, el Brasil se } \\
\text { convierte en el lugar de entrenamiento de los dos } \\
\text { grupos paramilitares hasta } 2005 .\end{array}$ & $\begin{array}{l}\text { Apropiación } \\
\text { paramilitar }\end{array}$ \\
\hline 2007 & $\begin{array}{l}\text { Transferencia de los predios a la empresa } \\
\text { Agualinda Englobe de los } 16 \text { predios para traspaso } \\
\text { a } 10 \text { empresas Creación de fiducia entre un banco y } \\
\text { Agualinda, las tierras se explotan bajo la figura de } \\
\text { comodato y arriendo. }\end{array}$ & $\begin{array}{c}\text { Venta irregular } \\
\text { Englobe } \\
\text { Fraccionamiento } \\
\text { Contrato Fiduciario }\end{array}$ \\
\hline 2013 & $\begin{array}{l}\text { INCODER y CGR denuncian acumulación indebida } \\
\text { de UAF por el Grupo Aliar. }\end{array}$ & Disputa legal \\
\hline
\end{tabular}


No hay ninguna acción judicial para la devolución

Consolidación del

de los predios al estado. agronegocio

\subsubsection{Caso No. 9. Predio Macondo}

\begin{tabular}{ll}
\hline Municipio: Mapiripán & Extensión predio: $5.577^{67}$ hectáreas \\
\hline \multirow{2}{*}{ Departamento: Meta } & Fuentes: (Verdad Abierta 2013a), (El \\
& Espectador 2017b) \\
\hline
\end{tabular}

En los años setenta un ganadero compra mejoras a colonos sobre un predio de 5.577 hectáreas (compra informal). En los años de 1980 llegan las FARC a la región. El INCORA hace titulaciones y el ganadero subdivide (en tres) el predio llamado Macondo, entre él y su mayordomo, para evitar acumulación ilegal de baldíos. Con la masacre de Mapiripán en 1997 por las AUC, la población se desplaza, entre ellos el ganadero que abandona 'Macondo'. En 1999 una mujer adquiere los 3 predios. La violencia continúa y en 2007 la Defensoría del Pueblo y el CMAIPD emiten orden de protección sobre los predios del municipio, donde 70 mil hectáreas se reportan abandonadas para ese año a causa de la violencia. En el año 2008 la multinacional Poligrow compra los predios Macondo, para lo cual la alcaldesa levanta la medida de protección y permite la venta. El dueño original dice que él nunca vendió a nadie. La empresa siembra palma de aceite desde 2009 y para 2015 ya tenía 8 predios más de su propiedad. El INCODER y CGR en 2013 denuncia la falsa titulación, irregularidades en traspaso de los predios y la acumulación ilegal de UAF. Entre 2015 y 2017 Poligrow es denunciada e investigada por irregularidades en la adquisición de predios, en la conformación de la empresa y por afectaciones a los trabajadores y al medio ambiente en Mapiripán, pero es absuelta de los cargos.

\begin{tabular}{llc}
\hline Período & Secuencia del proceso & $\begin{array}{c}\text { Etiqueta } \\
\text { (tipo de proceso) }\end{array}$ \\
\hline 1970 s & $\begin{array}{l}\text { Ganadero compra a colonos 5.577 ha (baldíos } \\
\text { ocupados) }\end{array}$ & $\begin{array}{l}\text { Ocupación } \\
\text { campesina }\end{array}$ \\
\hline
\end{tabular}

\footnotetext{
${ }^{67}$ El Informe de la CGR de 2014 registra 5.577 ha, mientras que Rodríguez (2013) y Verdad Abierta reporten 5.500 ha. Se decide trabajar con las cifras de documentos oficiales.
} 


\begin{tabular}{|c|c|c|}
\hline & & Venta irregular \\
\hline \multirow{2}{*}{$1980 s$} & Subdivisión del predio y titulación por el & Fraccionamiento \\
\hline & INCORA & Titulación ilegal \\
\hline 1997 & $\begin{array}{l}\text { Masacre de Mapiripán, el dueño abandona el } \\
\text { predio }\end{array}$ & $\begin{array}{c}\text { Violencia/desplaza } \\
\text { miento }\end{array}$ \\
\hline 1999 & Una mujer adquiere los predios & \multirow[t]{2}{*}{ Venta irregular } \\
\hline 2007 & $\begin{array}{l}\text { La Defensoría y CMAIPD de Mapiripán emiten } \\
\text { órdenes de protección de los predios del } \\
\text { municipio. }\end{array}$ & \\
\hline 2008 & $\begin{array}{l}\text { Poligrow Colombia LTDA compra los predios } \\
\text { Macondo, con la medida de protección vigente }\end{array}$ & Venta irregular \\
\hline $\begin{array}{l}2009- \\
2012\end{array}$ & $\begin{array}{l}\text { Poligrow siembra palma en el predio, crea otras } 3 \\
\text { empresas en Colombia, monta su propia planta } \\
\text { extractora de aceite. }\end{array}$ & $\begin{array}{l}\text { Consolidación } \\
\text { agronegocio }\end{array}$ \\
\hline 2013 & $\begin{array}{l}\text { INCODER y CGR denuncian a Poligrow por } \\
\text { acumulación ilegal de UAF, falsa tradición e } \\
\text { irregularidades en los traspasos de los predios }\end{array}$ & Disputa legal \\
\hline 2015- & $\begin{array}{l}\text { Somo \& Indepaz publican irregularidades en la } \\
\text { adquisición de predios, en la conformación de las } \\
\text { empresas de Poligrow y reporta afectaciones a los } \\
\text { trabajadores y al medio ambiente. }\end{array}$ & \\
\hline 2017 & $\begin{array}{l}\text { Poligrow es denunciada por fraude para adquirir } \\
\text { tierras en Mapiripán, pero fue absuelto en agosto } \\
\text { de } 2017 \text {. Continúa actividades contaminantes sin } \\
\text { ninguna acción del estado. }\end{array}$ & Disputa Legal \\
\hline
\end{tabular}

\subsubsection{Caso No. 10. Predio El Secreto}

\begin{tabular}{ll}
\hline Municipio: Mapiripán & Extensión: 4.656 hectáreas \\
\hline Departamento: Meta & Fuentes: (Verdad Abierta 2012a) \\
& (CGR 2014a) \\
\hline
\end{tabular}

En 1997 con la violencia paramilitar y la masacre en Mapiripán se desplazan miles de colonos que venían ocupando baldíos y cultivándolos por años sin tenencia formal. En 2006 el INCODER adjudica 4.656 ha repartidas en tres predios. En 2007 las tres personas venden los predios a Agropecuaria Villa Diana (creada por un empresario del Cesar). En 2008 se dictan las medidas de 
aseguramiento sobre los predios de Mapiripán, pero estos ya habían sido transferidos. Aparece la evidencia del levantamiento de las medidas de aseguramiento de los predios a favor de Agropecuaria Villa Diana. En sus declaraciones el paramilitar Daniel Rendón Herrera alias 'Don Mario', confesó que los predios de El Secreto formaban parte de 12 mil hectáreas de las que ellos se habían apropiado para sembrar palma y que para obtener los títulos del INCODER habían utilizado testaferros y habían creado una cooperativa. También declara que uno de los predios de El Secreto se ofreció para resarcir a las víctimas en el proceso de Justicia y Paz. El predio está en el Fondo para la Reparación de Víctimas (FRV)

\begin{tabular}{llc}
\hline Período & \multicolumn{1}{c}{ Secuencia del proceso } \\
\hline 1997 & $\begin{array}{l}\text { Desplazamiento de la población de Mapiripán por } \\
\text { violencia paramilitar }\end{array}$ & $\begin{array}{c}\text { Etiqueta } \\
\text { (tipo de proceso) }\end{array}$ \\
\hline 2006 & $\begin{array}{l}\text { Los 3 predios se adjudicaron } \\
\text { personas particulares. }\end{array}$ & $\begin{array}{c}\text { Campesina } \\
\text { Violencia/desplaza } \\
\text { miento }\end{array}$ \\
\hline 2007 & $\begin{array}{l}\text { Las tres personas traspasan los predios a } \\
\text { Agropecuaria Villa Diana. }\end{array}$ & Titulación ilegal \\
\hline 2008 & $\begin{array}{l}\text { Defensoría del Pueblo y CMAIPD realizan medidas } \\
\text { cautelares sobre cerca del 80\% de las tierras del } \\
\text { municipio por riesgo de desplazamiento. }\end{array}$ & Venta irregular \\
\hline 2010 & $\begin{array}{l}\text { La alcaldesa de Mapiripán, unilateralmente levanta } \\
\text { medidas cautelares sobre los predios a favor de la } \\
\text { Agropecuaria Villa Diana. }\end{array}$ & $\begin{array}{l}\text { Declaración de paramilitar desvela que la titulación } \\
\text { de los predios por el INCODER se hizo por medio } \\
\text { de sus testaferros. }\end{array}$ \\
\hline $2012-$ & $\begin{array}{l}\text { Uso de un predio por FNRV para proyectos } \\
\text { productivos }\end{array}$ & Titulación ilegal \\
\hline
\end{tabular}

7.1.11. Caso No. 11. Predio El Agrado

\begin{tabular}{ll}
\hline Municipio: Mapiripán & Extensión: 4.300 hectáreas \\
\hline Departamento: Meta & Fuentes: (Verdad Abierta 2012a), \\
& (URT 2017)
\end{tabular}


Varios predios quedan abandonados con la masacre de Mapiripán en 1997 y son apropiados por los paramilitares. En 2002, para legalizar la tenencia de los predios, el jefe del Bloque Centauro de las AUC, contrata un testaferro para que a través de la creación de una cooperativa (Coopalmallano), obtenga la titulación de los predios apropiados. Entre 2007 y 2008 el INCODER titula tres predios a tres testaferros, empleados de Coopalmallano. El paramilitar alias 'Don Mario' declara que entrego uno de los predios al proceso de Justicia y Paz para resarcir a las víctimas. En 2013 aparece una hermana de los testaferros solicitando la restitución del predio el Agrado III a la URT, alegando que su hermano desapareció en 2008 y en consecuencia el predio le pertenecía a ella. La URT procesa la solicitud de restitución y comprueba que el titular fue un testaferro, por lo cual ella no tiene derecho al predio y este queda embargado a la Unidad de Víctimas.

\begin{tabular}{|c|c|c|}
\hline Periodo & Secuencia del proceso & $\begin{array}{c}\text { Etiqueta } \\
\text { (tipo de proceso) }\end{array}$ \\
\hline 1997 & $\begin{array}{l}\text { Desplazamiento por violencia paramilitar, los } \\
\text { campesinos abandonan sus tierras. }\end{array}$ & $\begin{array}{c}\text { Ocupación } \\
\text { campesina } \\
\text { Violencia/desplaza } \\
\text { miento }\end{array}$ \\
\hline 2002 & $\begin{array}{l}\text { Jefe paramilitar contrata un testaferro para } \\
\text { legalizar la propiedad ante el INCODER, para lo } \\
\text { cual crea la cooperativa Copalmallano. }\end{array}$ & $\begin{array}{l}\text { Apropiación por } \\
\text { paramilitares }\end{array}$ \\
\hline $\begin{array}{l}2007- \\
2008\end{array}$ & $\begin{array}{l}\text { INCODER titula los tres predios a tres testaferros } \\
\text { relacionados (trabajadores de Copalmallano). }\end{array}$ & Titulación Ilegal \\
\hline 2008 & $\begin{array}{l}\text { El CMAIPD de Maripirán emite protección de los } \\
\text { predios del municipio por riesgo de } \\
\text { desplazamiento. }\end{array}$ & \\
\hline $\begin{array}{l}2009 \quad y \\
2011\end{array}$ & $\begin{array}{l}\text { El jefe paramilitar Don Mario en sus confesiones } \\
\text { dice que este predio lo entregó al proceso de } \\
\text { Justicia y Paz para resarcir a las víctimas }\end{array}$ & \\
\hline 2013 & $\begin{array}{l}\text { La hermana de uno de los testaferros solicita la } \\
\text { restitución del predio el Agrado III a la URT, } \\
\text { alegando que su hermano desapareció desde } \\
2008 \text { y el predio le pertenecía a ella. }\end{array}$ & \\
\hline 2017 & $\begin{array}{l}\text { La Unidad de Restitución de Tierras niega la } \\
\text { solicitud, el predio queda en la Unidad de } \\
\text { Víctimas. }\end{array}$ & $\begin{array}{l}\text { Apropiación por el } \\
\text { estado }\end{array}$ \\
\hline
\end{tabular}




\subsubsection{Caso No. 12. Predio Madreselva}

\begin{tabular}{ll}
\hline Municipio: Mapiripán & Extensión: 4.000 hectáreas \\
\hline Departamento: Meta & Fuentes: Verdad Abierta 2012a \\
\hline
\end{tabular}

El predio se adjudica a campesinos para el cultivo de alimentos. Cuando entran los paramilitares de las AUC en 1997 al municipio, se apropian del predio sin título alguno y siembran palma de aceite. Entre 2009 y 2011 en las confesiones del jefe paramilitar alias 'Don Mario' declara que este predio forma parte de las 12 mil hectáreas apropiadas que habían destinado al cultivo de palma, planeadas para que una vez desmovilizados, pudiesen emplear a sus hombres allí en el cultivo de palma y seguir controlando las tierras. Después de la desmovilización el predio pasa a manos de testaferros de los paramilitares y posteriormente son entregadas al Fondo para la Reparación de Víctimas.

\begin{tabular}{llc}
\hline Periodo & \multicolumn{1}{c}{ Secuencia del proceso } & \multicolumn{1}{c}{$\begin{array}{c}\text { Etiqueta } \\
\text { (tipo de proceso) }\end{array}$} \\
\hline 1996 & Adjudicado a campesinos & Titulación legal \\
\hline 1997 & $\begin{array}{l}\text { Violencia y desplazamiento por incursión de } \\
\text { las AUC }\end{array}$ & Violencia/desplazamiento \\
\hline $2001-$ & $\begin{array}{l}\text { Los paramilitares toman posesión del predio } \\
\text { sin título alguno y establecen cultivos de }\end{array}$ & $\begin{array}{c}\text { Apropiación paramilitar } \\
\text { Consolidación agronegocio }\end{array}$ \\
\hline 2005 & palma & \\
\hline & $\begin{array}{l}\text { En declaraciones del jefe paramilitar de las } \\
\text { AUC, se conoce que los predios se los } \\
\text { apropiaron ellos para sembrar palma. Y los } \\
\text { entregaron al Fondo para la Reparación de } \\
\text { las Víctimas (FRV) para establecer proyecto } \\
\text { productivo para desmovilizados. }\end{array}$ & Apropiación por el estado \\
& & \\
\hline
\end{tabular}

\subsection{La categorización de las estrategias de despojo y acaparamiento}

Tal como se explicaba anteriormente, a lo largo de la exposición y sistematización de los estudios de caso, hemos ido 'etiquetando' los 
acontecimientos y procesos que se han documentado para cada uno de ellos. Muchas de estas etiquetas corresponden a estrategias en las que se han materializado el despojo y el acaparamiento de tierras. Esta tipificación constituye una aportación original de esta investigación y podría ser utilizada en otros estudios similares, facilitando la comparación de resultados. A continuación, se detallan estas etiquetas y se explica qué hemos considerado dentro de cada una de ellas.

- Alianzas entre campesinos y empresarios: articulación mediante la aportación de la tierra o mano de obra por el pequeño productor al empresario en los cultivos agroindustriales.

- Alianzas para despojar: acuerdos establecidos entre terratenientes, empresarios y grupos paramilitares para despojar la tierra. Incluye también la participación de funcionarios públicos en la facilitación de transacciones ilegales de las tierras.

- Apropiación paramilitar: Toma por los paramilitares del predio para convertirlo en base de sus operaciones criminales. También cuando los han despojado a la fuerza y establecen actividades productivas.

- Apropiación por parte del estado: se presenta cuando el estado recupera tierras por medio de procesos agrarios y las mantiene sin adjudicar.

- Bloqueo con violencia a restitución material: se presenta cuando los grupos armados continúan ejerciendo la violencia en las zonas de los predios restituidos, impidiendo que su propietario tome posesión nuevamente del predio.

- Consolidación del agronegocio: establecimiento de los cultivos agroindustriales, forestales y ganadería.

- Contrato fiduciario: modalidad jurídica en la cual el propietario de los bienes (fideicomitente) transfiere los predios a otro (fiduciario) que los administra o los vende en provecho de él mismo o de un beneficiario. De esta forma los derechos de propiedad no están ni en el fideicomitente ni en el beneficiario. La fiducia de esta manera da los derechos de explotación al beneficiario. 
- Desalojos con violencia: Desalojo por la fuerza pública (ejército y/o policía), solicitado por los terratenientes para expulsar a los campesinos ocupantes de los predios, los cuales están generalmente inexplotados.

- Disputa legal: Hace referencia a los trámites jurídicos que realizan las partes en disputa (estado, terratenientes, empresarios y campesinos o indígenas) por los derechos de propiedad de un predio.

- Englobe: Agregación de uno o más predios con o sin cambio de propietario. Ha sido el paso previo para entregar las tierras a los contratos fiduciarios.

- Fraccionamiento: división de un predio en varios para su venta fraccionada. Modalidad utilizada para evadir la restricción de acumulación de Unidades Agrícolas Familiares (UAF).

- $\quad$ No ejecución de procesos agrarios ${ }^{68}$ : cuando a pesar de que se han ordenado legalmente la ejecución de los procesos agrarios, estos no se han llevado a cabo y las tierras continúan apropiadas indebidamente sin adjudicarlas a los campesinos solicitantes.

- Titulación ilegal: Adjudicación oficial a personas que no cumplen requisitos de ley para obtener los derechos de propiedad o ser beneficiarios de reforma agraria o aspirar a la titulación de tierras baldías.

\footnotetext{
${ }^{68}$ Los procesos agrarios son actuaciones de orden administrativos para corregir fenómenos irregulares del ejercicio de la propiedad entre los que están: i) clarificación de la propiedad que consiste en identificar las tierras que pertenecen al estado y facilitar el saneamiento de la propiedad privada, ii) deslinde que implica delimitar las tierras del estado de las de los particulares, iii) extinción de dominio, se da cuando se realiza extinción del derecho del dominio o de propiedad sobre predios rurales en los cuales se deja de ejercer posesión (por 3 años continuos, por violación de disposiciones sobre conservación del medio ambiente o por tener cultivos ilícitos), iv) recuperación de bienes baldíos cuando se deben recuperar y restituir al estado las tierras baldías indebidamente ocupadas por particulares.
} 
- Venta irregular: Incluye las ventas forzadas por presiones o amenazas, también las realizadas con documentos falsos o las realizadas por falsos propietarios.

- Venta Informal: Son las realizadas mediante carta de compra venta o cualquier otro documento informal, por la inexistencia de títulos de propiedad. Esta ha sido una forma generalizada de transferir la propiedad entre pobladores rurales en ausencia de un sistema de formalización.

- Violencia/desplazamiento: Referido a las acciones violentas por los actores armados paramilitares y fuerza pública contra la población local que genera su desplazamiento forzado $\mathrm{y} / \mathrm{o}$ abandono de los predios.

Las siguientes categorías que forman parte de los procesos de transacciones con los predios no se consideran estrategias de despojo. Se presenta su definición.

- Ludicialización del despojo: Se presenta cuando jueces y tribunales (en especial la CC) emiten sentencia de culpabilidad a los perpetradores del despojo y acaparamiento ${ }^{69}$.

- Ocupación campesina: Asentamiento de comunidades campesinas en tierras consideradas baldías, en predios abandonados o en procesos de colonización.

- Restitución: es el derecho que forma parte de la reparación integral a las víctimas de la violencia y al que pueden acceder las personas que han sido despojadas de sus tierras, para que estas le sean devueltas. Establecido en el Ley 1448 de 2011.

- Solicitud de restitución ${ }^{70}$ : Petición ante la Unidad Administrativa Especial de Restitución de Tierras Despojadas (UAERTD) por la

\footnotetext{
${ }^{69}$ La judicialización del despojo y el acaparamiento como lo sustenta Grajales (2015) forma parte del reconocimiento que hace la CC de los derechos a la población desplazada por la violencia, más que por el reconocimiento de derecho a la tierra en sí mismo.
} 
víctima de la violencia que ha sido despojada o se ha visto obligada a abandonar su predio.

- $\quad$ Titulación Colectiva: Aprobada en la ley 70 de 1993 donde se reconoce el derecho de comunidades negras a los territorios que han habitado ancestralmente.

- Titulación legal: Titulación oficial (por INCORA o INCODER, hoy por la Agencia Nacional de Tierras) a personas que cumplen requisitos de ley para ser beneficiarios de reforma agraria o de adjudicación de baldíos.

El etiquetado de estos procesos permite situar en un mismo esquema cronológico los estudios de caso analizados. La utilidad de este esquema cronológico basado en las etiquetas predefinidas deriva de la posibilidad de identificar secuencias de procesos de despojo y acaparamiento, que pueden mostrar patrones comunes entre los casos analizados o específicos de casos concretos. Este esquema es el que se recoge en la Figura 7.2.

\footnotetext{
${ }^{70}$ La Ley 1448 de 2011, establece que tienen derecho a solicitar la restitución las personas que hayan sido despojadas u obligadas a abandonar sus tierras (en calidad de propietarios o poseedoras de predios, o explotadoras de baldíos) como consecuencia directa o indirecta del conflicto armado entre el 1 de enero de 1991 y la vigencia de la Ley.
} 
Figura 7. 2. Secuencia de los procesos de acaparamiento en los estudios de caso

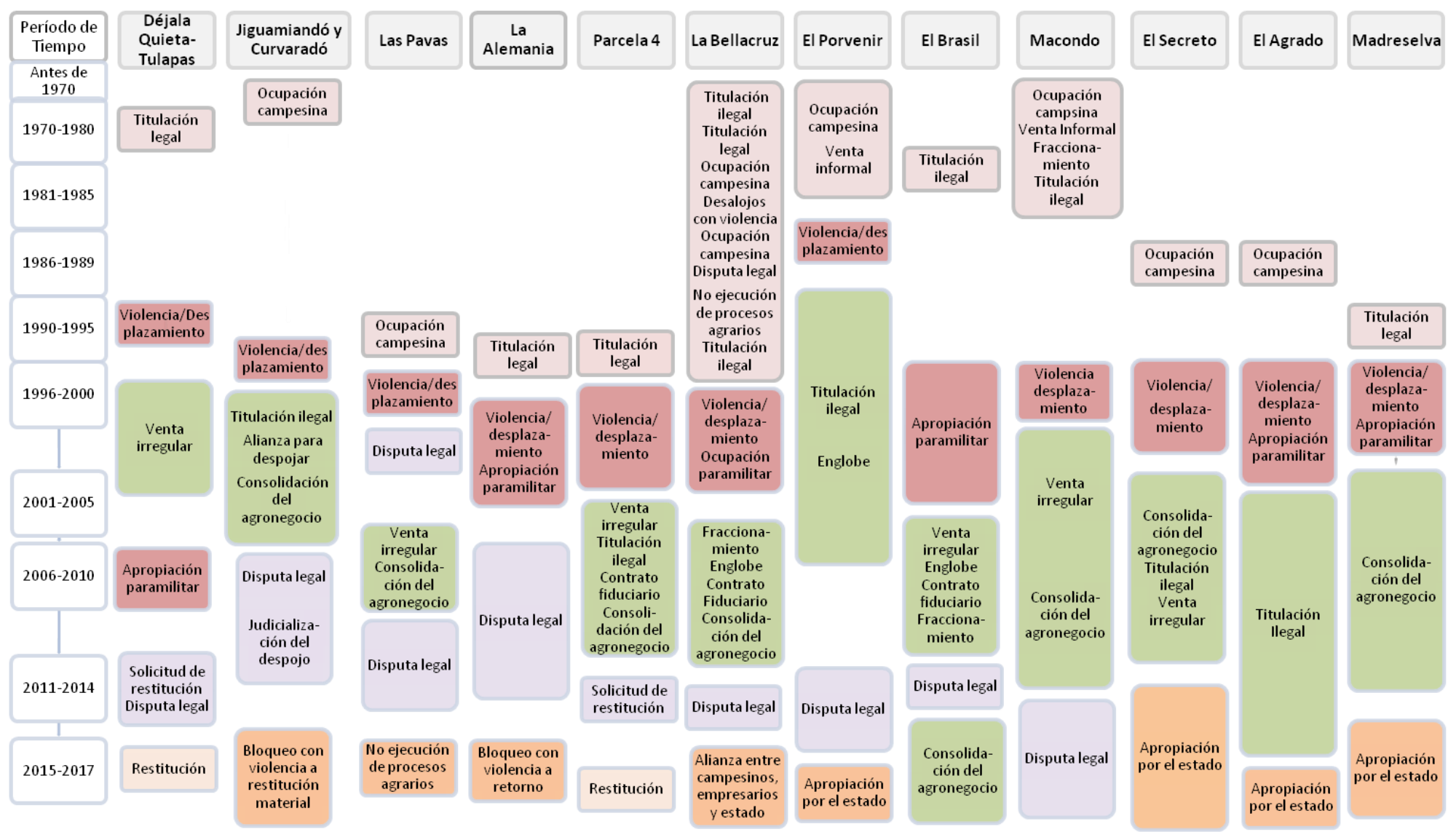


A partir de ese esquema global es posible identificar algunas secuencias de procesos que se repiten, con variantes, en casi todos los casos analizados. Los patrones de esas secuencias son objeto de discusión en el siguiente epígrafe.

\subsection{Las trayectorias de despojo y acaparamiento}

\subsubsection{De la expulsión del campesinado a la formalización fraudulenta}

La mayoría de los casos analizados comienzan con la presencia en los predios de campesinos. En efecto, estos predios que en su mayoría eran terrenos baldíos, fueron ocupados por campesinos colonos que se instalaron en ellos y empezaron a explotarlos sin título de propiedad. En algunos casos las tierras son adjudicadas legalmente a través de parcelaciones hechas por el INCORA o INCODER a población que cumplía los requisitos para ser titulados. Y en otras se adjudicaron sin cumplirlos.

La primera mitad de la década de 1990 corresponde a la consolidación paramilitar. De este modo, puede notarse en la secuencia de los casos cómo la legalización de las autodefensas en 1994 permite la consolidación organizativa paramilitar. En la segunda mitad de los años noventa, se elevan sus incursiones con masacres y ataques a la población para limpiar los territorios, que no van a disminuir hasta la segunda mitad de los años $2000^{71}$. En seis de los casos (Déjala Quieta, La Alemania, La Bellacruz, El Brasil, El Agrado y Madreselva) hubo una apropiación de predios directa por los paramilitares, en cuatro de los casos montaron su centro de operaciones criminales y en los otros dos, directamente establecieron ganado y sembraron palma de aceite.

A nivel nacional, estos procesos se reflejan en las cifras de desplazamiento forzado que para el período 1985-1995 registraron 388.089 personas desplazadas y en el período de expansión de las AUC, el decenio 1996-2005, la cifra ascendió a 3.936.214 personas desplazadas. La concentración de la propiedad en estos períodos se evidenció en un índice de Gini que paso de 0.84 en 1988 a 0.88 en 1996, según datos citados por Machado (1998)

\footnotetext{
${ }^{71}$ Entre 1990-2005 se cometieron 1.598 masacres, el 80\% del total (1.982) cometidas hasta 2012, donde 6 de cada 10 fueron cometidas por paramilitares (CMH 2013).
} 
Las zonas donde se ubican estos predios tienen en común que son tierras tituladas u ocupadas por campesinos y población afrodescendiente e indígena, zonas de frontera agropecuaria y apartadas del desarrollo, pero también abundantes en recursos estratégicos. Se convierten en objetivo de la ocupación paramilitar, justificada en su lucha contrainsurgente, aunque en algunos casos (las Pavas y la hacienda La Bellacruz) no había presencia guerrillera, y su actuación obedeció más a las alianzas de la clase política y terrateniente para sacar los campesinos de las tierras.

También es importante tener en cuenta que en la primera mitad de la década de los años noventa, con la nueva constitución nacional en 1991, se abren espacios de participación democrática para la población y se reconocen los derechos de las minorías étnicas, instrumentalizados a través de la legislación. Con la Ley 70 de 1993, se otorgan los derechos de las comunidades negras a la propiedad colectiva de tierras de las cuencas ribereñas del Pacífico, las cuales han habitado ancestralmente, así como el derecho a su identidad cultural, su desarrollo económico y social. No obstante, y de forma contradictoria, la usurpación de las tierras a las comunidades del Bajo Atrato y de otras regiones del Pacífico se presenta en el mismo período del reconocimiento de sus derechos.

Tras estos episodios de expulsión, en diez de los casos estudiados, una vez los predios son despojados o abandonados a causa de la violencia, los despojadores inician movimientos legales con los mismos, conducentes a lograr la legalización de los derechos de propiedad. De esta manera, para los predios que no tenían titulación legal (Bajo Atrato, El Secreto, El Agrado, El Porvenir) buscaron lograr una titulación con testaferros y falsos colonos. Para los que habían sido titulados legalmente, se realizaron ventas irregulares que incluyeron en algunos casos presión y/o amenazas, ventas por falsos propietarios, o con poderes de compraventa falsos (Déjala Quieta, Parcela 4).

En algunos casos a la apropiación paramilitar de los predios, le siguió la implementación de los agronegocios por los mismos paramilitares (El Secreto, Madreselva, Jiguamiandó y Curvaradó), compras por testaferros o efectuaron fraccionamientos y englobes para poderlos vender a grandes empresarios. Los empresarios para adquirirlos utilizaron una estrategia legal más sofisticada, el contrato fiduciario, que de un lado les permite acumular UAF, saltándose las 
restricciones legales y por otro, también desdibuja los derechos de propiedad, los cuales quedan a cargo de la fiducia, de esta forma pueden evadir cualquier demanda por apropiación ilegal. En el caso de las tierras de Jiguamiandó y Curvaradó una vez perpetrada la violencia, la estrategia de creación de empresas y cooperativas comunitarias por los paramilitares les facilitó la titulación de las tierras y los contratos de arrendamiento para su explotación.

Cuando los predios no contaban con títulos de propiedad (la Parcela 4, La Bellacruz y el Brasil), se hizo más fácil el traspaso y apropiación de los mismos, mientras que, cuando existía un título las estrategias para transferirlos fueron más complejas, sobre todo para que pasaran a manos de grandes empresas.

De todas maneras, en varias de las transacciones comerciales con los predios y de las titulaciones ilegales en este período, la participación y/o la omisión de los organismos públicos encargados (INCORA/INCODER) facilitó su apropiación, aún en los casos en que los predios estaban protegidos y su venta prohibida por ser zonas de alta violencia y desplazamiento forzado.

Estos movimientos de los predios, buscando sanear los derechos de propiedad, están en consonancia con el cambio de gobierno que tuvo lugar en 2002, cuando de un lado se incrementan los incentivos para los cultivos agroindustriales como la palma, que requiere grandes extensiones de tierra, y de otro, con la iniciación del proceso de desmovilización paramilitar, los jefes paramilitares que se habían hecho con la tierra, pretendían una vez estando en la legalidad, seguir manteniendo las tierras y los agronegocios a través de su Plan de Alternatividad Social (URT 2017; Ballvé 2013) .

Es en esta etapa, donde se puede observar como el despojo violento de las tierras, se convierte en el paso previo que va a facilitar el acaparamiento de tierras en los términos actuales del concepto, que implica el control sobre grandes extensiones de tierra, involucrando grandes inversiones, que requieren seguridad mediante la legalización de los derechos de propiedad de la tierra. 


\subsubsection{De los mecanismos irregulares de titulación a las disputas legales}

La reparación a las víctimas del conflicto se estableció mediante la Ley 975 de Justica y Paz en 2005, que otorgaba una pena alternativa a los desmovilizados cuando éstos colaboran con la justicia y la reparación a las víctimas. Esto incluía la entrega y/o devolución de bienes en poder de los sometidos a la justicia para los procesos de reparación. Así, se dio la posibilidad a la población desplazada y despojada de reclamar sus derechos al estado, entre ellos la devolución de sus tierras. Se observa de forma clara, en la secuencia de despojo de los predios estudiados, cómo las acciones legales por recuperar las tierras se inician a partir de esa fecha en alguno de los estudios de caso (finca de las Pavas, el Bajo Atrato y la finca La Alemania).

Pero el estudio permite observar que es a partir de la implementación de la Ley 1448 de 2011, cuando las contiendas legales por la tierra toman fuerza. El caso del Bajo Atrato es uno de los pocos casos donde se ha judicializado a algunas de las empresas que perpetraron el despojo. Asimismo, las investigaciones adelantadas por instituciones como la Contraloría General de la República y el mismo Ministerio de Agricultura a través del INCODER permitieron respaldar las demandas de los reclamantes de tierras. Las investigaciones de las instituciones públicas muestran casos como el de El Brasil, donde no hay demandantes de restitución, pero también fue objeto del despojo violento de tierras. En los casos de Mapiripán (Madreselva, el Agrado y Secreto), los paramilitares los entregaron al estado para restituir a las víctimas, no hubo una disputa legal como tal.

Las reclamaciones de tierras por parte de la población afectada, soportadas en el marco legal para la reparación a las víctimas, confirman lo planteado por Borras et al. (2012) en cuanto al rol contradictorio del estado en el acaparamiento de tierras. El estado, de una parte, facilita el acaparamiento con las políticas e incentivos a la inversión, y en el territorio ejerciendo la coerción, mediante la fuerza pública y los poderes paramilitares (Grajales 2015; Gómez et al. 2015). Y de otra, ante la necesidad de ejercer su legitimidad política, abre puertas dentro de la estructura legal para el ejercicio de los derechos de la población. Esto ocurre después de 20 años de violencia y despojo y cuando diferentes organizaciones de Derechos Humanos llevan las demandas de las 
víctimas a instancias internacionales, es decir solo cuando la legitimidad política del estado se ve amenazada.

\subsubsection{Cuatro finales inconclusos}

Las trayectorias que han seguido los estudios de caso han desembocado, hasta la fecha, en tres tipos de situaciones. En primer lugar, en dos de los casos se ha llevado a cabo la restitución de tierras solicitada por los campesinos titulados en los procesos de reforma agraria, habiéndose apoyado las resoluciones judiciales en el reconocimiento de la apropiación paramilitar (Déjala Quieta) y en la concentración de tierras despojadas en zona de violencia (Parcela 4). En ambos casos la justicia prueba la existencia de violencia causante del desplazamiento y el abandono de los predios, junto a la existencia de transacciones fraudulentas con las tierras.

En segundo lugar, en otros casos, la devolución no ha sido llevada a cabo a pesar de haber sido judicializado el despojo y ordenada la devolución a sus reales dueños. Es el caso de la Alemania, donde las personas que han retornado enfrentan las amenazas constantes de los actores armados y su retorno no es completo. El predio Las Pavas guarda similitud con estos casos, pues el estado no ha tenido la capacidad de hacer cumplir las sanciones legales dadas para la ejecución efectiva de los procesos agrarios (clarificación y extinción de dominio), con lo cual la compañía palmera sigue explotando el predio. En estos dos casos ninguna de las medidas ha servido para restituir los derechos a las víctimas a pesar de existir un fallo legal a su favor. Esto refleja claramente cómo los poderes facticos y económicos en el nivel local llegan a controlar y sobrepasar el poder nacional estatal (CMH 2012; Grajales 2015).

En tercer lugar, hay cuatro casos en que los predios regresan a los dominios del estado, tres en Mapiripán donde tanto los predios como los cultivos de palma pasan a ser administrados por el estado a través del Fondo Nacional de Reparación para las Víctimas (FNRV) y el caso de El Porvenir, que una vez comprobada la titulación ilegal a falsos colonos las tierras pasan a dominio del estado, a pesar de existir reclamantes que por años las han trabajado. En los tres primeros casos las tierras y los cultivos en ellas existentes son administrados por el FNRV, pero su usufructo va dirigido a reparar a las víctimas, sin salir la propiedad de los dominios del estado. Esta recuperación 
de tierras por el estado, que podría tomarse como un ejercicio de soberanía al tomar el control sobre sus bienes. No obstante, en estos casos específicos, lo que demuestra es un favorecimiento del acaparamiento y del agronegocio, al reservar tierras disponibles para las grandes inversiones, y no adjudicarlas a campesinos sin tierra.

Finalmente, en cuarto lugar, están también los casos donde gana la partida el agronegocio, como son El Brasil, Macondo y la Bellacruz. La industria la Fazenda (predio El Brasil) y la multinacional Poligrow (predio Macondo), hasta ahora invictas de las investigaciones y denuncias, son agroindustrias cuyo volumen de negocio y su influencia política y económica parece mantenerlas inmunes, pues responden a las expectativas de inversión planteadas por el gobierno para esa región. En el caso del predio Macondo, la multinacional no resultó culpable por la acumulación de UAF, pero la disputa legal continúa en un estadio posterior, donde se le acusa de contaminación ambiental y malas condiciones laborales. En el Brasil miembros de la comunidad indígena Sikuani han denunciado afectaciones de salud y muertes debido a la contaminación que genera La Fazenda (Misereor 2017).

En el caso de la Bellacruz, las alianzas productivas acordadas benefician la empresa que no se obliga a devolver los baldíos y además gana mano de obra de los campesinos victimizados. La influencia económica y política del actual dueño (presidente y mayor accionista de la aerolínea Avianca) supera las demandas de los reclamantes de tierras que después de décadas de lucha ceden ante las promesas de trabajo y acceso a tierras. Lo anterior encaja en el espíritu de la Ley 1776 para la creación de ZIDRES, que como se estudió en el capítulo anterior, privilegia las tierras baldías para los grandes inversionistas.

En general, los estudios de caso, reflejan en primer lugar cómo la ausencia del estado en los territorios apartados y alejados del desarrollo, dejan paso al control por otros poderes locales, los políticos, económicos, narcotraficantes y los grupos armados, que en la mayoría de los casos establecen alianzas para controlar la tierra y los recursos del territorio a través de un proceso violento de despojo. En segundo lugar, el estado, para recuperar el control sobre estos territorios ejerce la coerción y la violencia (Borras \& Franco 2013), apoyado en los poderes ilegales (Grajales 2015; Ballvé 2013) y fomentando la introducción de agronegocios. Y, en tercer lugar, se constata cómo el marco legal deja, a 
pesar de todo, vías a través de las cuales la población despojada puede reclamar sus derechos. Aunque en un gran número de casos continúan sin poderlos ejercer por la primacía del control de los poderes locales, los agronegocios y las actividades extractivas. Esta poca eficacia en la aplicación de las herramientas jurídicas para las personas reclamantes de tierras se ve reflejada en las estadísticas de restitución. Las cuales al mes de mayo de 2018 reportaron 111.626 solicitudes de restitución sobre 98.277 predios, de los cuales, solo se habían restituido 7.142 (URT 2018), correspondiente a un 7\%, en los casi siete años de implementación.

\subsection{El papel del estado: Entre la facilitación del acaparamiento y la protección de los derechos de las comunidades rurales}

Más allá de los patrones temporales que se derivan del epígrafe anterior, el análisis ha permitido también identificar la diversidad de mecanismos a través de los cuales el estado ha intervenido en los procesos de acaparamiento de tierras en Colombia. En efecto, en la mayoría de los casos se constata el papel que ha jugado el estado en la creación y aplicación de instrumentos que facilitan la acumulación y el acaparamiento de la tierra y otros recursos naturales. Sin embargo, el análisis también nos permite identificar otras actuaciones de distintas instituciones del Estado que, por el contrario, van en la línea de regular o incluso impedir dichos casos de acaparamiento. Esta aparente contradicción va en la línea de lo que plantean Borras et al (2012), aunque en el caso de Colombia el objetivo de estos últimos mecanismos no es tanto evitar la 'extranjerización' de la tierra como tratar de salvaguardar los derechos colectivos de la población rural pobre y víctima de la violencia.

En relación a los mecanismos de facilitación del acaparamiento, podemos mencionar, en primer lugar, las medidas indirectas (y/o por omisión) y las directas. Dentro de las primeras, las indirectas, encontramos el abandono histórico de zonas de colonización (de frontera agropecuaria) y de economía campesina, que al mantenerlas aisladas del desarrollo han sido en gran parte proclives al control por los grupos insurgentes y el narcotráfico. Esto, junto con la inexistencia de una política de formalización de los derechos de la propiedad sobre la tierra (incluidos los derechos de los pueblos étnicos), ha dado origen a múltiples conflictos entre campesinos y terratenientes como las apropiaciones 
indebidas de tierras públicas, las invasiones y ocupaciones campesinas y a la existencia de procesos informales para transferencia de la propiedad que han facilitado el despojo a las comunidades rurales. Podemos ubicar aquí también la falta de resolución en las disputas legales por procesos de definición de los derechos de propiedad, en los casos donde los campesinos reclaman tierras baldías que han ocupado y trabajado por muchos años, así como también los casos en que, aun resolviéndose los derechos a favor de los campesinos, el estado no garantiza la seguridad para el retorno de la población a sus tierras.

Dentro de los mecanismos directos implementados por el estado para favorecer las grandes inversiones en tierras, están todas las medidas de tipo legal y político como la creación de leyes sobre la declaratoria de zonas especiales para la agricultura a gran escala o zonas de interés especial para el desarrollo nacional (incluye zonas de explotación minera) que, en varias ocasiones, corresponden a tierras baldías, tierras de economías campesinas y de grupos étnicos. De igual manera las medidas coercitivas a través del uso de la violencia, que es común a todos los casos de acaparamiento y despojo de tierras de la población rural, han hecho también parte de las estrategias directas del estado para favorecer a las grandes inversiones y a la acumulación de tierras por el capital privado (Grajales 2011, 2013, 2015); Ballvé 2013; Gómez et al. 2015; GMH 2010). Se cuentan igualmente dentro de estas medidas directas la implementación de los programas de las alianzas productivas entre pequeños productores y los agronegocios, no solo como única salida de los primeros para acceder a la tierra en calidad de trabajadores, sino también como la solución dada a los despojados para acceder a su tierra cuando esta permanece en manos del acaparador.

Por el contrario, tal como planteábamos anteriormente, encontramos también los mecanismos de legitimidad que implementa el estado ante los casos de violencia y despojo, es decir, toda la legislación creada para la atención a población desplazada y las normativas para el registro y protección de predios abandonados y la Ley de Víctimas y Restitución de Tierras. Estas medidas han sido posibles gracias a las luchas de las víctimas despojadas y al apoyo y visibilidad que han logrado a nivel internacional en el marco de los Derechos Humanos. Lo que ha forzado en parte al estado (buscando legitimidad) a implementar estos marcos legales de protección. 
En definitiva, es necesario resaltar cómo el estado, y las diferentes instituciones que lo componen, no forman un ente monolítico y totalmente coherente en relación a su participación en los procesos de acaparamiento. Así, mientras que una mayoría de casos el estado colombiano ha tratado de configurar un entorno facilitador de las grandes inversiones en la tierra, instituciones como la Contraloría General de la República (CGR), la Corte Constitucional, otras instituciones judiciales (juzgados, Procuraduría) y miembros del Congreso, han participado abiertamente en la defensa de los derechos de las comunidades rurales. 



\section{Capítulo 8}

\section{Conclusiones}

Mediante este trabajo de investigación se ha buscado aportar al entendimiento del fenómeno del acaparamiento de tierras en Colombia, haciendo un esfuerzo por integrar en el análisis factores a nivel global, nacional y local que han permitido no solo su ocurrencia, sino que también, han generado unos resultados concretos en el país y en las regiones donde tienen lugar. Los desarrollos teóricos revisados aquí sobre el tema plantean que la influencia de las políticas globales ha sido decisiva en promover las inversiones en tierras, pues no solo ha generado los instrumentos para promoverla, sino también para regularla y ha llegado hasta la identificación de los países y territorios dónde se deben realizar (White et al. 2012).

Lo anterior es analizado con especial atención para el caso colombiano, al mostrar cómo a través de la intervención de organismos como el Banco Mundial y USAID, tanto los préstamos como las ayudas al desarrollo se dirigen especialmente a facilitar las grandes inversiones en las zonas rurales. Lo que se refleja en la priorización y financiación de programas que no apuntan a resolver las raíces del problema de la tenencia de la tierra, como lo son las dificultades para el acceso y la alta concentración, sino a una 
ampliación y disponibilidad de los recursos productivos para el capital privado.

Las influencias en ese sentido se aprecian desde la implementación de los programas de Desarrollo Rural Integrado (DRI) que tuvieron modestos resultados en la superación de la pobreza y en el incremento de la productividad de los pequeños productores rurales, posteriormente con la potenciación de un mercado asistido de tierras fallido que fomentó su concentración e incrementó los costos de la tierra para los más pobres, hasta el apoyo a la pacificación del territorio con más violencia y mayor ampliación de la frontera agropecuaria. Y en la última década con el interés por fomentar y financiar programas para la formalización de la tenencia de la tierra, indiscutible para defender los derechos de propiedad vulnerados por siglos en Colombia, pero planteada con un énfasis prioritario para atraer y dar seguridad a las inversiones. También se aprecia la influencia en la modelación de una estructura productiva a través de programas y proyectos como las alianzas productivas, enfocadas en cultivos altamente demandantes de tierra y capital, con destino al comercio internacional y priorizados por encima de otros cultivos y formas de producción alternativas. Dentro de este modelo, el tratamiento que se le da a la erradicación de la pobreza está más asociado a financiar programas de generación de ingresos básicos o transferencias monetarias condicionadas, que no generan desarrollo en el largo plazo.

De igual manera, la financiación y cooperación brindada para la construcción de la paz, incluye medidas contradictorias. Por un lado, apoyan procesos de desmovilización, restitución de tierras, pero la estructura económica propuesta es excluyente en cuanto a que no permite una inclusión productiva al no facilitar la capitalización de los sectores más pobres de la población. El acceso a los recursos (tierra, trabajo, tecnología) está a disposición de los grandes inversores principalmente, los pequeños y pobres solo son vinculados a través de alianzas productivas. En este mismo sentido, la ayuda de cooperación y desarrollo de los Estado Unidos, basada en fomentar la misma estructura productiva para dar salida al problema del narcotráfico y la guerra, se ha basado en apoyar el mismo tipo de programas productivos. $\mathrm{Y}$ adicionalmente la política de recuperación de los territorios por medio de la fuerza pública (Plan Colombia y Plan de Consolidación) incrementó la violencia y el despojo de tierras. 
Así pues, el análisis realizado muestra que los planes de gobierno no son completamente autónomos, dado que la financiación viene para unos objetivos específicos y son estos los que finalmente se implementan. Es claro que el problema de la concentración de la tierra no se ha solucionado, que la preocupación central sobre el tema es la formalización de los derechos de propiedad en las tierras de la frontera agropecuaria y en las tierras restituidas. El rol del estado es claro, pasa a ser regulador y garante de las inversiones en tierras y en explotación de recursos naturales. Participa en la identificación de las tierras disponibles, vacías o subutilizadas (Cotula 2012; White et al. 2012). También implementa medidas de tipo legal y administrativo, tal como se ha analizado para el caso de la región de la Altillanura, donde dado el volumen de tierras productivas que posee, se ha emprendido acciones para remover las restricciones legales que impiden las inversiones. En este caso también se pueden observar claramente las tres áreas de acción, estudiadas por Borras \& Franco (2013:1779), que siguen los estados para facilitar el acaparamiento de tierras: los procesos de simplificación, la afirmación de la autoridad y la soberanía y la coerción a través de la policía y las fuerzas militares y paramilitares.

Aunque para la Altillanura estas características no se dan en ese mismo orden que exponen los autores, sí son evidentes: En primer lugar, la ausencia casi total del estado en la región permitió la presencia de grupos armados insurgentes. La implementación de cultivos ilícitos justificó la arremetida paramilitar en los años 1990s, generando el desplazamiento de la población campesinos colonos e indígenas- obligando al abandono o a la venta forzada de sus tierras.

En segundo lugar, se evidencia la afirmación de la soberanía que el estado ejerció en esta región, como en otras del país, bajo el paraguas de la lucha contrainsurgente, a través de la imposición y acción de la fuerza pública en alianza con paramilitares, denominándola una 'conquista' del territorio. Y finalmente, en una última etapa, el estado inicia procesos de simplificación, buscando formalizar los derechos de propiedad sobre las tierras e inicia proyectos para la actualización de catastros y diversas tareas administrativas, como la reclasificación y reordenación del uso del suelo. De esta forma, el estado es el único que decide qué tipo de explotación y uso deben tener las 
tierras y quién ejerce el control sobre ellas y los demás recursos naturales. En este momento es cuando la definición de los derechos de propiedad se convierte en una prioridad para dar seguridad a los grandes inversionistas y no antes, cuando los colonos y campesinos reclamaban el derecho a la titulación de las tierras que han ocupado y trabajado por años.

La coerción del estado también se refleja en la modificación de la legislación agraria que priorizaba la asignación de las tierras baldías a campesinos y trabajadores rurales pobres y que ahora, con la Ley ZIDRES, legaliza el acaparamiento hecho por grandes inversionistas y élites políticas nacionales, permitiendo su implementación en las tierras baldías para ser dadas en concesión sin límite de tiempo ni extensión. No obstante, el estudio también refleja cómo el estado no es un ente monolítico, dado que algunas de sus instituciones (en especial de la rama judicial) son las que han frenado en varias ocasiones los intentos de cambio legal impulsado desde el ejecutivo. A su vez han denunciado las irregularidades en la acumulación de tierras.

Por su parte, el análisis basado en los estudios de caso ha permitido ilustrar y profundizar en cómo este tipo de medidas de política inciden en territorios concretos y configuran los procesos de acaparamiento de tierras. El análisis comparativo basado en la categorización de los acontecimientos y procesos concretos ha permitido, a pesar de las diferencias entre los casos, extraer unos patrones similares en la evolución de las prácticas de despojo y acaparamiento. Entendemos que el resultado de este análisis constituye una aportación útil para su utilización en otros estudios similares. De este modo, a través de la reconstrucción de la historia de las transacciones y traspasos de los que han sido objeto estos 12 predios, se puede conocer la trayectoria y los mecanismos utilizados para acapararlos. Sintetizamos a continuación las principales conclusiones que se derivan de esta parte del análisis.

- Tal como planteábamos, a pesar de las especificidades de cada caso, hemos podido identificar seis grandes procesos por los que han transcurrido la mayoría de las historias de estos predios: a) la ocupación de un predio por campesinos o colonos, por proceso de colonización o por titulación legal, b) el abandono del predio o despojo por la violencia, c) apropiación directa o traspasos y ventas irregulares, d) instalación de agroindustria, e) disputa legal, entre los reclamantes 
del predio, los nuevos poseedores y/o el estado, f) restitución positiva o no.

- La titulación o formalización de la propiedad en Colombia no ha servido a los pequeños propietarios para que se respeten sus derechos, pues varios de los predios estudiados se titularon por el estado a campesinos y sin embargo fueron despojados, incluso con la participación de funcionarios del estado. No obstante, el hecho de que haya existido una titulación legal ha obligado a la elaboración de estrategias más complejas para los traspasos irregulares y lograr así borrar el registro e historia de la tenencia del predio. Por otro lado, la existencia de un título ha permitido a varios despojados reclamar la restitución de sus predios.

- Las tierras despojadas han sido las ubicadas en zonas de frontera agropecuaria, en territorios donde el estado no tenía presencia y cuyo espacio ocuparon los grupos armados. El nivel de concentración al interior de la frontera, como se ha mostrado en este trabajo, ha hecho que estas tierras consideradas marginales sean el objetivo de los acaparadores, pues cumplen las condiciones de tener poca población, altos niveles de pobreza, pero tener abundancia de agua y recursos.

- El marco constitucional y legal ha dejado algunas ventanas a las que ha acudido la población para reclamar el derecho a la tierra y a sus territorios. Sin embargo, estos procesos han tomado muchos años, pues entran en un ciclo de litigios legales prolongados donde el vencedor raras veces es el despojado o desplazado. Y aun reconociendo los derechos sobre los predios, el estado no tiene la capacidad de hacer cumplir la ley, porque los predios siguen en manos de las compañías o testaferros.

- En el proceso de restitución, el estado también ha recuperado tierras y las tiene bajo su propiedad aun existiendo campesinos que las reclaman por haberlas trabajado durante años. En este ejercicio de soberanía y autoridad, el estado también está acaparando las tierras o reservándolas para los usos que considere prioritarios. 
- Los actores del despojo y acaparamiento también han variado en el tiempo; terratenientes tradicionales, narcotraficantes, grupos paramilitares, élites locales y nacionales y las compañías nacionales y extranjeras, junto al papel del estado ya mencionado.

- Dentro de las estrategias se han destacado las alianzas, locales y regionales, entre élites políticas y económicas con paramilitares y narcotraficantes hasta llegar a influir a nivel nacional a través de presión en el cambio de la legislación y de las políticas. En este sentido podemos decir que ese juego político interno se complementa o encuentra un respaldo en las directrices que vienen desde fuera, reforzando y alimentando las asimetrías de poder y control sobre los recursos productivos.

- Aunque escapa a los alcances planteados en esta investigación, se aprecia la persistencia y resistencia de las comunidades rurales para recuperar su tierra y territorio, que son para muchos más que un medio de producción, su espacio de vida. Los largos procesos de disputa legal, resistiendo a pesar de dejar cientos de vidas por el camino, permiten dar cuenta de la existencia de una organización comunitaria frente al acaparamiento, cuyas características y posibilidades vale la pena profundizar en futuras investigaciones. A su vez es importante resaltar que estas reivindicaciones también han sido posibles por la interlocución encontrada de estas comunidades con ONGs y partidos políticos, que han hecho eco de sus demandas liderando procesos judiciales y mediáticos a nivel nacional.

La violencia rural en Colombia, con claras raíces en una estructura agraria desigual y excluyente (kay, 2001; Fajardo, 2014; Machado, 1998; Thompson), fortalecida en varias ocasiones por las políticas de estado, ha tenido diferentes manifestaciones y niveles de intensidad a lo largo del tiempo. Esto se refleja claramente en los estudios de caso donde inicialmente los actos de violencia ocurrían mediante desalojos y expulsión con ayuda de la fuerza pública de los campesinos de las tierras por orden de los terratenientes. Con el auge del paramilitarismo y el narcotráfico, el destierro de las comunidades rurales mediante actos de terror (masacres y asesinatos) se convierte en la modalidad más efectiva para vaciar los territorios y para justificar en gran medida la 
llegada de nuevos capitales a las zonas rurales. Todos los procesos de acaparamiento de tierras estudiados aquí están precedidos de fuertes episodios de violencia y desplazamiento.

Finalmente, aunque en el reciente proceso de paz se haya reconocido el desigual acceso a la tierra y su concentración como uno de los motores de la violencia y el conflicto armado, los programas políticos y proyectos fomentados internacional y nacionalmente no han logrado remover estos problemas estructurales. Con lo cual, el apoyo e impulso al proceso de paz ha estado realmente orientado a reducir los niveles de conflicto para permitir un ambiente propicio para la inversión en las zonas rurales con abundantes recursos naturales. Los incipientes y débiles resultados en la restitución de tierras, la continuación de la violencia a mano de viejas y nuevas estructuras armadas, la política poco efectiva para acabar con el narcotráfico y la ausencia de medidas para abordar la redistribución de la tierra y el ingreso, evidencian las dificultades a las que se sigue enfrentando el medio rural colombiano para alcanzar una paz estable y duradera. 



\section{Referencias Bibliográficas}

Acción Social, 2010. Proteccion de Tierras y patrimonio de población desplazada.

Akram-Lodhi, A.H., 2015. Land grabs, the agrarian question and the corporate food regime. Canadian Food Studies / La Revue canadienne des études sur l'alimentation, 2(2), p.233.

Akram-Lodhi, A.H. \& Kay, C., 2009. Peasant Livelihoods and the Agrarian Question. The agrarian question: peasants and rural change. In A. H. AkramLodhi \& C. Kay, eds. Peasants and Globalization: Political Economy, Rural Transformation and The Agrarian Question. London: Routledge, pp. 1-34.

Akram-Lodhi, A.H., Kay, C. \& Borras, S.M., 2009. The Political Economy of Land and the Agrarian Question in an Era of Globalization. In A. H. Akram-Lodhi \& C. Kay, eds. Peasants and Globalization: Political Economy, Rural Transformation and The Agrarian Question. London: Routledge.

Alturo, G., Peña, L. \& Bohorques, J.P., 2015. Perspectivas del movimiento campesino colombiano. Revista Maré, (00), pp.1-19.

Arnalte, E., Baptista, F.O. \& Garrabou, R., 2012. Viejas y nuevas dimensiones de la cuestión de la tierra. Revista Española de Estudios Agrosociales y Pesqueros, 2012(231), pp.11-35.

Balcázar, Á., Vargas, A. \& Orozco, M.L., 1998. Del proteccionismo a la apertura. ¿El camino a la modernización agropecuaria? In Misión Rural. Bogotá: Tercer Mundo Editores.

Ballvé, T., 2013. Grassroots masquerades: Development, paramilitaries, and land laundering in Colombia. Geoforum, 50, pp.62-75.

Ballvé, T., 2012. Everyday state formation: territory, decentralization, and the narco landgrab in Colombia.Environment and Planning D: Society and Space, 30, pp.603-622.

Banco Mundial, 2011. Country Partnership Strategy for the Republic of Colombia 2012-2016. , (60620), pp.1-108.

Banco Mundial, 2008a. Alianza Estratégica con el País para la República de Colombia 2008-2011. , (42847), pp.1-97.

Banco Mundial, 2008b. Colombia: Peace Programmatic I. Demobilization and Reinsertion of Ex-Combatants in Colombia. , (39222), pp.1-100.

Banco Mundial, 2007. Colombia 2006-2010: Una ventana de oportunidad. Notas de política presentadas por el Banco Mundial.

Banco Mundial, 2004. Colombia: Land policy in transition., (27942), pp.1-82. http://documents.worldbank.org/curated/en/2004/10/5401837/colombialand-policy-transition $\% 5 \mathrm{Cn}$

Banco Mundial, 2003a. Colombia: Fundamentos Económicos de la paz. , (25426), pp.1452.

Banco Mundial, 2003b. Colombia Agricultural and Rural Competitiveness. (27523)

Banco Mundial, 2002. Country Assistance Strategy of the World Bank Group for the Republic of Colombia. 
Banco Mundial, 2001. Colombia: Productive Partnerships Support Project. , (May), pp.1-14. Available at: http://www.worldbank.org/content/dam/World bank/GEP/GEP2015a/pdfs/GEP15a_web_full.pdf.

Banco Mundial, 1997. Country Assistance Strategy of the World Bank Group for the Republic of Colombia. , pp.1-80.

Banco Mundial, 1996. Review of Colombia's Agriculture and Rural Development Strategy.p.142. Available at: http://documentos.bancomundial.org/ curated /es/437111468770711970/pdf/multi-page.pdf.

Banco Mundial, 1988. Project completetion report 7234. Third Agricultural Credit Project. Colombia. , pp.1-27.

Banco Mundial, 1983. Colombian Agriculture: Selected Issues and Some Directions for Strategy. , (4275), pp.1-75.

Baquero, J., 2012. Land grabbing and conflicts over territories: Agro-industrial projects in Lower Atrato. In Land Deal Politics Initiative. p. 32.

Bargent, J., 2012. Montes de María: Who inherited the AUC's bloodstained wealth? Kavilando, 3(1), pp.85-89.

Bejarano, J.A., 1983. Campesinado, luchas agrarias e historia social: Notas para un balance historiográfico. In Anuario Colombiano de Historia Social y de la Cultura. pp. 251-304.

Borras, S.M.J. \& Franco, J.C., 2013. Global Land Grabbing and Political Reactions 'From Below.' Third World Quarterly, 34(9), pp.1723-1747. Doi/abs/10.1080/01436597.2013.843845.

Borras, S.M., Kay, C., et al., 2012. Land grabbing and global capitalist accumulation: key features in Latin America. Canadian Food Studies / Revue canadienne des études du développement, 33(4), pp.402-416.

Borras, S.M., Franco, J.C., et al., 2012. Land grabbing in Latin America and the Caribbean. Journal of Peasant Studies, 39(3-4), pp.845-872.

Borras, S.M., 2003. Questioning Market Led Agrarian Reform: Experiences from Brazil, Colombia and South Africa. Journal of Agrarian Change, 3(3), pp.367394.

Carta Demanda, 2016. Demanda de inconstitucionalidad contra Ley Zidres.

CC, 2016a. Sentencia SU-426/16.

CC, 2016b. Sentencia SU235/16.

CC, 2012a. Sentencia C-644/12.

CC, 2012b. Sentencia C-820/12.

CC, 2009. Sentencia C-175/09.

Centro Nacional de Memoria Histórica, 2012. Justicia y Paz. Tierras y territorios en las versiones de los paramilitares. Y. Salinas \& J. Zarama, eds., CNMH.

CGR, 2017. Comunicado de prensa No. 49. , pp.8-11. Available at: https://www.contraloria.gov.co/contraloria/sala-de-prensa/boletines-deprensa/-/asset_publisher/J14Sa8JTmjbW/content/tras-10-anos-de-la-ley-dejusticia-y-paz-y-11-billones-invertidos-tan-solo-se-han-condenado-195postulados-en-47-sentencias/pop_up?_101_IN.

CGR, 2014a. Informe de Actuación Especial. Despojo y abandono de tierras en Mapiripán 2014., Bogotá. 
CGR, 2014b. Informe de Actuación Especial sobre acumulación irregular de predios baldíos en la Altillanura Colombiana, Bogotá.

Congreso de la República, 2014. Proyecto de Ley 133/2014. Zonas de Interés de Desarrollo Rural y Económico. Available at: http:/ / www.camara.gov.co/ portal2011/proceso-y-tramite legislativo/proyectosdeley?option=com proyectosdeley\&view=ver_proyectodeley\&idpry $=1596$.

Congreso de la República, 2013. Proyecto de Ley 162/2013. Se crea nuevas modalidades de acceso a la tierra y se modifica el régimen de baldíos. Available at: http://www.camara.gov.co/portal2011/proceso-y-tramitelegislativo/proyectos-deley?option=com_proyectosdeley\&view=ver_ proyectodeley\&idpry=1362.

Cotula, L., 2012. The international political economy of the global land rush: A critical appraisal of trends, scale, geography and drivers. Journal of Peasant Studies, 39(3-4), pp.649-680.

DANE, 2018. Boletín técnico Pobreza Monetaria y Multidimensional en Colombia. Available at: https://www.dane.gov.co/files/investigaciones/condiciones_ vida/pobreza/bol_pobreza_17.pdf.

DANE, 2014. Censo Nacional Agropecuario. Departamento Administrativo Nacional de Estadística. Available at: http:/ / www.dane.gov.co/index.php/estadisticaspor-tema/agropecuario/censo-nacional-agropecuario-2014. [Accessed January 20, 2018].

DANE, 2005. La visibilización estadística de los grupos étnicos colombianos.

Deininger, K. et al., 2011. Rising Global Interest in Farmland, Available at: http:/ / siteresources.worldbank.org/INTARD/Resources/ESW_Sept7_final_ final.pdf.

Dell'Angelo, J. et al., 2017. The Tragedy of the Grabbed Commons: Coercion and Dispossession in the Global Land Rush. World Development, 92, pp.1-12.

Dinero, 2011. Los nuevos llaneros. , 367, pp.34-40. Available at: http://www.dinero.com/caratula/edicion-impresa/articulo/los-nuevosllaneros/113492.

DNP, 2015. El campo Colombiano: Un camino hacia el bienestar y La paz. Misión para la Transformación del Campo., Bogotá.

DNP, 2014a. Documento CONPES 3797. Política para el desarrollo integral de la Orinoquia. Altillanura. Fase I. p.83.

DNP, 2014b. Plan nacional de desarrollo 2014-2018: Todos por un nuevo país. , p.872. Available at: https://www.dnp.gov.co/Portals/0/archivos/ documentos/Subdireccion/Conpes/3582.pdf.

DNP \& DJS, 2006. Balance del Plan Colombia 1999-2005. Available at: http://www.dnp.gov.co/portalDNP/plan-colombia/Bal_plan_Col_espanol final.pdf.

DNP, 2002. Plan nacional de desarrollo 2002-2004: Hacia un estado comunitario. p.284.

DNP, 1998. Plan nacional de desarrollo 1998-2002: Cambio para construir la paz. , p.146. Available at: https://colaboracion.dnp.gov.co/CDT/PND/ Pastrana2_ Contexto_Cambio.pdf. 
Edelman, M., 2016. Siete dimensiones del acaparamiento de tierras que todo investigador tendrían que tomar en cuenta. In Conferencia Internacional:Tierras y Territorios en las Américas: Acaparamientos, Resistencias y Alternativas. Bogotá: Universidad Externado de colombia, pp. 1-14.

Edelman, M., Oya, C. \& Borras, S.M., 2013. Global Land Grabs: historical processes, theoretical and methodological implications and current trajectories. Third World Quarterly, 34(9), p.1517. doi/abs/10.1080/01436597.2013.850190.

El Espectador, 2017a. Así opera el Clan del Golfo. El Espectador, 2020, p.5. Available at: http://www.pares.com.co/asi-opera-el-clan-del-golfo/.

El Espectador, 2017b. Contraloría pide que se investigue a Poligrow por acumulación de baldíos. El Espectador.

El Espectador, 2016. El Porvenir, un lío de 27.000 hectáreas. El Espectador.

El Espectador, 2012. Las tierras de Mónica Semillas. El Espectador.

Fajardo, D., 2014. Las guerras de la agricultura Colombiana 1980-2010., Bogotá: ILSA.

Fajardo, D., 2002. Para sembrar la paz hay que aflojar la tierra, Bogotá: IDEA.

Fajardo, D. \& Mondragón, H., 1997. Colonización y estrategias de desarrollo, Bogotá: IICA.

Fedepalma, 2011. Censo nacional de palma de aceite Colombia 2011.

FIP, 2011. Balance de la Política Nacional de Consolidación Territorial. , 14, p.54. Available at: http://archive.ideaspaz.org/images/consolidacionweb.pdf.

Fox, J., 1993. Food Politics. Ithaca, NY: Cornell University Press, esp ch 2.

García, P. \& Vargas, J., 2014. Land transactions and violent conflict, a review of the cases of Turbo, Antioquia and El Carmen de Bolívar. Análisis Político, (82), pp.22-44.

Gómez, C.J.L., Sánchez - Ayala, L. \& Vargas, G., 2015. Armed conflict, land grabs and primitive accumulation in Colombia: micro processes, macro trends and the puzzles in between. The Journal of Peasant Studies, 6150(July), pp.1-20. Doi/abs/10.1080/03066150.2014.990893.

González, D., 2017. El sesgo anti-campesino del Estado: el caso de las tierras de Argos en El Carmen de Bolívar (Bolívar) y Ovejas (Sucre), Colombia. Universidad Nacional del Rosario. Available at: http://repository.urosario.edu.co/handle/ 10336/13167.

GRAIN, 2016. The global farmland grab in 2016 how big , how bad ?, Barcelona.

Grajales, J., 2015. Land grabbing, legal contention and institutional change in Colombia. The Journal of Peasant Studies, 42(3-4), pp.541-560. Available at: http://www.tandfonline.com/doi/abs/10.1080/03066150.2014.992883.

Grajales, J., 2013. State Involvement, Land Grabbing and Counter-Insurgency in Colombia. Development and Change, 44(2), pp.211-232.

Grajales, J., 2011. The rifle and the title: paramilitary violence, land grab and land control in Colombia. Journal of Peasant Studies, 38(4), pp.771-792. Available at: http://www.tandfonline.com/doi/pdf/10.1080/03066150.2011.607701.

Grupo de Memoria Histórica, 2010. La Tierra en Disputa. Memorias del despojo y resistencias campesinas en la costa caribe 1960-2010. Grupo Nacional de Reparación y Reconciliación, p.528.

Gutiérrez, F., 2014. Propiedad, seguridad y despojo: el caso paramilitar. Estudios 
Socio-Jurídicos, 16(1), pp.43-74.

Hall, R. et al., 2015. Resistance, acquiescence or incorporation? An introduction to land grabbing and political reactions 'from below.' The Journal of Peasant Studies, 42(3-4), pp.467-488. Available at: http://www.tandfonline.com/ doi/full/10.1080/03066150.2015.1036746

Hall, R., 2011. Land grabbing in Southern Africa: the many faces of the investor rush. Review of African Political Economy, 38(128), pp.193-214.

Harvey, D., 2005. Breve historia del Neoliberalismo

Hurtado, M., Pereira, C. \& Villa, E., 2017. Oil palm development and forced displacement in Colombia: Causal or spurious? Cuadernos de Economía, 36(71), pp.441-468.

IGAC, 2012. Conflictos de uso del territorio colombiano. , p.214.

INCODER, 2014. Datos titulación de Baldíos.

Kalmanovitz, S. \& López, E., 2006. La agricultura Colombiana en el siglo XX, Bogotá: Fondo de Cultura Económica.

Kay, C., 2015. The agrarian question and the neoliberal rural transformation in Latin America. European Review of Latin American and Caribbean Studies, 100(100), pp.73-83.

Kay, C., 2001. Reflections on rural violence in Latin America. Third World Quarterly, 22(5), pp.741-775.

Levien, M., 2012. The land question: special economic zones and the political economy of dispossession in India. Journal of Peasant Studies, 39(3-4), pp.933969. Available at: http://dx.doi.org/10.1080/03066150.2012.656268.

Machado, A., 2013. La política de reforma agraria y tierras en Colombia. Esbozo de una memoria institucional, Centro Nacional de Memoria Histórica.

Machado, A., 2009. La reforma rural, una deuda social y política, Bogotá: CIDUniversidad Nacional de Colombia.

Machado, A., 1998. La cuestión agraria en Colombia a fines del milenio El Ancora Editores, Bogotá.

MADR, 2015a. Altillanura.

MADR, 2015b. Decreto 2363 de 2015 "por el cual se crea la Agencia Nacional de Tierras (ANT), se fija su objeto y estructura." , p.29.

MADR, 2013. Implementación de la política integral de tierras 2010-2013.

MADR, 2011. Decreto 4145 de 2011. , p.10. Available at: http://www.upra.gov.co/ documentos/Decreto 4145 de 2011.pdf.

Martínez, P., 2013. Ley de víctimas y restitución de tierras en Colombia en contexto. , p.36. Available at: https://www.tni.org/es/publicacion/ley-devictimas-y-restitucion-de-tierras-en-colombia-en-contexto.

Mejía, M.F. \& Mojica, J., 2015. Conocimientos necesarios sobre las tierras rurales en Colombia: apuntes esenciales, preguntas y respuestas. Oxfam.

Mendes, J.M. \& Fajardo, D., 2015. The World Bank's “Market Assisted Land Reform" in Brasil and Colombia (1994-2002). Revista Brasileira de História, 35(70), pp.157-180. Available at: http://www.scielo.br/scielo. php?script =sci_arttext\& pid=S0102-01882015000200157\&lng=pt\&nrm=iso\&tlng=en.

Mesa de Conversaciones de Paz, 2016. Acuerdo Final. , pp.1-310. 
Misereor, 2017. Desplazar y despojar. Estrategia para el desarrollo de la Orinoquía., Bogotá.

Nolte, K., Chamberlain, W. \& Giger, M., 2016. International Land Deals for Agriculture Fresh insights from the Land Matrix: Analytical Report II, Available at: http://landmatrix.org/media/filer_public/ab/c8/abc8b563-9d74-4a479548-cb59e4809b4e/land_matrix_2016_analytical_report_draft_ii.pdf.

Oberlack, C. et al., 2016. Sustainable livelihoods in the global land rush? Archetypes of livelihood vulnerability and sustainability potentials. Global Environmental Change, 41(October), pp.153-171. Available at: http:/ / dx.doi.org/10.1016/j.gloenvcha.2016.10.001.

Ocampo, J.A., 1996. Historia económica de Colombia. Fondo de Cultura Económica.

OCDE, 2015. OECD Review of Agricultural Policies: Colombia 2015.

Oliveira, G., 2013. Land Regularization in Brazil and the Global Land Grab. Development and Change, 44(2), pp.261-283.

Osorio, F.E., 2015. Tramas entre paramilitarismo y palmicultura en Colombia. In Memoria y Sociedad, 19(39), p.11. Available at: http://www.scielo.org.co/ scielo.php?script=sci_arttext\&pid=S012251972015012000002\&lng=en\&nrm $=$ is o\&tlng=en.

Oxfam, 2014. Vía libre al acaparamiento. Un nuevo intento de legalizar la acumulación irregular de baldíos., Bogotá.

Oxfam, 2013. Divide y comprarás. Una nueva forma de concentrar tierras baldías en Colombia. Oxfam, p.81.

Oya, C., 2013a. Methodological reflections on 'land grab' databases and the 'land grab' literature 'rush'. Journal of Peasant Studies, 40(3), pp.503-520.

Oya, C., 2013b. The Land Rush and Classic Agrarian Questions of Capital and Labour: a systematic scoping review of the socioeconomic impact of land grabs in Africa. Third World Quarterly, 34(9), pp.1532-1557.

El País, 2016. Presidente Juan Manuel Santos sanciona la ley que crea las Zidres.

Perfetti, J.J. et al., 2017. Política comercial agrícola: nivel, costos y efectos de la protección en Colombia, Bogotá. Available at: http://www.repository.fedesarrollo org.co/.bitstream/handle/11445/3443/Repor_Agosto_2017_Perfetti_et_al.pd $\mathrm{f}$ ? sequence $=3 \&$ isAllowed $=\mathrm{y}$.

Petticrew, M. \& Roberts, H., 2008. Systematic Reviews in the Social Sciences: A practical guide, Blackwell Publishing.

Portafolio, 2013. " Las tierras eran solo una parte de la inversión ". p.4.

Restrepo, J.C. \& Morales, A.B., 2014. La cuestión agraria. Tierra y postconflicto en Colombia, Bogotá. Editorial Géminis.

Reyes, A., 2009. Guerreros y campesinos. Despojo y restitución de tierras en Colombia., Bogotá: Editorial Norma.

Reyes, A., 1997. La compra de tierra por narcotraficantes. In F. Thoumi, ed. Drogras ilícitas en Colombia. Bogotá: Editorial Ariel.

Richani, N., 2005. Multinational Corporations, Rentier Capitalism and the War System in Colombia. Latin America Politics and Society, pp.113-144.

Rodríguez, I., 2014. Despojo, baldíos y conflicto armado en Puerto Gaitán y Mapiripán (Meta, Colombia) entre 1980 y 2010. Estudios Socio-Jurídicos, 16(1), 
pp.285-338. Available at: http://revistas.urosario.edu.co/ index.php/ sociojuridicos/article/view/esj16.1.2014.08.

Rutas del Conflicto, 2015. Vichada : tierra de hombres para hombres sin tierra.

Available at: http://rutasdelconflicto.com/especiales/vichada/tierra_ hombres_sin_tierra.

Sassen, S., 2015. Expulsiones. Brutalidad y complejidad en la economía global, Buenos Aires: Katz Editores.

Semana, 2016. Diez puntos para entender la ley Zidres que sancionó Santos. Semana.

Semana, 2013a. Don Víctor. Semana.

Semana, 2013b. El chicharrón de los baldíos. Semana.

Sentencia 054, 2014. Juzgado quinto penal del circuito especializado de Medellín.

Solimano, A. et al., 1999. Ensayos sobre paz y desarrollo. El caso de Colombia y la experiencia internacional. p.248.

Available at: http://documentos.bancomundial.org/ pdf/2159410paper.pdf.

Soto, F. \& Gómez, S., 2012. Dinámicas del mercado de la tierra en América Latina y el Caribe: concentración y extranjerización. , p.590.

Superintendencia de Sociedades, 2013. Sentencia contra Monica Colombia S.A.S.

Thomson, F., 2011. The Agrarian Question and Violence in Colombia: Conflict and Development. Journal of Agrarian Change, 11(3), pp.321-356.

Touch, S. \& Neef, A., 2015. Local Responses to Land Grabbing and Displacement in

Rural Cambodia. Global Implications of Development, Climate Change and Disasters: Responses to Displacement from Asia-Pacific, (16), pp.124-141.

Tribunal civil de Cúcuta, 2016. Sentencia Acta No. 16. Caso Argos.

Uribe, D. \& Rodríguez, M., 2016. Lucha por la tierra en la hacienda Bellacruz. In Semilleros de Investigación No. 27. Bogotá, pp. 17-86. Available at: http://www.bdigital.unal.edu.co/53289/.

URT, 2017. Solicitud de Restitución 31517572309130801. ID.119917..

USAID, 2016. U . S . Overseas Loans and Grants.

USAID, 2015. Colombia Land and Rural Development Program. Annual Report: october 2014-September 2015. , (September), p.44.

USAID, 2010a. Office of Inspector General Audit of USAID / Colombia' S Alternative Development Program.

USAID, 2010b. Usaid country profile. Property Rights and Resource Governance Colombia. , pp.1-21.

USDA, 2015. The Altillanura - An Uncertain Future. GAIN Report.

USDA, 2010. Colombia Colombian Government Signals Changes for Land Tenure Policy. GAIN Report.

USDA, 2009. The Altillanura-Colombia's Next Agricultural Frontier. GAIN Report.

Velásquez, E.D.J., 2007. Historia del paramilitarismo en Colombia. História, São Paulo, 26(1), pp.134-153. Available at: http://www.scielo.br/scielo.php? pid=S0101-90742007000100012\&script=sci_arttext.

Verdad Abierta, 2017. Consejo de Estado exige proteger a campesinos de Las Pavas. Verdad Abierta. Available at: https://verdadabierta.com/consejo-deestado-exige-proteger-a-campesinos-de-las-pavas/. 
Verdad Abierta, 2016a. A Argos le faltó mayor diligencia en compra de tierras. Verdad Abierta. Available at: https://verdadabierta.com/a-argos-le-faltomayor-diligencia-en-compra-de-tierras/ [Accessed May 20, 2017].

Verdad Abierta, 2016b. Corte les da la razón a campesinos de El Porvenir. Verdad Abierta. Available at: https://verdadabierta.com/corte-les-da-la-razon-acampesinos-de-el-porvenir/ [Accessed January 28, 2017]

Verdad Abierta, 2014. A la cárcel 16 empresarios de palma de Chocó. Verdad Abierta. Available at: https://verdadabierta.com/a-la-carcel-16-empresariosde-palma-de-choco/ [Accessed April 4, 2017].

Verdad Abierta, 2013a. El Macondo de Mapiripán. Verdad Abierta. Available at: https://verdadabierta.com/el-macondo-de-mapiripan/ [Accessed May 15, 2016].

Verdad Abierta, 2013b. La metamorfosis del Brasil. Verdad Abierta. Available at: https://verdadabierta.com/la-metamorfosis-de-el-brasil/ [Accessed June 8, 2016].

Verdad Abierta, 2012a. El Secreto de Mapiripán. Verdad Abierta. Available at: https://verdadabierta.com/el-secreto-de-mapiripan/.

Verdad Abierta, 2012b. Tulapas: el laboratorio del despojo. Available at: https://verdadabierta.com/tulapas-el-laboratorio-del-despojo/ [Accessed May 15, 2017].

Verdad Abierta, 2011. Incoder recuperará los baldios de la Bellacruz. Available at: https://verdadabierta.com/incoder-recuperara-los-baldios-de-la-bellacruz/ [Accessed May 8, 2017].

Verdad Abierta, 2008. Bloque Elmer Cárdenas de Urabá. Verdad Abierta, pp.1-4.

Villaveces, J. \& Sánchez, F., 2015. Tendencias históricas y regionales de la adjudicación de baldios en Colombia. Available at: http://repository.urosario.edu.co/ bitstream/handle/10336/10933/12538.pdf.

White, B. et al., 2012. The new enclosures. Critical perspectives on corporate land deals. Journal of Peasant Studies, 39(3-4), pp.619-647.

Wolford, W. et al., 2013. Governing Global Land Deals: The Role of the State in the Rush for Land. Development and Change, 44(2), pp.189-210.

World Bank, 2011. Special Economic Zones. Progress, Emerging Challenges, and Future Directions T. Farole \& A. Gokhan, eds. 


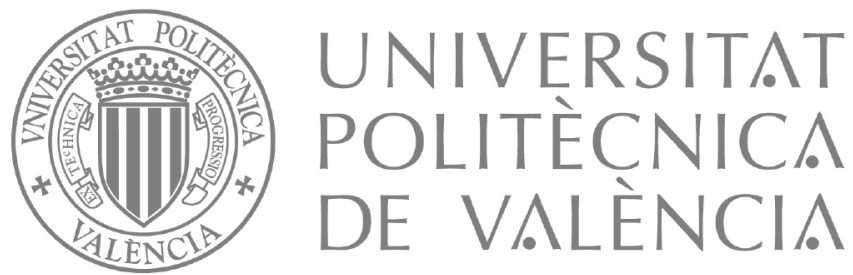

